\title{
Towards process-oriented care delivery in hospitals
}

Citation for published version (APA):

Vos, L. (2010). Towards process-oriented care delivery in hospitals. [Doctoral Thesis, Maastricht University]. NIVEL. https://doi.org/10.26481/dis.20101008lv

Document status and date:

Published: 01/01/2010

DOI:

10.26481/dis.20101008lv

Document Version:

Publisher's PDF, also known as Version of record

\section{Please check the document version of this publication:}

- A submitted manuscript is the version of the article upon submission and before peer-review. There can be important differences between the submitted version and the official published version of record.

People interested in the research are advised to contact the author for the final version of the publication, or visit the DOI to the publisher's website.

- The final author version and the galley proof are versions of the publication after peer review.

- The final published version features the final layout of the paper including the volume, issue and page numbers.

Link to publication

\footnotetext{
General rights rights.

- You may freely distribute the URL identifying the publication in the public portal. please follow below link for the End User Agreement:

www.umlib.nl/taverne-license

Take down policy

If you believe that this document breaches copyright please contact us at:

repository@maastrichtuniversity.nl

providing details and we will investigate your claim.
}

Copyright and moral rights for the publications made accessible in the public portal are retained by the authors and/or other copyright owners and it is a condition of accessing publications that users recognise and abide by the legal requirements associated with these

- Users may download and print one copy of any publication from the public portal for the purpose of private study or research.

- You may not further distribute the material or use it for any profit-making activity or commercial gain

If the publication is distributed under the terms of Article $25 \mathrm{fa}$ of the Dutch Copyright Act, indicated by the "Taverne" license above, 


\section{Towards process-oriented care delivery}

in hospitals

Leti Vos 
ISBN 978-94-6122-022-6

http://www.nivel.nl

nivel@nivel.nl

Telefoon 0302729700

Fax 0302729729

CC2010 NIVEL, Postbus 1568, 3500 BN UTRECHT

Cover design: Marc Obbens

Word processing/lay out: Christel van Well

Printing: Datawyse/Universitaire Pers Maastricht

All rights reserved. No part of this publication may be reproduced, stored in a retrieval system or transmitted, in any form or by any means, electronic, mechanical, photocopying, recording or otherwise, without the prior written permission of NIVEL. Exceptions are allowed in respect of any fair dealing for the purpose of research, private study or review. 


\title{
Towards process-oriented care delivery in hospitals
}

\author{
PROEFSCHRIFT
}

ter verkrijging van de graad van doctor aan de Universiteit Maastricht, op gezag van de Rector Magnificus, Prof. mr. G.P.M.F. Mols,

volgens het besluit van het College van Decanen,

in het openbaar te verdedigen

op vrijdag 8 oktober 2010 om 12.00 uur

door

Leti Vos 


\section{Promotores:}

Prof. dr. G.G. van Merode

Prof. dr. C. Wagner (Vrije Universiteit Amsterdam)

Prof. dr. P.P. Groenewegen (Universiteit Utrecht)

\section{Beoordelingscommissie:}

Prof. dr. C. Spreeuwenberg (voorzitter)

Prof. dr. H.J.J.M. Berden (Universiteit van Tilburg)

Prof. dr. J. van Engelshoven

Prof. dr. J.A.M. Maarse

Prof. dr. J. de Vries (Rijksuniversiteit Groningen)

The studies presented in this thesis were conducted at the Faculty of Health, Medicine and Life sciences, Maastricht University Medical Centre+ and NIVEL, the Netherlands Institute for Health Services Research in Utrecht. Part of the research was performed with financial support of MESOS Medical Centre and ZonMw, the Netherlands Organisation for Health Research and Development. Printing of the book has been supported financially by NIVEL, the Netherlands Institute for Health Services Research. 
'It sounded an excellent plan, no doubt, and very neatly and simply arranged; the only difficulty was, that she had not the smallest idea how to set about it; ...'

Alice's Adventures in Wonderland by Lewis Carroll 


\section{Contents}

1 General introduction 9

2 Towards an organisation-wide process-oriented organisation of care: a literature review

3 Evaluating hospital design from an operations management perspective

4 Does case-mix based reimbursement stimulate the development of process-oriented care delivery?

5 How to implement process-oriented care: a case study on the implementation of process-oriented in-hospital stroke care

6 Applying the quality improvement collaborative method to process redesign: a multiple case study

$7 \quad$ General discussion and conclusion

Summary

Samenvatting

Dankwoord

Curriculum Vitae

179

List of publications 


\section{Chapter 1}

General introduction 


\subsection{Introduction}

In April 2000, Susan M. went for her preventive breast cancer screening mammogram. The mammogram showed an abnormality, and Susan had to see a surgeon. The first available appointment date was five weeks later. The surgeon then decided he wanted the radiologist to perform a needle biopsy. The first available appointment date for the radiologist was another four weeks later. 'I completely freaked out,' Susan says. 'I couldn't imagine spending another month with this hanging over my head.' Ultimately, a week after the needle biopsy Susan was told by the surgeon that the abnormality was nothing to worry about.

Patients like Susan M. in the above example often have to wait for long periods before they are seen by medical specialists, and subsequently need to wait again for diagnostic examinations or for treatment while experiencing great uncertainty about their illness. In 2007, 19.7\% of all Dutch hospital departments (medical specialties) indicated that patients had to wait longer than four weeks for their first visit to the outpatients' clinic, and $6.4 \%$ of the departments indicated that after their first visit to the outpatients' clinic, patients had to wait longer than seven weeks for their clinical treatment ${ }^{1}$. Although these waiting times still exceeded the desired period, they were considerably less than they were in 2005. In 2005, respectively $22.8 \%$ and 9.1\% of all Dutch hospital departments indicated that patients had to wait longer than four weeks for their first visit to the outpatients' clinic, and longer than seven weeks for their clinical treatment ${ }^{1}$.

National and international attention to quality problems like waiting times and the poor coordination of care activities has made hospital management and medical specialists aware that the way care is delivered needs to be reorganised. However, little is known about how to improve the organisation of care delivery in terms of quality and efficiency. Moreover, it is not known how new ways of organising care delivery should be implemented into a hospital's organisation. Until now, many of the ideas for improvements of coordination and process control have been derived from research in industry, including the successful concept referred to as 'business process orientation'. This concept's breakthrough occurred at the beginning of the 1990s under the name 'Business Process Reengineering'2. Successful examples of the application of the principles of business process orientation for the organisation of care delivery to specific patient groups are known: for instance, involving women with suspected breast cancer (see Box 1.1). It is unknown, however, whether business process orientation or process-oriented care delivery can also be applied successfully at hospital level. 
Box 1.1 Process-oriented care delivery for women with suspected breast cancer

For women with suspected breast cancer, the organisation of care has improved considerably
during the last 10 years. In the past, women were forced to wait for many days, or even weeks, to
see the medical specialist; then they had to return to the hospital many times for diagnostic
examinations, and were given the results at the earliest one week after the last examination.
However, the introduction of an 'outpatient clinic for mamma care' changed this. Women with
suspected breast cancer now have access to a special outpatient clinic within five days of the
initial mammogram. In this clinic, patients are attended to by a surgeon on a multidisciplinary
team that is devoted to deliver mamma care. On the same day as seeing the surgeon, the patient
receives all prescribed diagnostic examinations (palpation by surgeon or nurse practitioner,
diagnostic imaging [mammogram, echography], and cytology or needle biopsy). In addition,
appointments are made for further diagnostic examination such as MRI when this is indicated.
The patient is given the results of the examinations within five days of this first visit to the
hospital.

Therefore, this thesis aims to extend the knowledge in the field of health care operations management by testing the hypothesis that the implementation of process-oriented care delivery leads to better outcomes in terms of quality and efficiency at hospital level. The scope of this thesis is limited to the processoriented organisation of patient flow. Hence, organisation of the flow of other resources through the hospital such as capital, labour, and materials (supplies needed for operations, medical files, and so on) are not taken into account.

In this introductory chapter, attention is first paid to the organisational characteristics of Dutch hospitals, the setting of this study. Next, we describe how care delivery has been organised traditionally, and try to explain why and how hospitals should work towards a process-oriented way of care delivery. Subsequently, certain conflicts that can evolve during the introduction of process-oriented care delivery in a hospital are discussed. This chapter ends with the general aim, research questions, and an outline of this thesis.

\subsection{Dutch hospitals: organisational characteristics}

As a result of the tendency towards specialisation in the medical profession, Dutch hospitals traditionally have functional organisation structures ${ }^{3}$. Within a functional structure, organisational departments are built around the skills and knowledge of their professionals, like internal medicine, radiology, and so on ${ }^{3-5}$. In this organisational structure, responsibilities are coupled to the different organisational departments and not to care delivery processes. Below the level of the hospital board are managers who are responsible for the performance of 
divisions or clusters. Within these divisions or clusters, operational units or departments function with their own responsible managers. In these units or departments, professionals are grouped according to their specialty.

In the Netherlands, most medical specialists (65\%) are contracted but not salaried by the hospital ${ }^{6,7}$. As a result, medical specialists are poorly integrated into the hospital organisation. However, specialists are responsible for the patient's medical care process and its outcome, and therefore play a crucial role in the realisation of the hospital organisation's objective. During the last 10 years, the hospital organisation and its contracted medical specialists have demonstrated increasing integration by the implementation of dual management structures, which means that medical specialists participate in the management of hospitals. Thus, medical specialists are co-responsible for the policies, management, and organisation of care delivery. In practice, hospitals give meaning to this dual management structure in different ways: for example, by making a medical specialist a member of the hospital board or by the comanagement of clusters of departments ${ }^{8}$. However, the divide between management and medical specialists is not diminished. The reality is a strategic control battle between hospital management and medical staff ${ }^{7,9}$.

Due to the above-mentioned characteristics, Dutch hospitals can be considered durable virtual organisations: the patient may have the impression that services are provided by one and the same organisation, but in fact many different autonomous organisations, the medical specialties, are operating behind the shared facade, and are involved in the delivery of services ${ }^{6}$. Within this virtual organisation, each department operates as a separate 'silo' with its own goals $^{3,4}$, because responsibilities are coupled to the different organisational departments and not to care delivery processes. As a consequence, the management of each organisational department is concerned with maximising its own efficiency rather than with the efficiency of entire patient care processes ${ }^{10}$. This means two sets of goals co-exist and perhaps compete: those at the strategic hospital level, where hospital policies and strategic targets are set and investments required are determined, and those at the operational department level, where freedom exists in terms of how to organise operations ${ }^{6}$.

Additional information about Dutch hospital care is presented in Box 1.2. 


\begin{abstract}
Hospital categories: Hospital care in the Netherlands is delivered almost exclusively in private not-for-profit organisations. In 2009, there were eighty-five general hospitals, eight university hospitals, and a number of specialised hospitals ${ }^{11}$. General hospitals concentrate on treatment and nursing. Twenty-six of the general hospitals also provide medical training and highly specialised care that requires expensive and specialised instruments (e.g. heart and neurosurgery, in vitro fertilisation). University hospitals also conduct scientific research and education for medical professionals, and develop new medical technologies and techniques. Specialised hospitals concentrate on specific forms of care or on a specific illness (e.g. orthopaedics, asthma, epilepsy, or dialysis).

Medical specialists (or clinicians): Most medical specialists work in one hospital. The majority is self-employed, working in a partnership with other specialists in the same field. In 2007, there were 15,360 medical specialists in the Netherlands for approximately 16,4 million Dutch inhabitants. This represents a growth of $20 \%$ compared to the number of medical specialists in $2000^{12}$. However, the growth in full-time equivalents of medical specialists is smaller: namely, $16 \%$. Medical specialists are represented in the Medical Board of a hospital and are organised in national professional groups per medical specialty.

Access to hospital care: In the Netherlands, general practitioners (GPs) are gatekeepers for hospital care. Except for cases of emergency, patients only consult a medical specialist after referral by a $\mathrm{GP}^{13}$. Between 2000 and 2007, the percentage of Dutch people who visited a medical specialist at least once a year increased from 38 to $41 \%{ }^{14}$. Some patients only visit a hospital for diagnosis and/or therapy and then leave (outpatients), while others are admitted and stay overnight (inpatients).
\end{abstract}

\title{
1.3 The organisation of care delivery within hospitals
}

Owing to institutional pressure, top management in Dutch hospitals currently feels the need to pay closer attention to patients' interests and to search for ways to tailor the organisation of care delivery accordingly. This section first explains the principles of the organisation of care delivery and the way in which care traditionally is organised; it then describes why and how hospitals can tailor the organisation of care delivery to patients' needs or make care delivery more process-oriented.

The organisation of care delivery in hospitals belongs to the field of Operations Management (OM). OM in hospitals concerns the design, planning, and control of coordination mechanisms between patient flow and diagnostic and therapeutic activities to maximise output/throughput given available resources, taking into account different requirements for delivery (elective, semi-urgent, urgent), acceptable standards for delivery reliability (waiting 
times), and acceptable medical outcomes ${ }^{15}$. OM in hospitals has two aims: increasing the efficiency and quality of care delivery.

The design, planning, and control of coordination mechanisms are determined by the structure of the handled logistical concept. This concept consists of four main elements ${ }^{16}$ :

1. The basic form of an organisation or the main organisation structure;

2. The operating system;

3. The information system (where in the organisation is what kind of information needed); and

4. The organisation of personnel (qualifications, competences and responsibilities per task).

The strategic goals of an organisation (including logistic goals) make up the starting point for the design of these four coherent elements. The alignment of the four elements ultimately determines how care delivery is organised.

\subsubsection{Traditional - functional - logistical concept for care delivery}

As described in Section 1.2, hospitals traditionally have a functional organisation structure. The structure of the logistical concept for the control of patient flow within this traditional organisation can be described as follows:

The basic form of the hospital looks like a network (see Figure 1.1). Within a functional structure, each department operates as a separate 'silo' with its own goals $^{3,4}$. Due to current increasing specialisation, the patient's care process frequently consists of a chain of care activities delivered by different departments.

Figure 1.1 Functional basic structure (based on: Van Merode et al. [2004] ${ }^{17}$ )
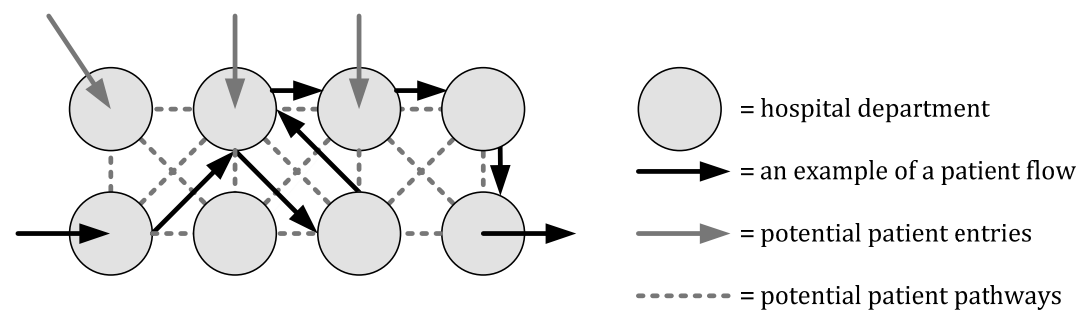

In the operating system of a hospital with a functional basic structure, departments are controlled independently of each other (see Figure 1.2), which means that they do not exchange information for the planning and control of patient flows ('stand-alone'). As a consequence of the functional structure, each 
care activity within a chain is planned on the basis of availability of resources, after the previous care activity is completed. This leads to considerable coordination and to a number of transfer points per patient. The result is an indeterministic or fuzzy pattern of patient flow through the hospital. After all, there are many ways in which each patient can move through the hospital's necessary chain of care activities.

In addition, the availability of departmental capacities is frequently not based on actual demand, but is determined without information about the volume and the type of patients needing to be served ('push' planning). For example, the planning of an operating theatre - which determines which medical specialty may use the operating theatre at which time of the week - is set down yearly. This planning is thus done before patients are scheduled for surgery, and therefore before the needed operating capacity per day per medical specialty is known.

Figure 1.2 Functional operational control system - 'stand alone'
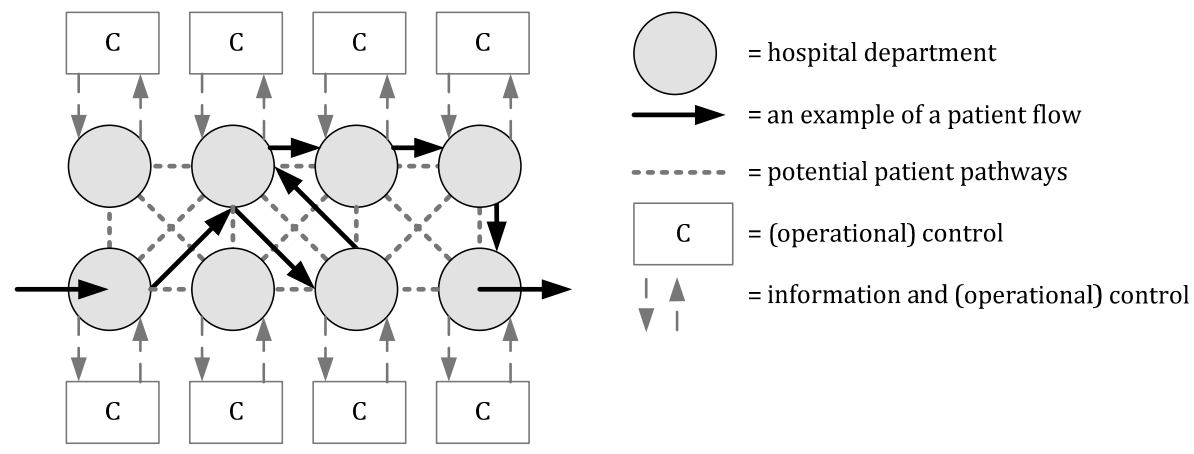

The way in which processes are controlled determines what information is needed by whom to take the appropriate decision at the right moment. In a functional logistical concept, every department controls its own patient flow with the aim to optimise its capacity use, which makes the degree of capacity utilisation important information with regard to controlling the departments.

Within the functional logistical concept, personnel is organised according to specialisation.

As described in this chapter's introduction, the use of this functional logistical concept has led to waiting times and delays in patients' care process. 


\subsubsection{A process-oriented logistical concept for care delivery}

Before explaining ways to tailor the organisation of care delivery with respect to patients' needs, the reasons for developing a process-oriented logistical concept as a manner to take patients' requirements into account are discussed.

\section{Reasons for changing the functional logistical concept of hospitals}

Hospitals are currently under external pressure to improve the quality and efficiency of care delivery, and more specifically to improve the coordination between specialists' subtasks to provide all components of care needed by patients. This is a result of several developments, which include:

- An increased complexity of processes as a result of changes in health care needs, the use of new technologies, and increased specialisation. The increasing number of patients with more multidisciplinary health care needs calls for additional coordination. At the same time, the increasing specialisation of medical professionals and the development of new technologies increasingly divides care delivery into specialist subtasks that require even more coordination ${ }^{18}$;

- The need for efficient utilisation of resources and reduction in costs due to political pressure to control health care expenditures. In the Netherlands, health care expenditures increased from 26,9 billion euro in 2000 to 42,5 billion euro in 200614;

- Increased pressure on the part of stakeholders - patients and health insurance companies - to improve the quality and efficiency of services, among others by decreasing waiting lists and in-process waiting times ${ }^{6}$.

These pressures to improve the quality and efficiency of care delivery are formalised by governmental actions. Since 1996, Dutch hospitals have, for example, been bound by law to provide effective, efficient, and patient-centred care delivery ${ }^{19}$. In addition, the Dutch government has introduced regulated competition in the hospital sector to force hospitals to rethink their performance (price-quality ratio, focus on patient's needs). Further, the government has implemented a new case-mix-based reimbursement system that aims to stimulate coordination of care activities in care processes and the efficiency of care delivery. This new reimbursement system will gradually replace the fee-for-service payment of hospital care, which rewards delivery of individual procedures (i.e. hospital admissions, number of in-patient days) up to a predefined maximum ${ }^{20}$. In this new system, hospital budgets are based on the number of delivered Diagnosis Treatment Combinations (DTC). A DTC consists of all diagnosis- and treatment-related costs incurred by the hospital and the medical specialists. Thus, it covers the whole chain of delivered 
services: from an initial consultation or examination to the final check-up ${ }^{21}$. Consequently, instead of on the number of individual procedures, hospital budgets become dependent on the efficient and effective delivery of DTCs, and thus the total path of diagnosis and treatment of a patient, which consists of several subtasks. However, also within this new system hospital budgets are not open ended. Hospitals negotiate with health care insurers regarding the maximum number of DTCs they may deliver within 1 year.

However, it is difficult to meet these requirements for care delivery within a functional organisation because of the limited possibilities of managers to control the many coordination and transfer points in the care processes ${ }^{5}$. This is due to:

- The ill-defined ownership of care processes for a defined category of patients versus the clearly defined responsibilities of the medical specialties contributing services. Specialists play a key role, as they decide on the patient's transfer to a next stage in the process, but the coordination of care activities within the process as a whole does not lie in their hands ${ }^{6}$;

- $\quad$ The limited sharing between medical specialists and managers with regard to available information about the chain of operations that forms the patient process;

- The need to coordinate different parts (departments) of the hospital organisation, without being able to control all parts of the organisation 6 .

Therefore, the need to improve the quality and efficiency of care delivery calls for a new logistical concept.

\section{Process-oriented logistical concepts}

To optimise patients' care paths through the hospital, the complexity of service integration with its many coordination and transfer points in the care process must be reduced ${ }^{17}$. According to Galbraith, this can be accomplished in two different ways:

A. Changing the operating system of the logistical concept; or

B. Changing the basic form of the organisation ${ }^{22}$.

Both ways lead theoretically to a more process-oriented organisation of care delivery.

\section{Ad. A. Changing the operating system to a process-oriented operational control} system

Within this approach, top management decides to keep the functional basic structure and to change the operating system towards a process-oriented operational control system for patients who need standard care: namely, those for whom the required components of care delivery are known ahead of time 
because they are embedded in guidelines, task routines or protocols ${ }^{23}$ (see Figure 1.3). This system implies that individual patients' demands are aggregated into logistically homogeneous groups and that departments exchange information to coordinate the flow of these patient groups across department boundaries. Information exchange is then used to bridge barriers erected by the functional organisation structure by bringing together all medical specialists that are involved in the delivery of care to a specific patient group 24 . As well as this, the information exchange gives departments the opportunity to adjust their capacity planning to the expected demand of these patient groups, which reduces the chance of waiting times and delays for those patients ('pull' planning).

Figure 1.3 Process-oriented operational control system within functional organisational structure - 'integration by communication'

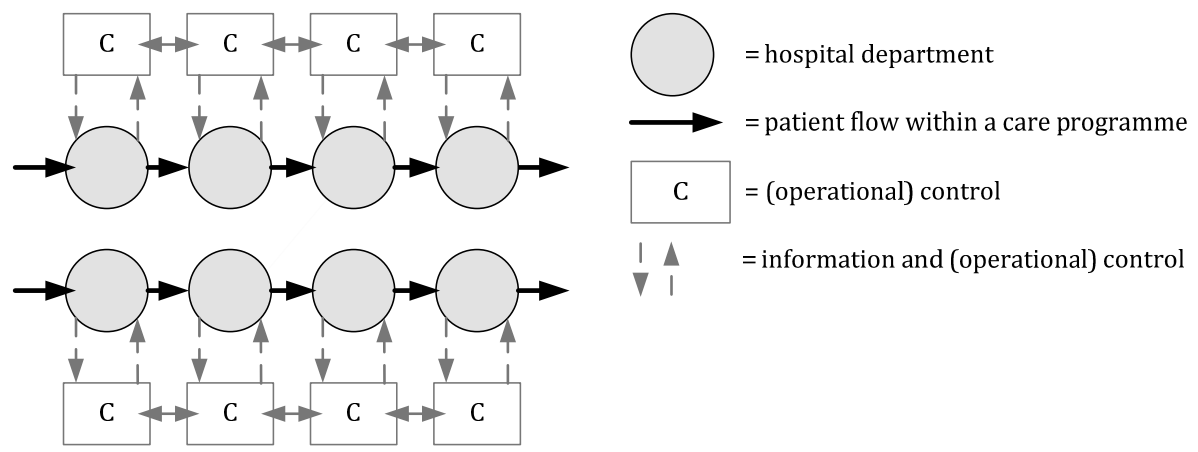

Thus, within this approach, hospitals organise care pathways or programmes for specific patient groups, which establish the sequence of care activities (diagnostics, consultations, treatment) along with the responsibilities of professionals involved in the diagnosis and treatment of homogeneous patient groups, as in the example of 'process-oriented care delivery for women with suspected breast cancer' described in Box 1.1.

\section{Ad. B. Changing the basic form of the organisation to a process-oriented basic} structure

In this approach, top management decides to restructure its basic structure into new self-contained multidisciplinary departments that are based on the needs of the patients (see Figure 1.4). These departments are then composed in such a way that they can handle a care process as comprehensively as possible, have relatively few interdependencies with other departments, and an indeterministic patient flow is reduced $4,25,26$. 
Figure 1.4 Process-oriented basic structure
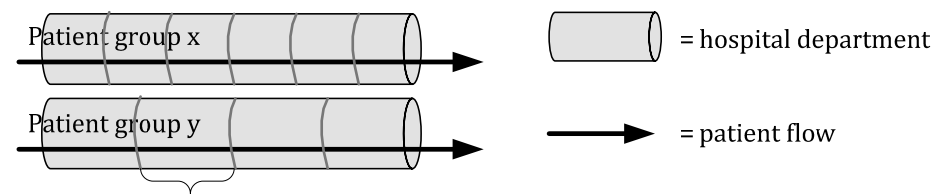

Specialised subtask

As a result of this change in basic structure, a change in the operational control system is not needed because departments now handle a care process integrally (see Figure 1.5). Within the organisational units, the tasks are performed autonomously and integratively by cross-functional teams ${ }^{27}$. In comparison with functional logistical concepts, employees are confronted with more diversified and multifaceted tasks. In the case of complex processes, the functional division of work within the team can be maintained; the coordination is still facilitated by the elimination of departmental borders between team members ${ }^{4}$.

Figure 1.5 Process-oriented operational system within a process-oriented basic structure ('integral control')
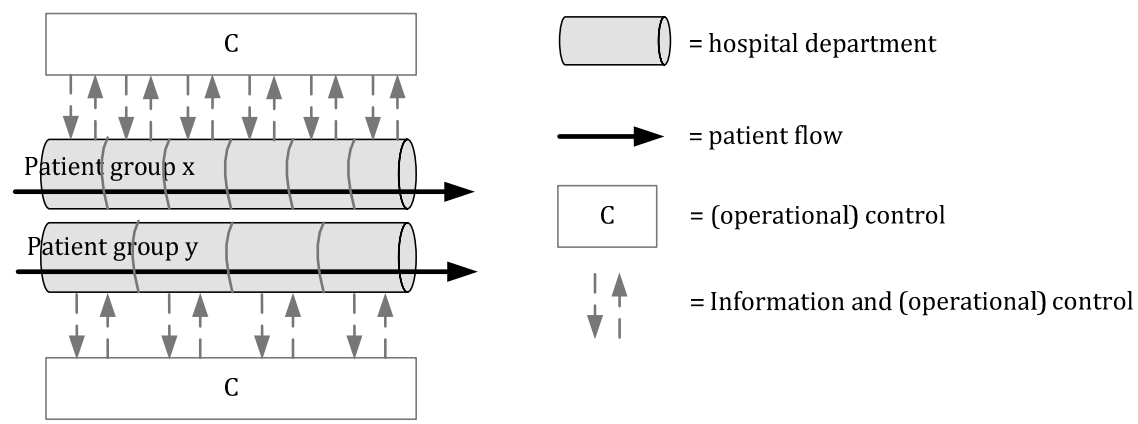

This change in the basic structure is not only convenient for patients who fit within one multidisciplinary department (shorter waiting time, even fewer patient transfers between departments) but it also simplifies the coordination of patient flow in the organisation, which in its turn makes more precise planning possible ${ }^{28}$. Patients who have to be treated within more than one multidisciplinary department also experience advantages because fewer transfers are needed. The feasibility of a process-oriented basic structure is limited by the pronounced functional specialisation of medical professionals, which is indispensable because of the know-how intensity of many hospital services ${ }^{4}$. Moreover, it is not clear whether the creation of multidisciplinary departments will be feasible for strategically less important services (e.g. to small multidisciplinary patient groups). 
An example of a hospital that handles such a process-oriented basic structure is the Mayo Clinic in Rochester (US). This hospital is strongly differentiated with respect to patient groups or type of illness. For each patient group, for example heart diseases, an integrated system exists from prevention to revalidation. Medical specialists and allied health professionals are specialised in the treatment of a certain patient group. Each patient experiences a hospital specialised for a specific illness.

These process-oriented logistical concepts described in this section ([A] the implementation of a process-oriented operational control system and [B] the implementation of a process-oriented basic structure) require different information systems and another organisation of personnel. In this kind of organisation, the performance of care processes and in-process waiting times become more important than the capacity utilisation of departments. This means that ICT systems have to be redesigned to deliver the correct information to the person who has to take the timely decision to control care processes. In addition, division of tasks, competences, and responsibilities have to be reconsidered. It requires that medical specialists and allied health care professionals specialise in specific diseases, and that management is responsible for the efficient performance of care processes instead of for the capacity utilisation of their department.

To achieve optimal efficiency, the physical layout of a building ideally has to support the new process-oriented logistical concept ${ }^{29}$. The layout influences work processes, patient flow, information, and decisions across the organisation. However, as experts have noted, a supporting physical layout is extremely difficult to realise in a pre-existing building ${ }^{30}$.

\subsection{Implementation of new logistical concepts in a hospital organisation}

In the previous section, we described two possible ways to change the logistical concept in such a way that patients' needs are integrated into the way care is delivered. These changes need to be introduced into the hospital system. As described in Section 1.2, a traditional hospital system exists of top management, divisions, and functional departments, in which medical professionals are grouped according to their specialty; this system needs to operate within a hospital building in order to reach organisational goals. Conflicts arise when goals and decisions of the components of this traditional hospital system (top management, divisions/departments, medical profes- 
sionals) and preconditions such as the hospital building layout are not aligned with each other when a new logistical system is introduced. Figure 1.6 visualises three types of conflict. In this section, these conflicts are discussed and possible solutions are suggested.

Figure 1.6 Three types of conflict

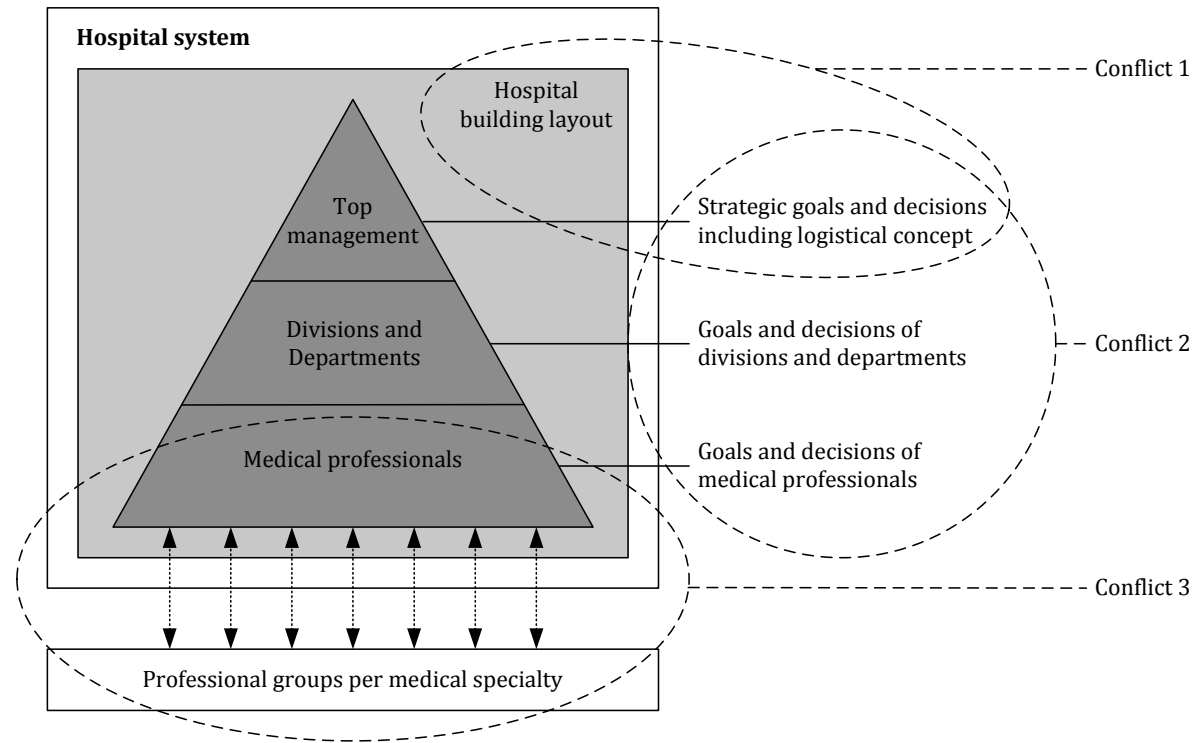

Conflict 1: Conflict between the physical lay-out of a hospital building and a process-oriented logistical concept

To achieve optimal efficiency, the physical layout of a building ideally has to support the logistical concept being applied. The basic form of the logistical concept is frequently also the basis for the layout of the hospital building, such as the organisational separation of outpatients' and inpatients' clinics in a functional basic form ${ }^{31}$. However, the life cycle of a hospital building is much longer than that of a logistical concept. During the life of a building, environmental changes occur, such as ageing populations, more demanding patients, new insights concerning treatment, and technological developments. These may lead to changes in the logistical concept, like the change towards a process-oriented logistical concept. As a consequence, there will be a conflict between the layout of a hospital building (which is based on the basic form of a previous functional logistical concept) and the newly applied logistical concept, which can result in the implementation of the process-oriented logistical concept having limited effects. 
Possible solution: since a hospital building layout is static and can only be altered at considerable expense, it is essential to create flexibility in the building to overcome this conflict between the layout of the building and newly developed logistical concepts. This flexibility can, for example, be created through the standardisation of consultation rooms ${ }^{32}$. Medical professionals of different specialties are then no longer bound to a specific section of the hospital to perform their subtask in a care process. To ensure that the flexibility of the designed hospital building layout fits a desired logistical concept, the layout should be assessed before the hospital is built, based on possible future developments in logistical concepts and changes in patient mix.

\section{Conflict 2: Conflict between top management's wish to implement a process-oriented logistical concept, the responsibilities of departments, and interests of medical specialists}

An effective implementation of a process-oriented logistical concept requires that the efficiency of care processes is given priority above the capacity utilisation of a department, both by department managers and medical specialists. After all, there is a trade-off between short waiting times and capacity utilisation: a higher capacity utilisation ('full agendas') reduces the possibility of immediate care for patients, and leads to waiting times ${ }^{28}$. In the traditional Dutch hospital organisations in which middle managers are responsible for the performance of their departments or divisions, the need for coordination at process level can consequently lead to friction with management responsibilities at division or department level. As departments lose autonomy, medical specialists feel they are less able to influence working conditions and to have control over their production. This hampers the implementation of a process-oriented logistical concept.

Possible solution: One way to overcome this conflict between top management's wish to implement a process-oriented logistical concept on the one hand, and the responsibilities of departments and the interests of medical specialists on the other hand, is for top management to base the allocation of financial means, in whole or in part, on the total care of a patient during an acute episode of illness ${ }^{33}$. This is in line with the theory of target engineering, which states that external pressures related to payment systems can be used to bridge internal conflicts of interests hampering efficiency and quality5, 34. As a result of the process-based payments, chain of care members have to work together from the start to organise care delivery in such a way that it will deliver full value. The result should be that the care delivery becomes better adapted to the needs of patients, but also that quality and efficiency improves as chain of care members analyse, redesign, and monitor their processes in more detail. 
Conflict 3: Conflict between the autonomy of medical specialists while delivering care in accordance with the values of their own professional groups and the requirements of a process-oriented logistical concept

The introduction of a process-oriented logistical concept requires from managers and medical specialists another view of the reality. They have to shift their focus from function to process. However, this change of perspective brings professionals into an area of conflict: medical specialists want to practise their profession autonomously in accordance with the high professional values of their own group, but are also expected to contribute to the process-oriented care delivery ${ }^{35}$. Medical professionals who have grown accustomed to working in keeping with particular procedures during years of training and education have to change their routines ${ }^{36}$. They feel that their autonomy at the level of care delivery to an individual patient is being limited because their action has to fit the path chosen ${ }^{37}$. This feels to them as though they have to give up part of their professional autonomy, as the implementation of process-oriented logistical concepts requires that the components of care delivery to specific patient groups be standardised. Consequently, these new routines or 'rules for work processes' do not develop automatically when top management decides to implement a process-oriented logistical concept.

Possible solution: There are many kinds of process improvement or innovation methods to develop routines that fit a process-oriented logistical concept. It is, for instance, assumed that the use of process improvement or innovation methods that focus on changing the patterns of interaction between professionals and the redesign of the overall work flow stimulates professionals to develop and implement new routines. However, a precondition is that professionals are motivated to participate in projects that aim to set new routines. Professionals can then execute their autonomy with other involved professionals in deciding what form a standard care programme should take.

\subsection{Study aim and research questions}

Central hypothesis: 'The implementation of process-oriented care delivery leads to better outcomes in terms of quality and efficiency at hospital level'.

In order to test the central hypothesis of this thesis, the overall research question is:

'Is the implementation of a process-oriented logistical concept effective for improving quality and efficiency of care delivery at hospital level?' 
The general research question is divided into a number of sub-questions and is explored in several studies. The designs and methods used in these studies are described in the chapters of this thesis. First, it is important to know which process-oriented logistical concepts top management wants to implement to improve the quality and efficiency of care delivery at hospital level: does top management tend to change the operating system and/or the basic form to strive towards process-oriented care delivery? And how effective are these logistical concepts in improving the quality and efficiency of care delivery? This leads to the first research question:

1. 'Which process-oriented logistical concepts do hospitals implement to deliver process-oriented care, and how effective are these in improving the quality and efficiency of care delivery?'

As described in Section 1.4, it may be expected that the success of a processoriented logistical concept is influenced by a number of conflicts that may arise when a new logistical concept is introduced in a hospital organisation. In this thesis, the possible effects of an evaluation of the flexibility of hospital building layout, a process-based payment system, and implementation methods used to overcome the accompanying conflicts are assessed in order to explore whether the use of these 'tools' may positively affect the outcomes of the implementation of a process-oriented logistical concept. This leads to the following research questions.

2. 'Does evaluation of the flexibility of hospital building layout contribute to the implementation of a new logistical concept?'

3. 'Do process-based payments contribute to the implementation of a processoriented logistical concept?'

4. 'Do improvement and innovation methods contribute to the implementation of a process-oriented logistical concept?'

\subsection{Outline of thesis}

The research questions are addressed in Chapters 2-7 of this thesis (see Table 1.1). Chapter 2 deals with the first research question. It presents a literature review on experiences of hospitals that have implemented process-oriented logistical concepts of care delivery. Next, in Chapter 3, the contribution of an evaluation method to examine the flexibility of hospital building layout with 
regard to the implementation of new logistical concepts is assessed using computer simulation techniques. Chapter 4 is concerned with the third research question, analysing the effect of process-based payment systems on the implementation of a process-oriented logistical concept. Subsequently, the contributions of a process innovation and improvement method on the implementation of a process-oriented logistical concept are assessed in Chapters 5 and 6. Chapter 5 focuses on the effectiveness of a process innovation method that radically implements the process-oriented logistical concept, and Chapter 6 centres on the effect of a process improvement method that aims to implement incrementally a process-oriented logistical concept with the help of standardised change ideas. Finally, Chapter 7 presents the main findings of this thesis on the sub-questions, along with a discussion addressing some considerations of the research, and conclusions regarding the main research question. In addition, several recommendations for future research and hospital practice are presented.

Table 1.1 Overview of the thesis

\begin{tabular}{lll}
\hline Research question & Chapter \\
\hline $\begin{array}{l}\text { 1. } \\
\begin{array}{l}\text { Implementation of process-oriented } \\
\text { logistical concepts and their } \\
\text { effectiveness in hospitals }\end{array}\end{array}$ & $\begin{array}{l}\text { Chapter 2 Towards an organisation-wide process- } \\
\text { oriented organisation of care: a literature review }\end{array}$ \\
\hline $\begin{array}{l}\text { Contribution of an ex-ante evaluation } \\
\text { method for hospital building layout } \\
\text { to the implementation of new logistical } \\
\text { concepts }\end{array}$ & $\begin{array}{l}\text { Chapter 3 Evaluating hospital design from an } \\
\text { operations management perspective }\end{array}$ \\
\hline
\end{tabular}

3. Contribution of process-based payment Chapter 4 Does case-mix-based reimbursement systems to the implementation of a stimulate the development of process-oriented care process-oriented logistical concept delivery?

4. Contribution of process improvement/ Chapter 5 How to implement process-oriented care: innovation methods to the a case study on the implementation of processimplementation of a process-oriented oriented in-hospital stroke care logistical concept 


\section{References}

1. Westert GP, Van den Berg MJ, Koolman X, Verkleij H: Dutch health care performance report. Bilthoven: National Institute for Public Health and Environment; 2008.

2. Hammer M, Champy J: Reengineering the corporation: a manifesto for business revolution. London: Nicholas Brealey; 1993.

3. Lega F, DePietro C: Converging patterns in hospital organization: beyond the professional bureaucracy. Health Policy 2005, 74(3):261-281.

4. Vera A, Kuntz L: Process-based organization design and hospital efficiency. Health Care Management Review 2007, 32(1):55-65.

5. Van Merode GG: A prelude of 2004 Antwerp quality conference: targets and target values - integrating quality management and costing. Accreditation and Quality Assurance 2004, 9:168-171.

6. De Vries G, Bertrand JWM, Vissers JMH: Design requirements for health care production control systems. Production Planning \& Control 1999, 10(6):559-569.

7. Plochg T, Lombarts K, Witman Y, Klazinga NS, Kruijthof K: Doctors and managers. Problems in Dutch hospitals resemble those in British hospitals. British Medical Journal 2003, 326(7390):656.

8. Van Lindert H, Hutten J, Groenewegen P: Specialist and hospital policy: the classical organsiation disappears (in Dutch). Medisch Contact 2003, 58(30/31):1164-1166.

9. Groenewegen PP, Hansen J, Ter Bekke S: Professies en de toekomst: veranderende verhoudingen in de gezondheidszorg. Utrecht: VVAA/Springer; 2007.

10. Ludwig M, Van Merode F, Groot W: Principal agent relationships and the efficiency of hospitals. The European Journal of Health Economics 2010, 11: 291304.

11. RIVM: Volksgezondheid toekomst verkenning, nationale atlas volksgezondheid (http://www.zorgatlas.nl), versie 3.18. Bilthoven: RIVM.

12. Capaciteitsorgaan: Capaciteitsplan 2008 voor de medische, tandheelkundige, klinisch technologische en aanverwante vervolgopleidingen. Utrecht; 2008.

13. Schäfer W, Kroneman M, Boerma W, Van den Berg M, Westert G, Devillé W, Van Ginneken E: The Netherlands: health system review. Health systems in transition 2010, 12(2):1-240.

14. CBS, Statistisch jaarboek. Voorburg/Heerlen: Centraal Bureau voor de Statistiek; 2008.

15. Vissers JMH, Beech R: Health operations management: patient flow logistics in health care. London: Routledge; 2005.

16. Visser HM, Van Goor AR: Working with logistics (in Dutch). Groningen/Houten: Wolters-Noordhoff; 2004. 
17. Van Merode F, Molema H, Goldschmidt H: GUM and six sigma approaches positioned as deterministic tools in quality target engineering. Accreditation and Quality Assurance 2004, 10:32-36.

18. Lee KH: The hospital movement - A complex adaptive response to fragmentation of care in hospitals. Annals Academy of Medicine Singapore 2008, 37(2).

19. Ministry of Health, Welfare and Sport: Care institutions quality act (in Dutch). The Hague; 1996.

20. Folmer K, Mot E: Diagnosis and treatment combinations in Dutch hospitals. The Hague: CPB Netherlands Bureau for Economic Policy Analysis; 2003.

21. Custers T, Arah OA, Klazinga NS: Is there a business case for quality in the Netherlands? A critical analysis of the recent reforms of the health care system. Health Policy 2007, 82(2):226-239.

22. Galbraith JR: Organization design: an information processing view. Interfaces 1974, 4(3):28-36.

23. Bohmer RMJ: Medicine's service challenge: blending custom and standard care. Health Care Management Review 2005, 30(4):322-330.

24. Gemmel P, Vandaele D, Tambeur W: Hospital process orientation (HPO): the development of a measurement tool. Gent: Ghent University, Belgium; 2007.

25. Vanhaverbeke W, Torremans H: Organizational structure in process-based organizations. Knowledge and Process Management 1999, 6(1):41-52.

26. Love PED, Gunasekaran A, Li H: Putting an engine into re-engineering: toward a process-oriented organisation. International Journal of Operations \& Production Management 1998, 18(9/10):937-949.

27. Majchrzak A, Wang Q: Breaking the functional mind-set in process organizations. Harvard Business Review 1996, 74(5):93-99.

28. Van Merode GG: Planning and reaction in care logistics. Oration (in Dutch). University Maastricht; 2002.

29. Liker JK: The Toyota way: 14 management principles from the world's greatest manufacturer. New York [etc.]: McGraw-Hill; 2004.

30. Bevan H, Glenn R, Bate P, Maher L, Wells J: Using a design approach to assist large-scale organizational change: '10 high impact changes' to improve the national health service in England. The Journal of Applied Behavioral Science 2007, 43(1):135-152.

31. Vissers JMH, De Vries G: Working on care processes. Oration (in Dutch). Rotterdam: Erasmus University; 2005.

32. Van Merode GG, Verreusel R, Vrieze KOJ, Zeemering S: Constructing new hospitals: the effects of innovative care organization. In Health Sciences Simulation Conference Proceedings: 2004; San Diego; 2004:25-28.

33. Davis K: Paying for care episodes and care coordination. New England Journal of Medicine 2007, 356(11):1166-1168. 
34. Kaplan RS, Cooper R: Cost and effect: using integrated cost systems to drive profitability and performance. Boston: Harvard Business School Press; 1997.

35. De Vries G, Van Tuijl H (Eds.): Health care under pressure: vital tension in the middle of organisations, a business approach. Houten: Bohn Stafleu van Loghum; 2006.

36. Van Raak A, Groothuis S, Van der Aa R, Limburg M, Vos L: Shifting stroke care from the hospital to the nursing home: explaining the outcomes of a Dutch case. Journal of Evaluation in Clinical Practice (accepted for publication).

37. Berg M, Schellekens W, Bergen C: Bridging the quality chasm: integrating professional and organizational approaches to quality. International Journal for Quality in Health Care 2005, 17(1):75-82. 


\section{Chapter 2}

\section{Towards an organisation-wide process-oriented organisation of care \\ a literature review \\ a literature review}

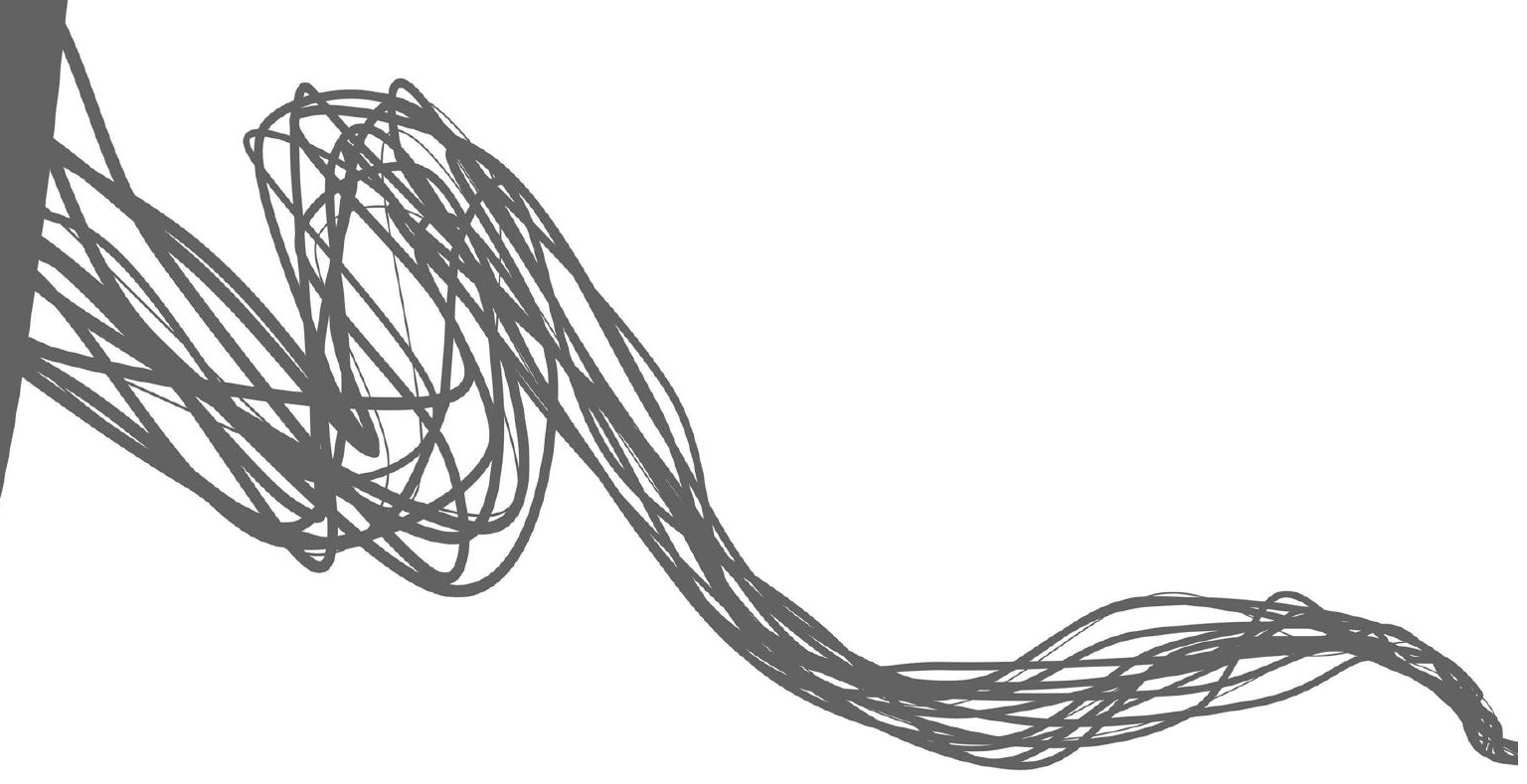

A revised version of this chapter was submitted as:

Leti Vos, Sarah E. Chalmers, Michel L.A. Dückers, Peter P. Groenewegen, Cordula Wagner, Godefridus G. van Merode. Towards an organisation-wide process-oriented organisation of care: a literature review. 


\subsection{Background}

During the last decade, hospitals have tried to move from functional to processoriented organisation forms. In a process-oriented hospital, the focus is on the process of care instead of on functional departments such as radiology and internal medicine. The central idea of process-oriented organisation design is that organising a hospital around care processes leads to more patient centred care, cost reductions and quality improvements ${ }^{1}$. The breakthrough of the process-orientation concept took place at the beginning of the 1990s under the name 'business process reengineering'1. Since then, many hospitals have undertaken actions to make care delivery more process-oriented, for example by the implementation of care programmes, clinical pathways or care pathways for specific patient groups. However, many hospitals struggle with the question of how to deal with process-orientation at hospital level. The realisation of process-orientation within the entire hospital organisation demands more of an organisation than performing single projects. Hospitals need to balance the optimisation of care processes with efficiency in use of resources in the functional departments, for example the use of scarce resources by several patient groups ${ }^{2}$.

\subsubsection{Theory}

\section{Process-oriented organisation design}

Traditionally, hospitals have a functional organisation structure. Within this organisational design individuals with a similar area of expertise are grouped into departments ${ }^{1,3-6}$. In this functional organisation design all departments strive to optimise their own functioning, but are often unable to integrate their services to meet the needs of patients ${ }^{7}$. A complex set of patient flows emerges where the care of the patient, their records, and the resources necessary for care have to be transferred across department boundaries in ways that are hard to predict 7 . Bottlenecks occur where one department pushes patients into another department that is not ready to take care of them. Due to this lack of coordination between departments, a functional organisation usually struggles with adaptation and efficiency problems in care processes ${ }^{7}$.

According to Vera et al. (2007) ${ }^{1}$, it is necessary to overcome the functional division of labour when an organisation wants to become process-oriented. Within a process-oriented organisational design the focus is on the process of care instead of organisational departments. The organisational design is then dominated by cross-functional patient flow. Further, the optimisation of the 
performance of each department becomes subordinate to the optimisation of the patient flow across the hospital ${ }^{2}, 8$. Additionally, it is important that all members of the different disciplines involved in the care delivery of a patient work together as a group and strive to achieve common goals ${ }^{4}{ }^{9}$. Ideally, the physical layout is also adapted to the care processes ${ }^{7,10}$. However, experts have noted that this is extremely hard to achieve in a pre-existing building ${ }^{11}$. Table 2.1 outlines the distinctions between functional and process-oriented organisational design.

Table 2.1 Characteristics of functional organisation and process-oriented organisations

\begin{tabular}{|c|c|c|}
\hline & Functional organisation & Process-oriented organisation \\
\hline $\begin{array}{l}\text { Organisation } \\
\text { design }\end{array}$ & $\begin{array}{l}\text { Similar capacities are grouped in a } \\
\text { department (according to their } \\
\text { specialisation, education and } \\
\text { training) }{ }^{1,3} \text {, product layout }{ }^{39}\end{array}$ & $\begin{array}{l}\text { Similar capacities are grouped in a } \\
\text { department (according to their speciali- } \\
\text { sation, education and training) }{ }^{1,3}, \\
\text { product layout }^{39} \text { with additional } \\
\text { coordinating structures (e.g. care } \\
\text { programmes) }{ }^{4} \\
\text { - or - } \\
\text { Multidisciplinary organisational } \\
\text { departments which are organised } \\
\text { around and based on care processes }{ }^{1,13} \text {, } \\
\text { process layout }^{7,10,39} \text {, layout follows } \\
\text { process }^{13}\end{array}$ \\
\hline $\begin{array}{l}\text { Organisational } \\
\text { Orientation }\end{array}$ & $\begin{array}{l}\text { Vertical orientation }{ }^{40} \text {, objectives for } \\
\text { an organisational department can } \\
\text { only be linked indirectly to value for } \\
\text { the patient }{ }^{13}\end{array}$ & $\begin{array}{l}\text { Patient-oriented }{ }^{13} \text {; horizontal } \\
\text { orientation that cuts across the } \\
\text { organisational departments }{ }^{4,13} \text {, } \\
\text { activities can directly be linked to value } \\
\text { for the patients }{ }^{10,40}\end{array}$ \\
\hline $\begin{array}{l}\text { Management } \\
\text { focus }\end{array}$ & $\begin{array}{l}\text { Managing departments (pieces of the } \\
\text { process) }{ }^{40} \text {, optimising department } \\
\text { performance (capacity use) }{ }^{7}\end{array}$ & $\begin{array}{l}\text { Managing processes (holistic view) }{ }^{14,40} \text {, } \\
\text { optimising patient flow }\end{array}$ \\
\hline $\begin{array}{l}\text { Decision } \\
\text { making }\end{array}$ & Centralised ${ }^{14}$ & Devolved to multidisciplinary teams ${ }^{13}$ \\
\hline $\begin{array}{l}\text { Responsibility } \\
\text { for care } \\
\text { processes }\end{array}$ & $\begin{array}{l}\text { No one is in charge of the processes, } \\
\text { because work is organised around } \\
\text { tasks }{ }^{13}\end{array}$ & $\begin{array}{l}\text { Process owners have the full } \\
\text { responsibility for the effective and } \\
\text { efficient running of a care process }{ }^{13}\end{array}$ \\
\hline
\end{tabular}

- table 2.1 continues - 
- table 2.1 continued -

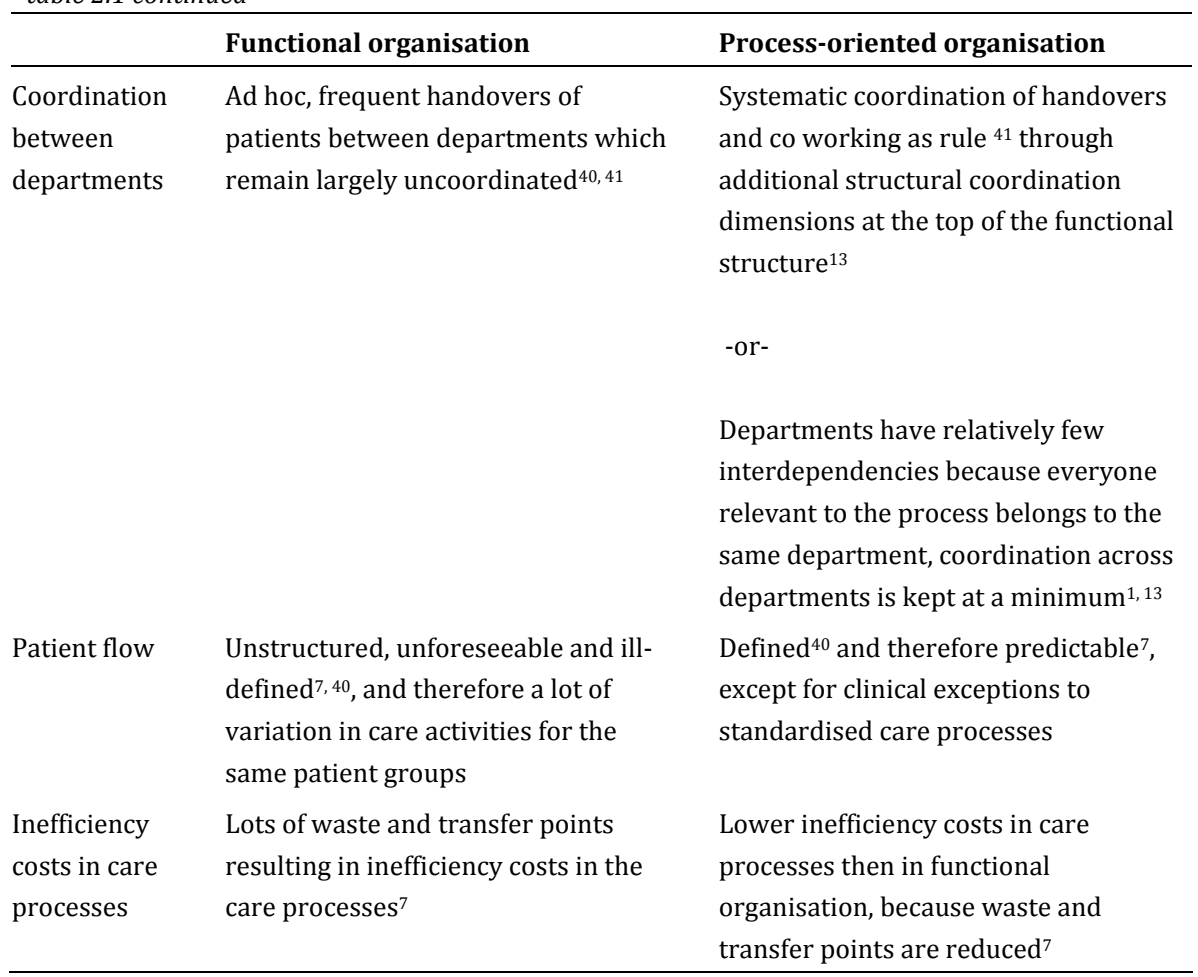

\section{Implementation of hospital wide process-orientation}

Vera et al. (2007) ${ }^{1}$ and Gemmel et al. (2008) ${ }^{4}$ described two main approaches to redesign functionally oriented care delivery to a more process-oriented care delivery:

A. By implementing coordination mechanisms;

B. By organisational restructuring.

\section{Ad. A. By implementing coordination mechanisms}

In the coordination mechanism approach the functional organisation is not changed, but coordinating structures, like care programmes or clinical pathways, are put on top of the existing organisation structure for the realisation of a smooth patient flow across boundaries of hospital departments ${ }^{4}$. These coordinating structures, in the form of lateral connections, are used to bridge barriers erected by an organisation's structure. They establish the sequence of care activities (diagnostics, consultations, treatment) and the responsibilities of professionals involved in the diagnosis and treatment of homogeneous patient groups. As a consequence, everybody 
involved in the care process should know what to expect in the next, and previous, steps.

\section{Ad. B. By organisational restructuring}

In the organisational restructuring approach, an organisational restructuring has to take place in which the needs of a patient form the basis of the new organisation structure 4 . This means that the health care chain, which contains multiple services and disciplines, has to be optimally organised and integrated with reference to the actual needs of the patient. In the extreme case, every patient can be regarded as a 'project' for which specific resources are temporarily united ${ }^{4}$. An aggregation of similar projects has been called a 'product line'12. These product lines are then organised in separate multidisciplinary departments, which bring together clinicians, nurses, allied health professionals, management staff, and clerical staff. These multidisciplinary departments can handle a care process as comprehensively as possible and have relatively few interdependencies with other multidisciplinary departments ${ }^{1,13,14}$.

The adoption of either of these approaches does not automatically imply an increase in process-orientation ${ }^{4}$. To effectuate process-orientation, a change of work processes is needed as well. Clinicians, for example, have grown accustomed to working according to particular procedures during years of training and education ${ }^{15}$. These routines are repetitive, recognisable, patterns of actions. Routines are confirmed and bound by formal, informal, written or unwritten rules ${ }^{16,17}$ like organisational procedures, protocols and guidelines for care delivery, contracts, agreements and job descriptions ${ }^{15}$. Adoption of an approach to move towards a process-oriented organisation is an adoption of a collection of rules as well, which, like other rules, are intended to structure, guide, constitute, allow, oblige or prohibit particular actions and interactions. However, these new rules are not always followed ${ }^{17}$ and it is unknown which (combination of) rules are effective.

\subsubsection{Study aim}

In an effort to extend the knowledge about transitions towards processorientation at hospital level, we performed a literature review. The aim of the literature review is to report and discuss approaches that hospitals adopt for the development to process-oriented organisations and the accompanying factors for success and failure in order to derive lessons for future transitions. 


\subsection{Methods}

\subsubsection{Search strategy}

We searched the Pubmed, Embase and Business Source Premier (BSP) databases for relevant English language articles with an abstract from January 1998 through May 2009. First, we searched the Medical Subject Headings database to find useful keywords (MeSH headings) and selected six potentially relevant terms: Efficiency, Organisational; Patient-Centred Care; Process Assessment (health care); Organisational Innovation; Product Line Management; Hospital Restructuring. Next, we performed a Major Topic search in Pubmed using these MeSH terms in combination with the MeSH headings Hospitals and Hospital Administration. These two terms were added to the search command because every study had to involve a hospital redesign regarding the management of the internal organisation of the hospital. In Embase we used the selected MeSH subheadings as keywords in our search. For the search in BSP, the list with all available standard keywords (subjects) in the database was scanned to find useful subjects. We selected 15 potentially relevant terms ('advanced planning \& optimisation', 'advanced planning \& scheduling', 'business logistics', 'business logistics management', 'corporate reorganisations', 'health care reform', 'organisational change', 'organisational structure', 'process optimisation', 'product lines', 'product orientation', 'production engineering', 'reengineering [Management]', 'work design', 'workflow'). We searched the BSP database with these keywords in combination with the term 'hospital'.

\subsubsection{Study selection and data extraction}

After performing our search with the selected MeSH headings, articles were reviewed on the basis of the title and abstract. The studies had to assess hospital redesign that aimed to improve the control of at least two interfering care processes in terms of process-related topics. The studied redesigns should not (mainly) be aimed at changing the specifics of clinical practice, but should concern improvements in the flow of patients through the hospital. Inclusion and exclusion criteria are summarised in Table 2.2. We decided not to specify inclusion criteria on outcome measures too strictly beforehand. Processorientation is a broad concept, covering a variety of structure, process and outcome parameters. Furthermore, we did not set criteria for the used study designs for the evaluation of the redesigns towards process-oriented organisations. In order to understand and evaluate this kind of interventions 
research methods need to shed light on the interaction between the intervention and its context ${ }^{18}$. Therefore, studies using observational research methods are also included in this study next to quantitative studies.

Table 2.2 Inclusion and exclusion criteria literature review

\begin{tabular}{|c|c|}
\hline Inclusion criteria & Exclusion criteria \\
\hline $\begin{array}{l}\text { Article should: } \\
\text { - Contain an abstract; } \\
\text { - } \text { Be written in English; } \\
\text { - } \text { Focus on hospital organisations; } \\
\text { - } \text { Address a restructure or redesign of } \\
\text { patient flow at organisational level, or at } \\
\text { least for two interfering care processes; } \\
\text { - } \quad \text { Contain a description of the } \\
\text { transformation process/actual } \\
\text { intervention; } \\
\text { - Be a study and not an editorial, letter to } \\
\text { the editor, or opinion piece; } \\
\text { - Have been published after January } 1^{\text {st }} \\
1998 \text { and before May } 1^{\text {st }} 2009 .\end{array}$ & $\begin{array}{l}\text { Article focuses on: } \\
\text { - Staff satisfaction and/or change only concerns job } \\
\text { redesign or responsibility changes; } \\
\text { - Changing the organisational structure or } \\
\text { redesigning at organisational level without aiming } \\
\text { improvement of patient flow; } \\
\text { - Changing the health structures at national levels; } \\
\text { - Changing hospital ownership or affiliation; } \\
\text { - Projects with main purpose of financial } \\
\text { improvement, except where this is used to form } \\
\text { basis of organisational change or incentives; } \\
\text { - Changing the organisation of a single functional } \\
\text { unit or a single care pathway; } \\
\text { - Change in software and/or hardware and IT with } \\
\text { no intended effect on patients flows; } \\
\text { - Description of methods, model and theories } \\
\text { without empirical data; } \\
\text { - The management of redesign and change projects; } \\
\text { - Redesign of buildings. }\end{array}$ \\
\hline
\end{tabular}

Two reviewers (LV and SC) independently scanned titles and abstracts to select studies for consideration. Initial disagreements on study selection were resolved by reaching consensus. Publications were selected for further assessment of the full text if inclusion criteria were met or if it was impossible to determine this based on the abstract. We used a standardised extraction checklist to obtain data on the main characteristics of the redesigns, study design, approaches used, relevant results, and factors for success and failure. Further, we looked in particular whether hospitals undertook specific measures to promote the adoption of new rules of the process-oriented organisation design within working procedures.

Additionally, we performed an extra search on the internet using Google $₫$ to find additional information about the redesigns that were described in the included articles of our search. For this search we used the name of the hospital and the keywords 'redesign' and 'reengineering'. 


\subsection{Results}

Figure 2.1 shows the flow of papers through the review. Overall, 325 abstracts of articles published between January 1998 and May 2009 were identified. During abstract screening, 282 articles were excluded because they did not meet the inclusion criteria. A total of 43 articles was selected for detailed review, 33 additional articles were excluded subsequently for not meeting inclusion criteria. Three of the ten remaining articles described different aspects of the redesign of policlinico A. Gemelli (PG) ${ }^{19-21}$, and two other articles described different aspects of the redesign of the Leicester Royal Infirmary (LRI) ${ }^{22,}$ 23. The remaining four articles described redesigns of Denver Health (DH), Flinders Medical Center (FMC) and University of Wisconsin Hospitals and Clinics (UWHC). As a result, a total of five redesigns are described in this review. Our search on the internet using Google $\AA$ provided extra information about the redesigns of $\mathrm{DH}^{24}, \mathrm{FMC}^{25-27}$ and $\mathrm{LRI}^{28,29}$.

The study designs, approaches used, applied supporting measures for the adoption of the approach, reported outcomes and factors for success and faced challenges of the five included redesigns are summarised in Table 2.3 based on the retrieved literature. 
Figure 2.1 Selection process for studies included in analysis

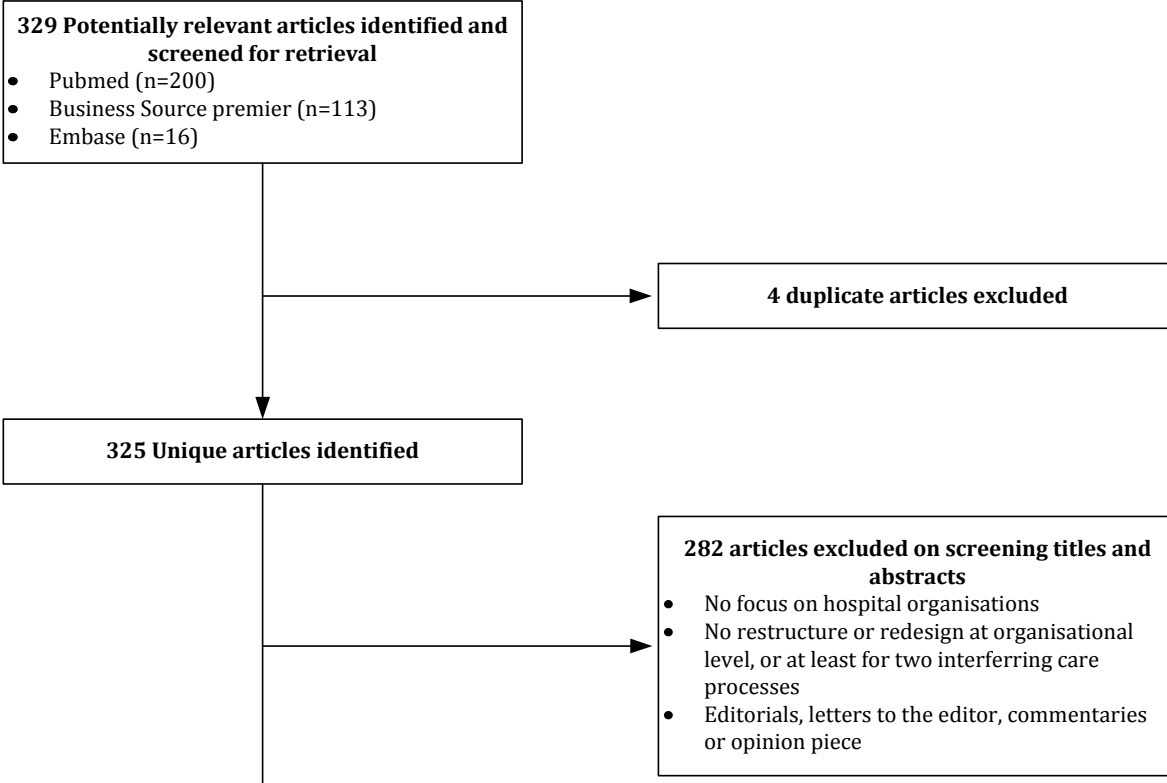

43 Potentially appropriate articles identified for

- Pubmed (n=37)

- Business Source Premier $(n=6)$

- Embase $(\mathrm{n}=0)$

33 articles excluded after full-text review

- No focus on hospital organisations

- No restructure or redesign at organisational level, or at least for two interfering care processes

Focus is on staff satisfaction/ job redesign, health structures at national level, change of hospital ownership/ affliation, financial improvement, change of a single department/ care pathway, change in ICT, redesign of supply systems, redesign of buildings

- Editorials, letters to the editor, commentaries or opinion piece

10 articles included in final review 


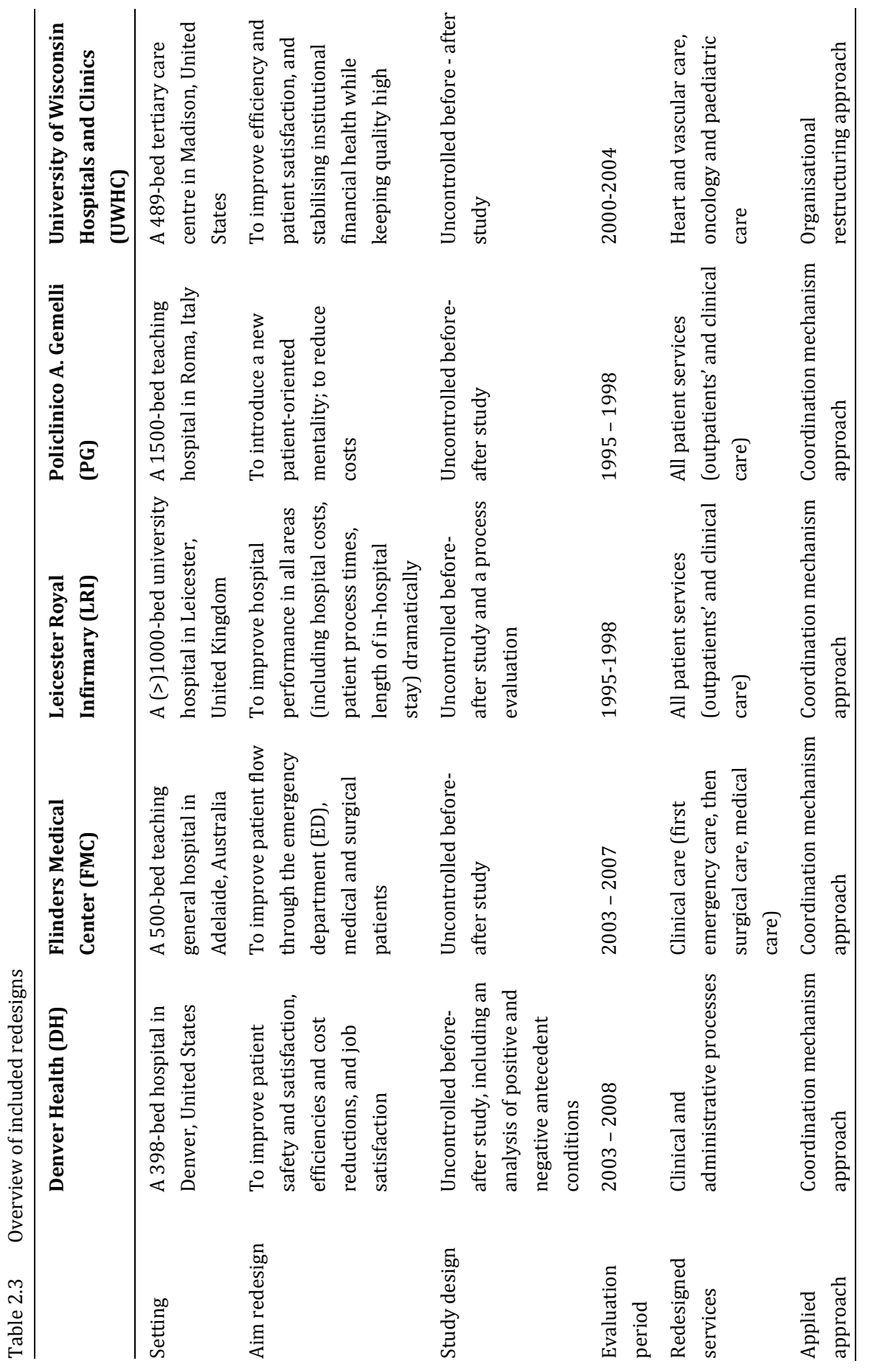




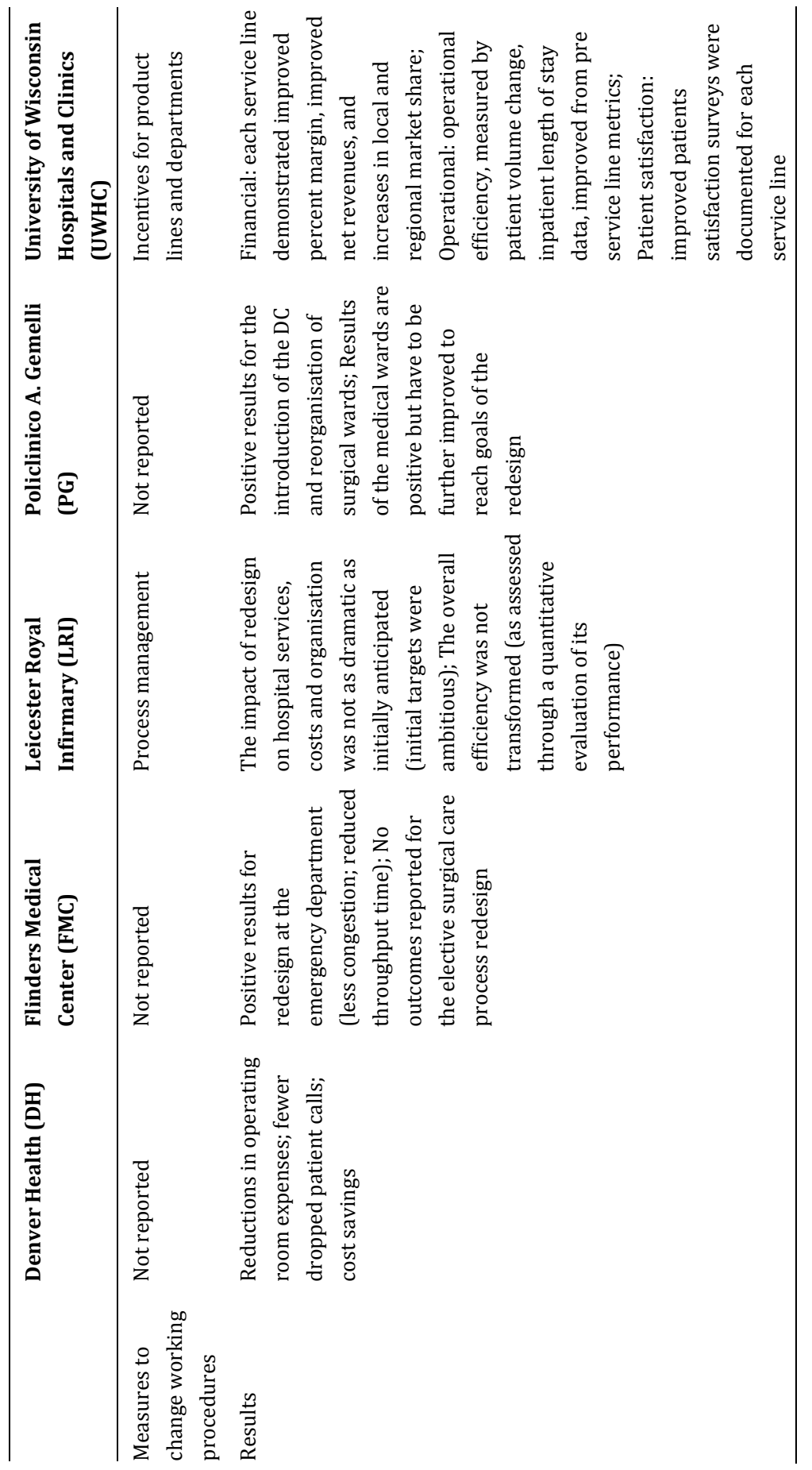




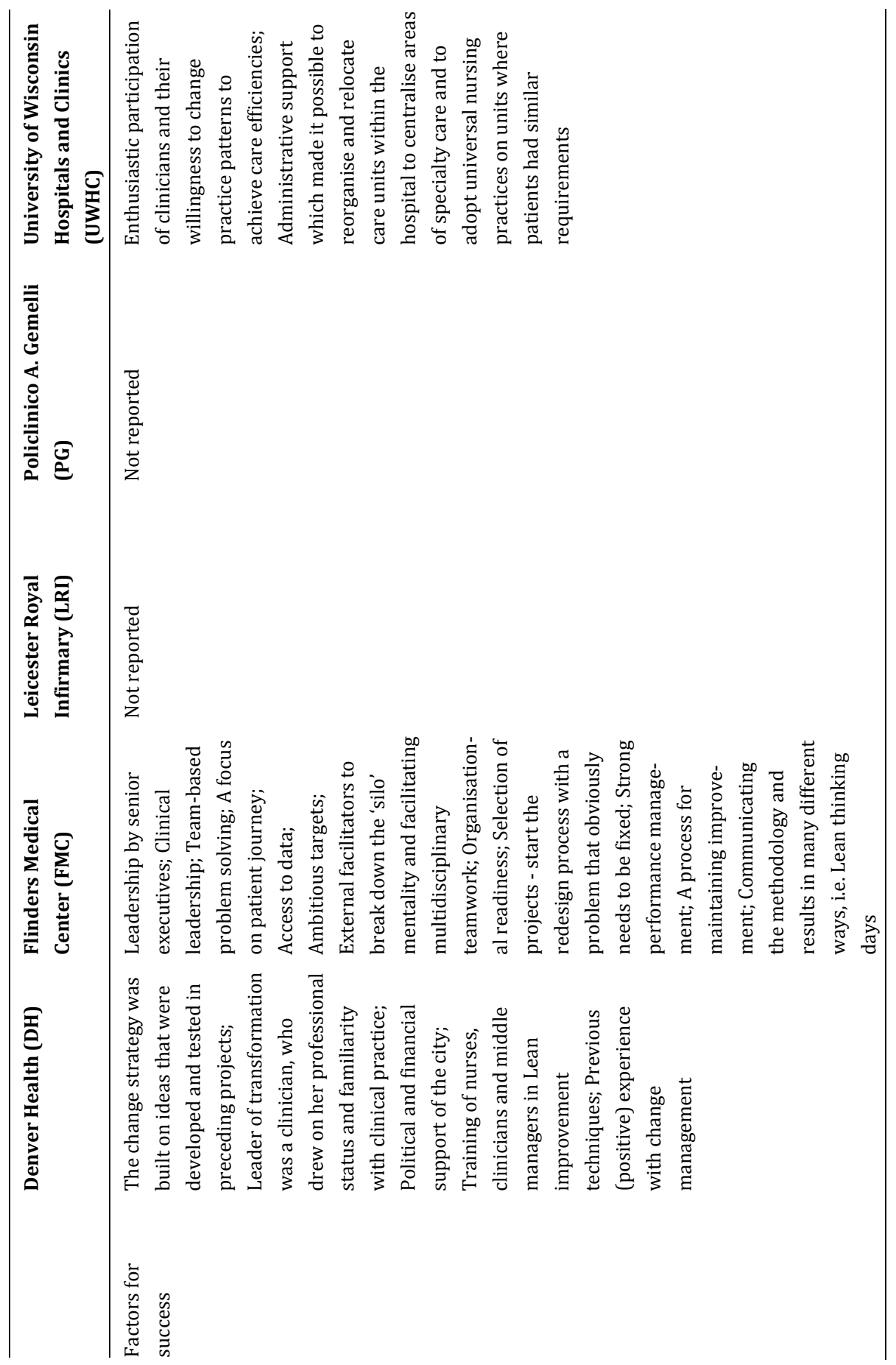




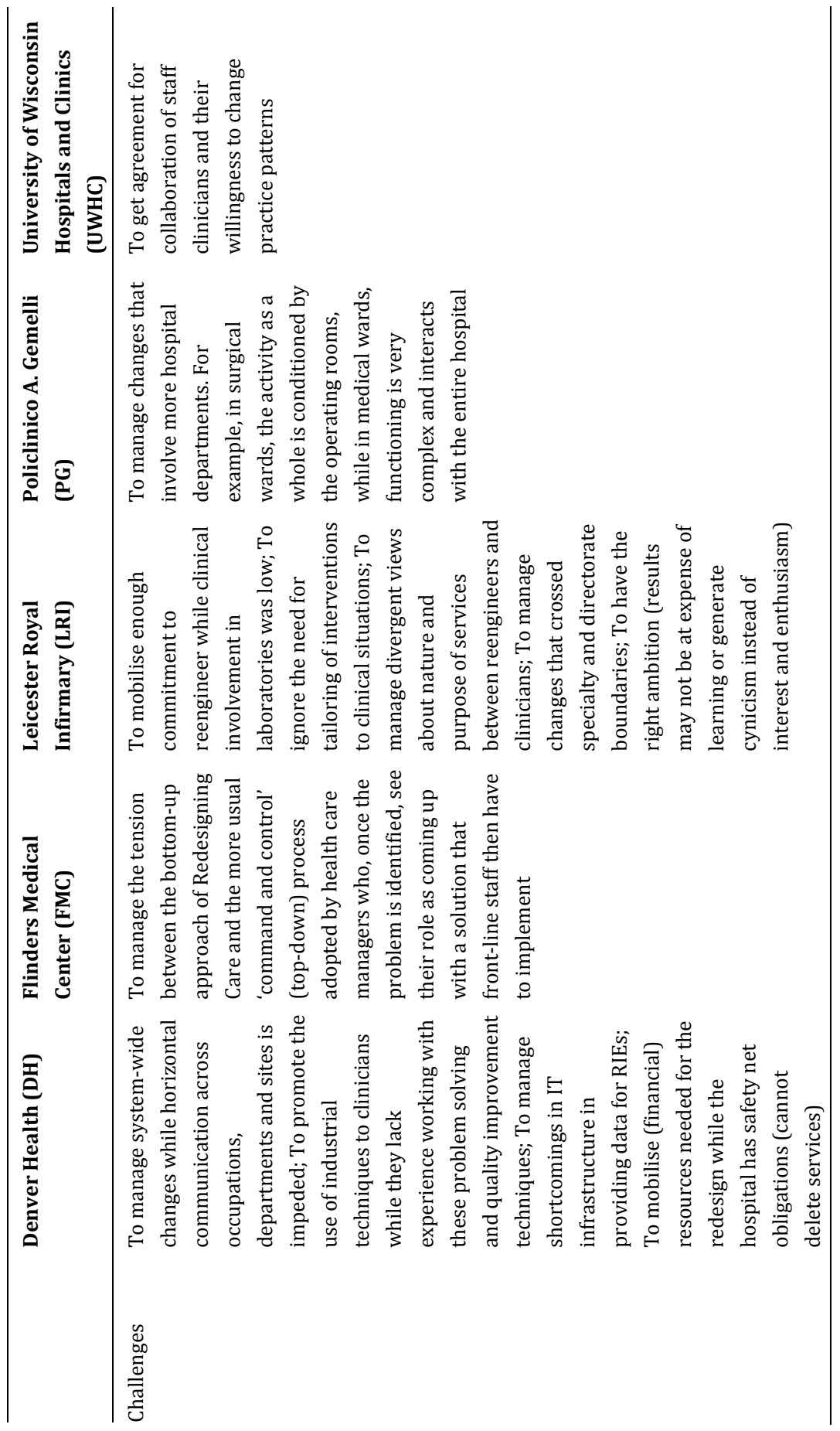




\subsubsection{Main characteristics of redesigns found}

The articles reported on redesigns in Australia (FMC), Italy (PG), United Kingdom (LRI) and United States (DH, UWHC) ${ }^{19-23,30-32}$. Two of these redesigns aimed to implement process-orientation for all hospital services (PG, LRI) ${ }^{19-23}$. The other redesigns were limited to clinical care (DH, FMC) ${ }^{30}, 31$ and three service lines (heart and vascular care, oncology and paediatric care) (UWHC) ${ }^{32}$. All redesigns aimed to improve the patient flow through the hospital, and some had additional goals: cost reductions/efficiency improvements ${ }^{19-23,31,32}$, patient safety $^{31}$, patient satisfaction ${ }^{31,32}$ and job satisfaction ${ }^{31}$.

\subsubsection{Study designs}

All redesigns were evaluated in uncontrolled before-after study designs. From the assessment of the PG, DH and FMC redesigns precise information on study design, data gathering strategies and outcome measures were lacking. The evaluation of the LRI redesign contained an assessment of changes in quantity and costs of the health care delivered using routine hospital and health authority data sources and specific monitoring data of the redesign programme ${ }^{29}$. Besides, a process evaluation that aimed to describe antecedents, context, implementation and impact of the LRI redesign and to derive lessons regarding management of change, was performed ${ }^{29}$. For this process evaluation additional qualitative data were gathered by documentation research, interviews, and notes from informal conversations and observational data from meetings. The evaluation of the UWHC redesign included service-line metrics on financial performance, operational efficiency and patient satisfaction, using hospital data and patient surveys ${ }^{32}$.

\subsubsection{Approaches used to move towards a process-oriented organisation}

\section{Coordination mechanism approach}

Four of the five redesigns (DH, FMC, LRI and PG) followed the coordination mechanism approach for the implementation of process-orientation. Three of these redesigns (DH, LRI and PG) identified first common processing steps in medical treatment processes of patients, e.g. triage, diagnosis and treatment. They subsequently analysed and optimised these processing steps by implementing coordination measures. 
Denver Health's (DH) selected five overarching processing steps, 'access', 'inpatient flow', 'outpatient flow', 'operating room flow' and 'billing', as targets for the redesign of clinical and administrative processes 24,31 . For each processing step, a detailed map was created to diagram its current state, ideal state, and likely future state. DH then initiated a series of week-long 'RapidImprovement Events (RIEs)' five of which were conducted each month to improve individual processes within each processing step. In these RIEs processes were mapped and unnecessary activities removed. A RIE for the processing step 'access' was for example to improve the telephone-call abandonment rate. Next to the optimisation of common processing steps, DH focused on development of its infrastructure for information technology and workforce (identifying the 'right people' through personnel selection techniques).

Leicester Royal Infirmary (LRI) identified four hospital processing steps, 'patient visit', 'patient test', 'emergency entry', 'hospital stay', and planned to redesign these processing steps within specially created 'laboratories'22, 23. Originally, they planned to redesign the 'patient test' and 'patient visit' (diagnostic services and outpatient clinics) first before redesigning 'emergency access' and 'patient visit' (clinical care processes). However, this phased approach was replaced by plans to redesign the processing steps concurrently to reduce chances of creating a partially redesigned organisation and to manage the interaction between hospital processes and challenging existing departmental and functional boundaries. Nevertheless, reengineering became more local than corporate because it was shaped and managed at the level of groupings of functional departments. The 'laboratories' were dismantled and the responsibility and accountability for redesign projects were shifted from reengineers in laboratories to functional departments to better suit the redesign of the processing steps to local interests and agendas.

The Policlinico A. Gemelli (PG) identified five processing steps of the medical treatment process of patients as targets for their redesign: 'emergency care', 'outpatient care', 'diagnostic service and laboratories', 'operating rooms' and 'medical/surgical care'19, 20. Subsequently, PG identified patient groups that are processed equally within these processing steps, e.g. outpatients or inpatients that are booking an outpatient (follow-up) appointment. Next, they optimised these processing steps, starting at the pre-hospitalisation process and the scheduling for outpatients appointments. The pre-hospitalisation process was for example optimised by planning all preoperative care activities (routine tests, initial patient evaluation) on 1 day. 
In contrast to the three redesigns described, the Flinders Medical Center (FMC) did not focus its redesign at the optimisation of individual processing steps of care processes (e.g. scheduling outpatients' appointments), but on the optimisation of the patient flow between and within processing steps of care processes $^{25}$, 30. The FMC first divided the clinical care processes in emergency, surgical and medical care. Within these three groups, FMC identified high volume patient flows by searching for patient groups that had a number of processing steps in common ('patient-care families'), for example for 'short emergency care' (likely to be discharged) and for 'long emergency care' (likely to be admitted). Next, they looked at the processing steps of the identified patient-care families to improve the sequencing of the processes involved by eliminating 'waste': steps in a care process that do not add value to a care process (e.g. waiting times, unnecessary movement of personnel and patients). This involved mapping out the daily processes for clinical teams, then obtaining agreement on new sequences. Once an efficient and effective way of undertaking a process had been developed and agreed on, it became a standard procedure. This happened for instance for the way medical staff organise their day across the hospital ${ }^{25,30}$. While using this method, the FMC worked gradually towards process-orientation of their clinical care processes: first they redesigned all emergency care processes, followed by the surgical and medical care processes.

\section{Organisational restructuring approach}

University of Wisconsin Hospitals and Clinics (UWHC) followed the organisational restructuring approach. The UWHC gradually worked to a product line matrix structure, in which disease-and patient based processes are streamlined in focused clinical units. An internal and external market analysis led to the selection of the first three clinical areas (heart and vascular care, oncology and paediatric care) for service line development ${ }^{32}$. These three areas had the necessary leadership in place, institutional strength, and there was regional need for these services. The services were centralised to geographical areas of the hospital dedicated to care and management of these patient groups. This included relocation and redesign of hospital units and diagnostic facilities for heart and vascular patients, the oncology service line and the construction of a free standing adjacent children's hospital tower ${ }^{32}$. In 2006, the UWHC was planning to expand from three to six service lines. The newest additions were transplantation, neuroscience and orthopaedics. 


\subsubsection{Supporting measures to change working procedures}

It appeared that two hospitals took supporting measures to promote compliance to the rules of the process-oriented organisation design on the work floor. Within the redesign of LRI, hospital management tried to enforce compliance by changing authority and power structures. LRI introduced process management as an attempt to strengthen managerial accountability and responsibility for patient processes at the level of the functional departments; and to improve managerial communication and decision making across functional departments ${ }^{22,23}$. UWHC developed an incentivisation process which allowed both departments and product lines to have financial rewards for success, in order to enforce compliance to the new working methods as well as to sustain the quality of all services that were not yet redesigned ${ }^{32}$.

\subsubsection{Reported outcomes of the redesigns}

There are large differences between the types of outcomes described. Of four redesigns (FMC, PG, LRI and UWHC) data from before and after implementing changes to become process-oriented were reported ${ }^{20,30,32}$. The reported results of the FMC and PG redesigns were limited to a number of positive process related outcomes of patient groups or specific departments (e.g. throughput times, waiting times, length of in-hospital stay) ${ }^{20,}{ }^{30}$. LRI's redesign led to improvements but these were not as big as initially anticipated. Besides this LRI's system redesign did not lead to more overall efficiency 22,23 . LRI did not succeed in significantly reconfiguring previous patterns of organisation: clinical directorates and specialties survived as organisational forms ${ }^{23}$. The redesign of UWHC resulted in improved operational efficiency, patient satisfaction and financial performance ${ }^{32}$. Of the remaining redesign, $\mathrm{DH}$, only qualitative descriptions of the results were reported in the retrieved literature: 'It led to reductions in operating room expenses, fewer dropped patient calls and cost savings'31.

\subsubsection{Factors for success and challenges faced}

In three redesigns (FMC, DH and UWHC) we found factors for success in the retrieved literature, including: senior management support ${ }^{27}$; clinical leadership and involvement ${ }^{27}$, 31, 32; team-based problem solving 27 ; adequate ICT support 27,31 ; administrative support ${ }^{32}$; ambitious targets ${ }^{27}$; external facilitators ${ }^{27}$; organisational readiness ${ }^{27}$; selection and execution of projects in 
order of urgency ${ }^{27}$; using a change strategy that already proved to be successful ${ }^{31}$; good communication and training in the quality improvement techniques ${ }^{27,31}$.

In the retrieved literature about all five redesigns challenges to the redesigns were reported (see also Table 2.3). The main challenges that were reported by the hospitals that followed the organisational restructuring approach were related to the improvement techniques used within the redesigns, the organisational structure, and the nature of care delivery. Three of the four hospitals (FMC, DH and LRI) mentioned that the technique used for process improvement was sometimes challenging. Two of these hospitals made use of 'Lean' as core technique, which originates from industry. The aim of this technique is to optimise care processes or processing steps by the elimination of activities that do not add value to the patients, like waiting times or movements of staff and patients. In DH, the application of 'Lean' was sometimes difficult because clinicians lack experience with this kind of improvement technique ${ }^{31}$. In FMC, the 'Lean' technique posed a challenge to the middle and senior managers ${ }^{30}$. They had to change roles from the traditional, top down, problem solving responsibilities towards a more bottom-up approach, in which they first had to understand how the work is done as well, as what the root causes of delays are and other impediments to flow, before they could come up with a solution. In LRI, the redesign was based on Business Process Redesign, which aims at radical improvements. Consistent with the logic that people need to think big and radically to realise big improvements, LRI set ambitious aims for its redesign, but these turned out to be too ambitious, which came at the expense of learning and generated cynicism instead of interest and enthusiasm ${ }^{28}$.

Furthermore, two hospitals (LRI and DH) reported that the nature of care delivery prevented them to fully apply the selected approach to come to a process-oriented organisation. DH, did not feel free, like most firms in industry, to delete services and focus on strategically important services ${ }^{31}$. This hampered DH to free financial resources needed for the redesign. In LRI, the nature of care delivery hampered 'rolling out' a redesigned process in a rapid and mechanistic fashion. The need to tailor the redesigned processes to different clinical situations took time.

In addition, three hospitals (PG, DH and LRI) reported that the existing departmental and functional boundaries hampered the implementation of the redesign. PG experienced that making changes was much more difficult in departments which interact with the entire hospital than in departments, e.g. 
surgical wards, that are conditioned by one department, like the operating room $^{20}$. DH perceived a lack of horizontal communication across occupations, departments and sites ${ }^{31}$. LRI experienced that making changes across the interfaces of existing specialties and clinical directorates was a slow and difficult process. The introduction of process management to improve managerial communication and decision making across specialties and clinical directorates could not significantly change this pattern ${ }^{23}$. In contrast, the hospital that adopted the organisational restructuring approach did not report any of the above mentioned difficulties. Instead, the UWHC reported difficulties in clinician collaboration ${ }^{32}$.

\subsection{Discussion}

Worldwide, hospital organisations are changing their functional structure into structures which focus on patient care processes. In this literature review we assessed five examples of hospitals that pursued a process-oriented organisational form and the accompanying factors affecting their success of failure in the redesign process. The study points out that four out of five hospitals tried to move to a process-oriented organisation of care by the implementation of coordination mechanisms. Only one of them followed the organisational restructuring approach. From the results of these hospitals it seems that the adoption of either approach can possibly lead to the desired process-orientation. The UWHC redesign demonstrated that the adoption of the organisational restructuring approach can be relatively successful: patient satisfaction, financial outcomes and operational outcomes of the redesigned services were improved. However, the UWHC adopted the organisational restructuring approach for only three, and later on six, strategically important patient groups. This leaves the question whether the organisational restructuring approach would also be successful for strategically less important services or for the organisation of care delivery for patients with needs not that do not fit within existing product lines. Vera et al. (2007) ${ }^{1}$ already pointed out that this could be difficult, because political and ethical obligations of hospitals prevented them from withdrawing services to focus only on strategically important ones.

Three of the four other hospitals (DH, FMC and PG) demonstrated that the coordination mechanism approach can lead to positive results, but they did not report on the results very extensively. FMC and PG only reported some general results on process measures, and DH only reported qualitative descriptions. LRI, on the other hand, evaluated its redesign extensively, but the results were 
disappointing: financial outcomes and practice patterns showed no improvement. Patient satisfaction was not measured. From the reported factors for failure it appeared that the adoption of the coordination mechanism approach was constrained, particularly by the functional organisational design of hospitals. Improvement of control at process level requires that departments subordinate the performance of their department (utilisation of resources) to the service level provided to patients (e.g. short access times, waiting times for diagnostic examinations, and throughput times) ${ }^{33}$. An attempt of LRI to break the previous pattern of the functional organisation by the implementation of non committal process management, did not work ${ }^{23,28}$. This underlines the importance of measures that enforce compliance. Vera et al. (2007) ${ }^{1}$ recommend, for example, the establishment of incentives that are based on the performance of care processes. Further, it seems that within this approach an initial focus on logistically homogeneous patient groups, assisted by bottom-up knowledge of health care professionals, could help to overcome the functional division of labour. From the description of the redesigns it appeared that the redesigns that had an initial focus on overarching processing steps of medical treatment of patients (DH, LRI and PG), in the end mainly implemented improvements in departmental processes instead of improvements that made patient flow more smoothly. For example, PG optimised the scheduling of outpatients, DH optimised the outpatient flow and LRI the patient visit at the outpatient clinic. Optimisation of these 'isolated' processing steps does not lead to more collaboration between departments and more process-orientation within the whole care trajectory of patients. Besides, the optimisation of linkages between the processing steps will in this way escape from the attention of the hospital. However, it appeared from the FMC redesign that an initial focus on logistically homogenous patient groups encouraged health care professionals to work together as a group to optimise linkages between processing steps, and to delete all steps in a care process that did not add value.

Next to these specific points of interest for the different approaches to become process-oriented, we could derive some more general lessons for future redesigns from the results of the literature review. First, tailoring is needed. LRI tried to roll-out general redesigns of processing steps to every clinical situation, but this appeared to be impossible due to the multitude of different clinical and disease patterns. Second, clinical engagement, and additional support for the use of quality improvement techniques, is crucial to the success of the redesign. The evaluations of the DH, FMC, LRI and the UWHC redesigns pointed out that changes to clinical services cannot succeed without the input of clinicians. On the other hand, it appeared in two redesigns (FMC and DH) that clinicians lack experience in applying improvement techniques. Besides, professionals 
working in hospitals already face huge demands on their time, and, justifiably, may not always be willing to prioritise time consuming service redesign over spending time with patients. Therefore, it is very important to involve clinicians in redesigning services and to also offer them administrative support.

Unfortunately, we are not able to judge which of the two approaches delivers the best results in which circumstances. For such an assessment more studies are needed. Such studies have to include evidence on study design, objectives, approach, patient population and results. Limitations of the review method followed should be considered in interpreting the results. As in any review we may have missed relevant studies. We believe that given the worldwide amount of activity of hospitals to become process-oriented, a very limited number of studies has been published addressing approaches to move towards a processoriented organisation design. This is probably due to the nature of the phenomenon studied. Like other types of planned change or innovation, (successful) organisation wide redesign moves sequentially from awareness of gaps, to identification of solutions, implementation of selected solutions, and institutionalisation of solutions ${ }^{12}$. This hampers evaluation and publication of these kinds of interventions. Another explanation of the limited number of studies we found could be the fact that process-orientation in hospitals does not succeed and that studies about failures are not published. The cause of failure could be the strong institutionalised functional division of tasks in health care systems, which is also apparent within the education of medical professionals.

To extend theories and knowledge about the best approaches to become process-oriented, and how to overcome barriers to success, it is important to assess each effort to implement a redesign and to assess it properly. Since redesigns are complex interventions that are introduced into complex and diverse 'social worlds'34,35, it is important that the types of research methods used to understand and evaluate these redesigns shed light on the interaction between the characteristics of the redesign and its context. Quantitative research methods tend to focus on general trends and are unlikely to clarify interaction processes between the redesign and its context ${ }^{35-38}$. Therefore we recommend the use of diverse qualitative research methods (e.g. observation, semi-structured interviews) as well as quantitative methods. Qualitative research methods provide an informative analysis 'discerning what works for whom, in what circumstances, in what respects and how'18. This analysis is needed to provide a 'thick description' of the redesign process, i.e. a meaningful description of the redesign process in its context. The quantitative measurements have to include a wide range of measurements. Besides 
logistical outcomes, it is also important to measure financial outcomes, patient satisfaction and process-orientation of health care professionals. These last measurements are very important: after all, top management may change structures, including reporting responsibilities of middle and lower management, but this does not automatically lead to more process-orientation in work processes, which is needed to effectuate the process-orientation at hospital level. Frequently, additional measures are needed to change old working habits and routines.

\subsection{Conclusion}

Due to the limitations of the evidence, it is not known which approach, implementation of coordination measures or organisational restructuring, produces the best results in which situation. Therefore, more research is needed. Within this research, the use of diverse qualitative methods in addition to quantitative measures is recommended to be able to understand the interaction between the characteristics of the redesigns and their context. Hospitals are advised to take the factors for failure described into account and to take suitable actions to counteract these obstacles on their way to become process-oriented organisations. 


\section{References}

1. Vera A, Kuntz L: Process-based organization design and hospital efficiency. Health Care Management Review 2007, 32(1):55-65.

2. Vissers JMH, Beech R: Health operations management: patient flow logistics in health care. London: Routledge; 2005.

3. Braithwaite J: Strategic management and organisational structure: transformational processes at work in hospitals. Australian Health Review 1993, 16:383-404.

4. Gemmel P, Vandeale D, Tambeur W: Hospital process orientation (HPO): the development of a measurement tool. Total Quality Management \& Business Excellence 2008, 19(12):1207-1217.

5. Lega F, DePietro C: Converging patterns in hospital organization: beyond the professional bureaucracy. Health Policy 2005, 74(3):261-281.

6. Van Merode GG: A prelude of 2004 Antwerp quality conference: targets and target values - integrating quality management and costing. Accreditation and Quality Assurance 2004, 9:168-171.

7. Van Merode F, Molema H, Goldschmidt H: GUM and six sigma approaches positioned as deterministic tools in quality target engineering. Accreditation and Quality Assurance 2004, 10:32-36.

8. Berg M, Schellekens W, Bergen C: Bridging the quality chasm: integrating professional and organizational approaches to quality. International Journal for Quality in Health Care 2005, 17(1):75-82.

9. Ludwig M, Van Merode F, Groot W: Principal agent relationships and the efficiency of hospitals. The European Journal of Health Economics 2010, 11: 291304.

10. Liker JK: The Toyota way: 14 management principles from the world's greatest manufacturer. New York [etc.]: McGraw-Hill; 2004.

11. Bevan H, Glenn R, Bate P, Maher L, Wells J: Using a design approach to assist large-scale organizational change: '10 high impact changes' to improve the national health service in England. The Journal of Applied Behavioral Science 2007, 43(1):135-152.

12. Shortell SM, Kaluzny AD (Eds.): Health care management: organization design and behaviour. 4th edition. Clifton Park: Thomson Delmar; 2000.

13. Vanhaverbeke W, Torremans H: Organizational structure in process-based organizations. Knowledge and Process Management 1999, 6(1):41-52.

14. Love PED, Gunasekaran A, Li H: Putting an engine into re-engineering: toward a process-oriented organisation. International Journal of Operations \& Production Management 1998, 18(9/10):937-949. 
15. Van Raak A, Groothuis S, Van der Aa R, Limburg M, Vos L: Shifting stroke care from the hospital to the nursing home: explaining the outcomes of a Dutch case. Journal of Evaluation in Clinical Practice (accepted for publication).

16. Scott RW: Institutions and organizations (2sd edition). Thousand Oaks: Sage; 2001.

17. Van Raak A, Paulus A, Cuijpers R, Velde C: Problems of integrated palliative care: a Dutch case study and cooperation in the region of Arnhem. Health \& Place 2008, 14(4):768-778.

18. Pawson R, Greenhalgh T, Harvey G, Walshe K: Realist Review - a new method of systematic review designed for complex policy interventions. Journal of Health Services Research and Policy 2005, 10(S1):21-34.

19. Catananti C, Celani F, Cambieri A, De Angelis C: Phase 1: identifying critical success factors. Rays 1998, 23(2):270-287.

20. Catananti C, Celani F, Marchetti M: Management process reengineering of the 'Policlinico A. Gemelli': outcomes of testing. Rays 1998, 23(2):295-309.

21. Marano P, Fioretti P, Bellomo S, Ceruti R, Masera P, Zaccheo L: Hospital reengineering project at the 'Policlinico A. Gemelli'. Rays 1998, 23(2):263-269.

22. McNulty T: Reengineering as knowledge management: a case of change in UK healthcare. Management Learning 2002, 33(4):439.

23. McNulty T, Ferlie E: Process transformation: limitations to radical organizational change within public service organizations. Organization Studies (01708406) 2004, 25(8):1389-1412.

24. Nuzum R, McCarthy D, Gauthier A, Beck C: Denver health: a high-performance public health system. New York: The Commonwealth Fund; 2007.

25. Ben Tovim DI, Bassham JE, Bennett DM, Dougherty ML, Martin MA, O'Neill SJ, Sincock JL, Szwarcbord MG: Redesigning care at the Flinders medical centre: clinical process redesign using 'lean thinking'. Medical Journal of Australia 2008, 188(6 Suppl):S27-31.

26. Ben Tovim DI, Dougherty ML, O'Connell TJ, McGrath KM: Patient journeys: the process of clinical redesign. Medical Journal of Australia 2008, 188(6 Suppl):S1417.

27. McGrath KM, Bennett DM, Ben Tovim DI, Boyages SC, Lyons NJ, O'Connell TJ: Implementing and sustaining transformational change in health care: lessons learnt about clinical process redesign. Medical Journal of Australia 2008, 188(6 Suppl):S32-35.

28. McNulty T, Ferlie E: Reengineering health care. The complexities of organizational transformation. Oxford: Oxford University Press; 2004.

29. Browns IR, McNulty T: Re-engineering Leicester Royal Infirmary: an independent evaluation of implementation and impact. Sheffield: School of Health and Related Research; 1999. 
30. Ben Tovim DI, Bassham JE, Bolch D, Martin MA, Dougherty M, Szwarcbord M: Lean thinking across a hospital: redesigning care at the Flinders medical centre. Australian Health Review 2007, 31(1):10-15.

31. Harrison MI, Kimani J: Building capacity for a transformation initiative: system redesign at Denver Health. Health Care Management Review 2009, 34(1):42-53.

32. Turnipseed WD, Lund DP, Sollenberger D: Product line development: a strategy for clinical success in academic centers. Annals of Surgery 2007, 246(4):585-590.

33. Vissers JMH: The development of operations management in hospitals and the role of middle managers (in Dutch). In Health care under pressure: vital tension in the middle of organisations, a business approach. Edited by De Vries G, Van Tuijl H. Houten: Bohn Stafleu van Loghum; 2006.

34. Bate P, Medel P, Robert G: Organizing for quality: the improvement of leading hospitals in Europe and the United States. Oxford: Radcliffe; 2008.

35. Powell A, Rushmer R, Davies H: A systematic narrative review of quality improvement models in health care. Edinburgh: NHS Quality Improvement Scotland; 2009.

36. Berwick DM: The science of improvement. JAMA 2008, 299(10):1182-1184.

37. Øvretveit J, Staines A: Sustained improvement? Findings from an independent case study of the Jonkoping quality program. Quality Management in Health Care 2007, 16(1):68-83.

38. Øvretveit J: A framework for quality improvement translation: understanding the conditionality of interventions. Joint Commission Journal on Quality and Safety 2004(Global Supplement):15-24.

39. Ozcan YA: Quantitative methods in health care management: techniques and applications. San Francisco: Jossey-Bass; 2005.

40. McCormack KP, Johnson WC: Business process orientation: gaining the ebusiness competitive advantage. Boca Raton: CRC Press LLC; 2001.

41. Feachem RG, Sekhri NK, White KL: Getting more for their dollar: a comparison of the NHS with California's Kaiser Permanente. BMJ 2002, 324(7330):135-141. 


\section{Chapter 3}

\section{Evaluating hospital design from an operations management perspective}

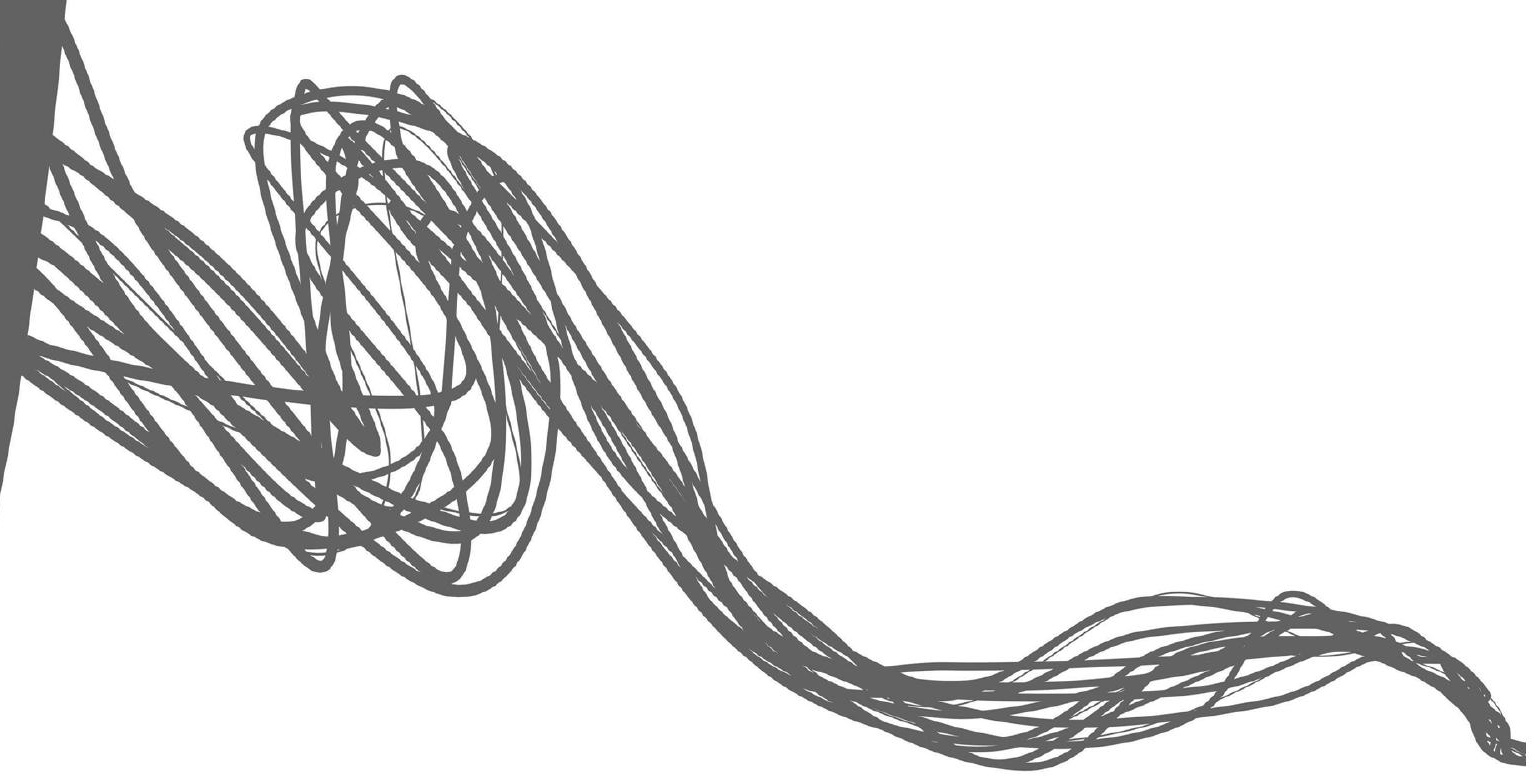

This chapter was published as:

Leti Vos, Siebren Groothuis, Godefridus G. van Merode. Evaluating hospital redesign from an operations management perspective. Health Care Management Science 2007: 10: $357-364$. 


\subsection{Introduction}

In many western countries we observe tendencies towards process driven care. Ideally, the layout of the building should be adjusted to this logistical concept in order to group the facilities along the line of the phases of the care process. This facilitates the integration of various operations in one flow at a rate determined by the needs of a patient and with least amount of delay and waiting 1 . Building a new hospital gives opportunities to match the layout of the hospital building with the desired logistical concept. In that case the layout must be suitable to deal with all the flows of patients and goods now and in many years to come. After all, the layout cannot be adapted very easily and only at high cost. Designing a layout is a challenging job because of the uncertainties concerning future numbers of patients, patient mix and new medical technologies. How can we accomplish that the layout of a hospital, which creates conditions for the dynamic operational control, stays appropriate for care delivery in the future?

It is important to design a hospital layout which supports hospital strategy, but also takes the future circumstances and the uncertainties into account. In order to assure that a design supports the efficient and effective operating of care processes now and in the future, it would be useful to have an evaluation method for the assessment of the flexibility and fit of the building design. The purpose of this research is to test such a method and illustrate it by a case. The remainder of this paper is divided into four major sections. First we explain the relationship between the operations management and hospital floor plan design. In the following section a method for evaluation of the flexibility and fit of the building design will be presented. Next this method will be applied in a case study. In the last part we discuss the case and the contribution of the evaluation method for the field of operations management.

\subsection{Relationship between operations management and hospital design}

From an operations management perspective hospitals need to maximise output/ throughput with available resources, taking into account different requirements for delivery flexibility (elective/appointment, semi-urgent, urgent), acceptable standards for delivery reliability (waiting list, waitingtimes) and acceptable medical outcomes by the design, planning, implementation and control of coordination mechanisms between patient flows and diagnostic and therapeutic activities ${ }^{2}$. In order to realise short throughput 
times and short displacement distances in the building the different flows between the various locations must be taken into account.

From an architectural view hospitals consist of static floor plans, with elements like corridors, consultation and examination rooms, reception desks, waiting facilities etcetera. From the view of operations management hospitals are systems in which all building elements are related to each other. Persons, goods and information move from one building element to another. This results in flows of people, goods and information. A logistic system has to control these flows and support the hospital's operations.

There is a close link between hospital strategy, the choice of the system for operational planning and control and the hospital's layout. A hospital strategy is an action plan for future development and includes choice of patient mix in terms of disease and treatment and market segments, medical technology and service concept. A realistic horizon for the hospital strategy is always limited: between 5 and 10 years. However the life cycle of a building is much longer. During the life of the building environmental changes may occur, like ageing of population, more demanding patients, and new insights about treatments. This may lead to changes in the hospital's strategy and thus the patient mix, medical technology and the operations management system. This means that the fit between hospital's layout, patient mix and the operations management system is a difficult issue because the time horizons do not match. The cost of changing the layout of an existing hospital building can be enormous. Flexibility of the building to adapt to changes in patient mix, operations management concept and technology is therefore essential.

In this paper we assume that the floor plan design is 'flexible and fit' if it supports and facilitates the operational control now and is appropriate to deal with future developments. The degree of circulation of the flow can be used to measure this flexibility and fit. After all it is congestion of flow that indicates that there is a local capacity problem and thus a non optimal fit between building design and operational control. In that case the design is not flexible enough to deal with (variations in) the flow. Due to this disturbance in flow in one place, capacity in other places cannot be used in an efficient way ${ }^{3}$. Blockages in the flow can increase waiting and throughput times which have a negative effect on the quality of service delivery and capacity use. The number of people that is walking around and how many goods are transported through the hallways at the same time at the same place in the building is a measure of the degree of circulation or congestion of the flow. 
Figure 3.1 represents the relationship between floor plans and operational planning and control system as described above. On the basis of this model we designed an evaluation method for the flexibility and fit of the building design for operations management, which will be described in the following section.

Figure 3.1 Relationship between operations management and hospital design/ floor plan

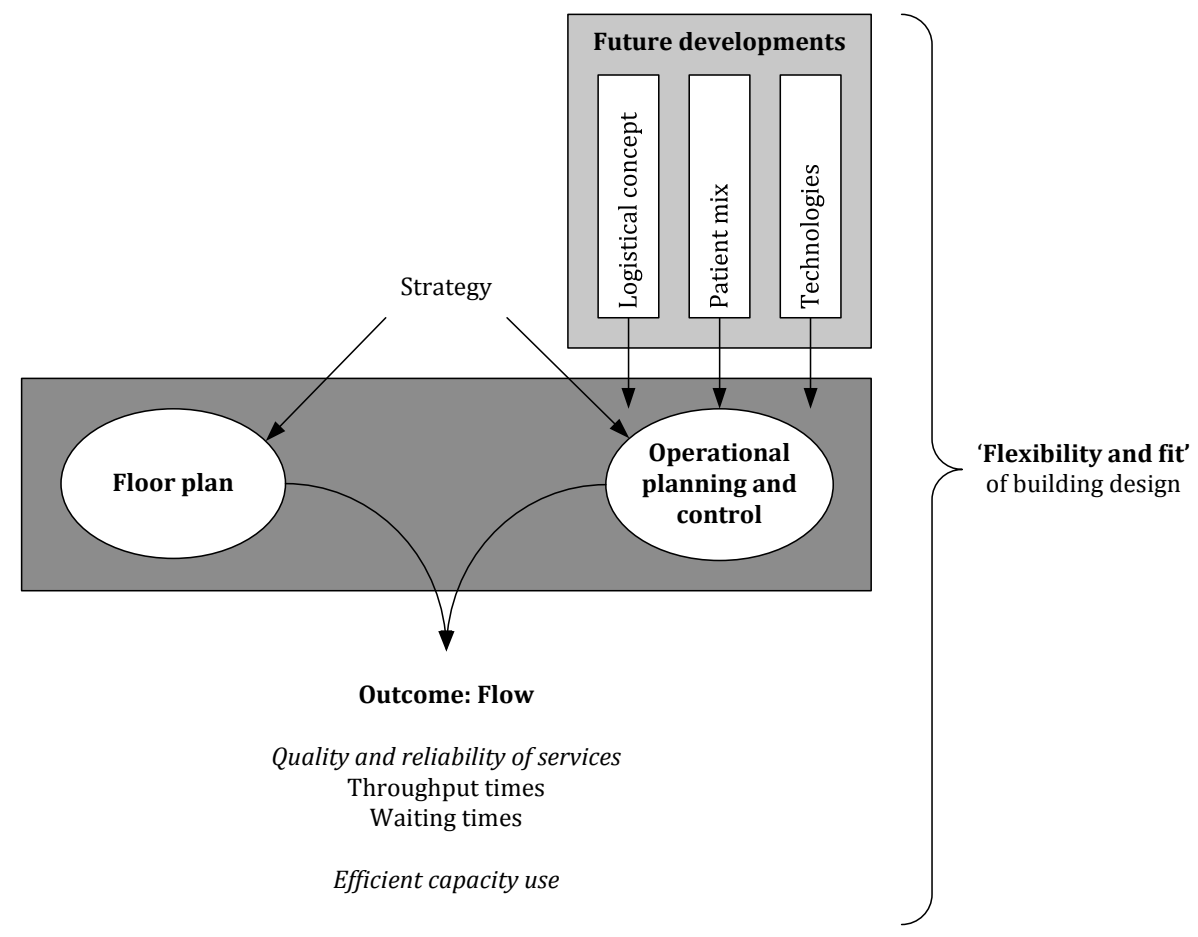

\subsection{Evaluation method}

In this section a method to evaluate the flow and thus the flexibility and fit of building design will be described (see also Table 3.1). One of the key features of this method is discrete event simulation.

To determine the degree of circulation of the flow, the hospital system can be defined as a flow system in which different segments of the building are distinguished (step 1). Each segment represents a part of the corridor of the building through which people and goods flow to their destination. Corridors can be divided in segments on basis of function of segments: part of the 
corridor along receptions desks, along entrances of clinics, along waiting rooms or parts of the corridor which do not have a specific function.

Table 3.1 Steps of the evaluation method

\begin{tabular}{ll} 
Step number & \\
\hline 1 & Distinguish segments of the floor plan \\
2 & Determine flows of persons and goods \\
3 & Design experiments \\
4 & Implement the model \\
5 & Run the simulation model, experiment and analyse the results \\
\hline
\end{tabular}

An example is given in Figure 3.2. The different segments in this figure are numbered.

Figure 3.2 Example of division in segments

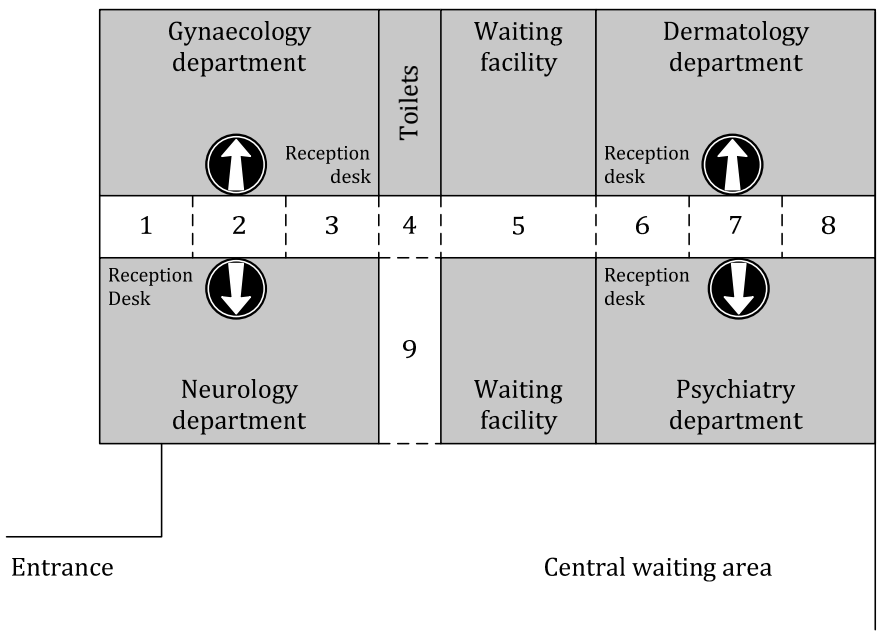

\section{Legend:}

$1,3=$ segment along one reception desk

$2,7=$ segment along an entrance of a clinic

$4=$ intersection of two corridors

$5=$ segment along waiting rooms

$6=$ segment along two reception desks

$8,9=$ segment with no specific function (remaining)

(1) = entrance ambulatory department

The time spent by people and goods in each segment is determined by (walking) speed and the dimensions of each segment. Walking speed can be estimated on 85 meter $/ \mathrm{min}^{4}$. After dividing the flow system in segments, the flows, based on floor plans and data on (present) numbers of patients 
(appointments) and of personnel and the movement of goods, including the logistical planning concept for controlling these flows (push or pull) have to be defined (step 2). Measurement of the degree of circulation based on these flows gives an indication of the functionality of the system. Next an experimental design is developed indicating ranges of changes of flow intensity and direction (result of change of logistical concept), and on changes or increase of intensity of the flow (result of changed patient mix and new technologies) (step 3). The next step is assessing the number of people and goods which are present on the same place at the same time in the different experimental scenarios (step 4).

To accomplish the above steps a discrete event simulation model has been built. Discrete event simulation is the modelling of a system as it evolves over time by representation in which state variables changes instantaneously at separate points in time ${ }^{5}$. The floor plan of the hospital is represented as segments in the simulation model. Furthermore the simulation model contains the expected amount of flows of people and goods. The segments are locations with limited capacity.

The number of people in a segment is represented by the performance indicator of maximum value of the number of people who are present on the same time in the same segment. The floor plan design has to be able to deal with this maximum number of people. Therefore it is important to assess this maximum value. Besides the maximum value it is even more important to know how often this maximum value occurs within single timeslots of one hour. Step 5 exists of running the simulation model (to test functionality). In this phase several experiments regarding flow intensity and direction can be done (to test the ability to adapt to developments). These experiments are determined according to an experimental design ${ }^{6}$. After simulation results have to be interpreted. The steps described above are summarised in Table 3.1. The usefulness of this method is illustrated in a case study.

\subsection{Case study}

In this section we apply this method for the evaluation of the flexibility and fit of the design for operations management to a case. The case selected concerns a new Dutch hospital which is the result of the merger of two hospitals and will be built on a new location. This new hospital wants to introduce a ' $21^{\text {st }}$ century airport' operations management concept for the design of an outpatient clinic. The purpose of the ' $21^{\text {st }}$ century airport' concept is the efficient use of space of the hospital building by centralising the waiting areas. The assessment answers 
the question whether the hospital design will allow a free flow of patients and goods.

\subsubsection{Setting}

The outpatient clinic has one central waiting area and a limited waiting capacity in the different ambulatory departments. Each ambulatory department has its own reception desk, which is located along the main corridors. Two rooms for consultation and/or examining patients are available for each medical specialist. According to the ' $21^{\text {st }}$ century airport' concept patients and their companions will wait in the central waiting area for a call to leave for their destination: the ambulatory department of their specialist. Every ambulatory department is situated at a main corridor. Patients take the main corridor to walk to their destination. The '21 st century airport' concept assumes that no patients and companions have to wait at the ambulatory departments. This means that the consultation or examination room is directly available at the time the patient and his companion arrive at the ambulatory department. A patient will only move from one room, e.g. a consultation room to another room, e.g. an examination room at the department when the examination room is available. This logistical concept can only be applied to highly standardised patients groups. The flow of these patients is certain. The successive care activities (consultations, examinations, diagnostics, and treatments) are already planned before the patient arrives at the hospital. Non standard patients will wait in (highly equipped) rooms before they can go to another room. After their visit some patients make a new appointment at the reception desk. The number of patients that will make an appointment differs per specialism. Also personnel walks through the corridors to their destination at the beginning and end of their working day.

Data concerning the routing of the existing patient mix and staff were provided by the hospital. The hospital provided also the data concerning the working hours of the staff. These data were considered as facts and were not subject of this research. Data on the movement of goods were not available and therefore not included in this study.

\subsubsection{Method}

This paragraph describes how the evaluation method is used in the case described in paragraph 3.4.1. 


\section{Step 1: Distinguish segments of the floor plan}

To measure the degree of circulation the corridors of the outpatient's clinic have been divided in segments on basis of available floor plans. Each segment represents a part of the corridor. The segments can be classified in five categories: segments with one reception desk at the side of the corridor, segments with two reception desks, segments which are part of an intersection of two corridors, segments which are part of a main way to another building, remaining segments (Figure 3.2). The width of each segment was 2.55 meter, the lengths varied from 2 to 5.4 meters.

\section{Step 2: Determine flows of persons and goods}

For this case data were available on (present) numbers of patients (appointments) and of personnel and the movement of goods in the two hospitals and were extrapolated by the hospital to the new hospital. The hospital assumes that fifty percent of the patients will be accompanied by one person and the other fifty percent by two persons. On basis of these data expected flows are defined to assess the functionality of the design. To control the flows on the outpatient clinic the hospital uses a pull system in line with the proposed logistical concept. In order to have the right patient on the right time on the right place, the hospital tries to reduce the variation in arrivals at the departments by the creation of a central waiting area. From this area patients are asked at a specific moment to move to a specific location at the department. This moment is determined by the availability of the needed resources (staff and/or equipment).

\section{Step 3: Design experiments}

According to the presented model in Figure 3.1 uncertainties in flow intensity can be the result of three factors: used logistical concept, and development of patient mix and technologies. The ability of the design of the outpatients' clinic to meet these uncertainties is assessed in an experimental design. Therefore we determined three parameters: arrival pattern (logistical concept, intensity of the flow), number of patients (patient mix and technologies) and the duration of making an appointment (logistical concept, flow direction). Three values are used for simulating different arrival patterns (parameter 1) at the ambulatory departments of the outpatients' clinic in the experimental design: arrival schedule A (arrivals per hour determined by means of a probability distribution), arrival schedule $B$ (patients arrive every 10 minutes with an uncertainty of 5 minutes), arrival schedule $C$ (patients arrive every 10 minutes with an uncertainty of 2 minutes). Parameter 2, number of patients, which concerns the flow intensity, has only two values: the present number of patients and a situation in which the number of patients increased with $25 \%$. 
Parameter 3, the duration of the process of making an appointment, has also two values: $T(1,2,3)$ (Triangular distribution [minimum, modus, maximum]) and $\mathrm{T}(1.5,2.5,3.5)$. A full experimental design was applied which resulted in 12 experiments (see Table 3.2). This study assessed one fixed logistical concept and therefore this was not a factor in the experimental design.

Table 3.2 Experiments

\begin{tabular}{|c|c|c|c|c|c|c|c|}
\hline \multirow[b]{2}{*}{ Experiment } & \multicolumn{3}{|c|}{ Arrival pattern } & \multicolumn{2}{|c|}{ Number of patients } & \multicolumn{2}{|c|}{$\begin{array}{c}\text { Duration of making an } \\
\text { appointment }\end{array}$} \\
\hline & A & B & C & $\begin{array}{l}\text { Present } \\
\text { number }\end{array}$ & $+25 \%$ & $\begin{array}{c}T \\
(1,2,3)\end{array}$ & $\begin{array}{c}T \\
(1.5,2.5,3.5)\end{array}$ \\
\hline 1. & $\mathrm{X}$ & & & $X$ & & $X$ & \\
\hline 2. & & $\mathrm{X}$ & & $\mathrm{X}$ & & $\mathrm{X}$ & \\
\hline 3. & & & $\mathrm{X}$ & $\mathrm{X}$ & & $\mathrm{X}$ & \\
\hline 4. & $\mathrm{X}$ & & & $\mathrm{x}$ & & & $\mathrm{X}$ \\
\hline 5. & & $\mathrm{X}$ & & $\mathrm{X}$ & & & $\mathrm{x}$ \\
\hline 6. & & & $\mathrm{X}$ & $\mathrm{X}$ & & & $\mathrm{x}$ \\
\hline 7. & $\mathrm{X}$ & & & & $\mathrm{x}$ & $\mathrm{X}$ & \\
\hline 8. & & $\mathrm{X}$ & & & $\mathrm{x}$ & $\mathrm{x}$ & \\
\hline 9. & & & $\mathrm{x}$ & & $\mathrm{x}$ & $\mathrm{x}$ & \\
\hline 10. & $\mathrm{x}$ & & & & $\mathrm{x}$ & & $\mathrm{x}$ \\
\hline 11. & & $\mathrm{X}$ & & & $\mathrm{x}$ & & $\mathrm{x}$ \\
\hline 12. & & & $\mathrm{X}$ & & $\mathrm{x}$ & & $\mathrm{X}$ \\
\hline
\end{tabular}

\section{Step 4: Implement the model}

In our case the model is implemented in MedModel ${ }^{7}$. MedModel is a discrete event simulation environment with a graphical interface.

Step 5: Run the simulation model, experiment and analyse the results

We simulated 100 days (100 replications). We also simulated single timeslots (see evaluation method section).

\subsection{Results}

The results concern the flow of patients, companions, staff and visitors. Data were gathered for each of the hundred replications.

\section{Functionality}

For the results of the simulation of the expected flows see Table 3.3, schedule A. The results for seven segments of the main corridors of the outpatients' clinic are presented. These seven segments represent the five categories as described 
in step 1. These results show that there are more people in corridors with reception desks at the side of it.

Table 3.3 Results of experiment 1, 2 and 3. Maximum value of number of people in a segment (100 replications) and the service time at a desk is $T(1,2,3)$ distributed for different schedules

\begin{tabular}{|c|c|c|c|c|c|c|c|c|c|c|}
\hline \multirow[b]{3}{*}{$\begin{array}{l}\text { Segment } \\
\text { (category)* }\end{array}$} & \multirow[b]{3}{*}{$\begin{array}{l}\text { Dimensions } \\
\text { (meters) }\end{array}$} & \multicolumn{9}{|c|}{ More strictly organised arrival pattern } \\
\hline & & \multicolumn{3}{|c|}{ Schedule A } & \multicolumn{3}{|c|}{ Schedule B } & \multicolumn{3}{|c|}{ Schedule C } \\
\hline & & Min & Max & Mdn & Min & Max & Mdn & Min & Max & Mdn \\
\hline $\begin{array}{l}\text { B11 (2) } \\
2 \text { reception } \\
\text { desks }\end{array}$ & $5.4 * 2.55$ & 6 & 14 & 9 & 6 & 10 & 8 & 8 & 12 & 9 \\
\hline $\begin{array}{l}\mathbf{B 1 3} \mathbf{( 1 )} \\
1 \text { reception de }\end{array}$ & $5.4 * 2.55$ & 9 & 18 & 11 & 6 & 11 & 8 & 7 & 12 & 9 \\
\hline $\begin{array}{l}\text { B14 (3) } \\
\text { Intersection }\end{array}$ & $2 * 2.55$ & 4 & 9 & 6 & 4 & 9 & 6 & 5 & 9 & 6 \\
\hline $\begin{array}{l}\text { D11 (5) } \\
\text { No specific } \\
\text { function }\end{array}$ & $5.4 * 2.55$ & 7 & 15 & 9 & 7 & 14 & 9 & 7 & 13 & 9 \\
\hline $\begin{array}{l}\text { D13 (5) } \\
\text { No specific } \\
\text { function }\end{array}$ & $5.4 * 2.55$ & 4 & 10 & 6 & 4 & 9 & 6 & 4 & 10 & 6 \\
\hline $\begin{array}{l}\mathbf{F 5} \mathbf{( 1 )} \\
\text { One reception } \\
\text { desk }\end{array}$ & $5.4 * 2.55$ & 9 & 18 & 11 & 8 & 14 & 9 & 9 & 15 & 11 \\
\hline $\begin{array}{l}\text { F16 (4) } \\
\text { Corridor to } \\
\text { psychiatric } \\
\text { centre }\end{array}$ & $5.4 * 2.55$ & 8 & 18 & 12 & 8 & 20 & 12 & 6 & 24 & 12 \\
\hline
\end{tabular}

* The segments can be classified in five categories: segments with one reception desk at the side of it (1), segments with two reception desks (2), segments which are part of a intersection of two corridors (3), segments which are part of a main way to another building (4), segments with no specific function (remaining) (5).

Min = minimum value of the maximum number of patients; Max = maximum value of the maximum number of patients; Mdn = median value of the maximum number of patients.

\section{Ability to meet future developments}

To assess the ability of the system to meet future developments we performed the 12 experiments of the experimental design. Table 3.3 shows the results of experiment 1, 2 and 3: the simulation of several arrival patterns in arrival schedules A, B and C. The values measured per schedule do not differ 
significantly. A minimum value of the maximum number of patients represents the lowest maximum number of patients that is present at the same time in a segment in hundred days. A maximum value of 18 means that there were 18 people at the same time present in the same segment on at least one day (of the hundred days simulated). The same values were measured when we collected data during specific time slots, e.g. from 9 till 10 a.m. Only during lunch break of personnel the maximum values decreased.

When the patients' stay at the reception desk increased with half a minute $\mathrm{T}(1.5,2.5,3.5)$ but the number of people remained the same in experiment 7,8 and 9 , the maximum values were not affected (see Table 3.4).

The results of experiment 7, 8 and 9 which assess increase of flow volume, show that the maximum values increased with 1 or 2 persons when the number of patients increased with $25 \%$ (see Table 3.5 ).

In experiment 10, 11 and 12 both the number of patients and the duration of the process are increased. The results are presented in Table 3.6. 
Table 3.4 Results of experiment 4, 5 and 6. Maximum value of number of people in a segment (100 replications) and the service time at a desk is $T(1.5,2.5,3.5)$ distributed for different schedules

\begin{tabular}{|c|c|c|c|c|c|c|c|c|c|c|}
\hline \multirow[b]{3}{*}{$\begin{array}{l}\text { Segment } \\
\text { (category) }\end{array}$} & \multirow[b]{3}{*}{$\begin{array}{l}\text { Dimensions } \\
\text { (meters) }\end{array}$} & \multicolumn{9}{|c|}{ More strictly organised arrival pattern } \\
\hline & & \multicolumn{3}{|c|}{ Schedule A } & \multicolumn{3}{|c|}{ Schedule B } & \multicolumn{3}{|c|}{ Schedule C } \\
\hline & & Min & Max & Mdn & Min & Max & Mdn & Min & Max & Mdn \\
\hline $\begin{array}{l}\text { B11 (2) } \\
2 \text { reception } \\
\text { desks }\end{array}$ & $5.4 * 2.55$ & 8 & 17 & 10 & 7 & 11 & 8 & 8 & 13 & 9 \\
\hline $\begin{array}{l}\text { B13 (1) } \\
1 \text { reception } \\
\text { desk }\end{array}$ & $5.4 * 2.55$ & 9 & 18 & 12 & 7 & 11 & 8 & 7 & 12 & 9 \\
\hline $\begin{array}{l}\text { B14 (3) } \\
\text { Intersection }\end{array}$ & $2 * 2.55$ & 5 & 9 & 6 & 4 & 7 & 6 & 4 & 8 & 6 \\
\hline $\begin{array}{l}\text { D11 (5) } \\
\text { No specific } \\
\text { function }\end{array}$ & $5.4 * 2.55$ & 7 & 14 & 9 & 7 & 13 & 9 & 7 & 15 & 10 \\
\hline $\begin{array}{l}\text { D13 (5) } \\
\text { No specific } \\
\text { function }\end{array}$ & $5.4 * 2.55$ & 4 & 8 & 6 & 4 & 9 & 6 & 4 & 10 & 6 \\
\hline $\begin{array}{l}\text { F5 (1) } \\
\text { One reception } \\
\text { desk }\end{array}$ & $5.4 * 2.55$ & 9 & 20 & 13 & 8 & 16 & 11 & 9 & 17 & 11 \\
\hline $\begin{array}{l}\text { F16 (4) } \\
\text { Corridor to } \\
\text { psychiatric } \\
\text { centre }\end{array}$ & $5.4 * 2.55$ & 8 & 18 & 12 & 6 & 16 & 12 & 8 & 18 & 12 \\
\hline
\end{tabular}

Min = minimum value of the maximum number of patients; Max = maximum value of the maximum number of patients; $\mathrm{Mdn}=$ median value of the maximum number of patients. 
Table 3.5 Results of experiment 7, 8 and 9. Maximum value of number of people in a segment (100 replications) and the service time at a desk is $T(1,2,3)$ distributed for different schedules with an increased number of patients

\begin{tabular}{|c|c|c|c|c|c|c|c|c|c|c|}
\hline \multirow[b]{3}{*}{$\begin{array}{l}\text { Segment } \\
\text { (category) }\end{array}$} & \multirow[b]{3}{*}{$\begin{array}{l}\text { Dimensions } \\
\text { (meters) }\end{array}$} & \multicolumn{9}{|c|}{ More strictly organised arrival pattern } \\
\hline & & \multicolumn{3}{|c|}{ Schedule A } & \multicolumn{3}{|c|}{ Schedule B } & \multicolumn{3}{|c|}{ Schedule C } \\
\hline & & Min & Max & Mdn & Min & Max & Mdn & Min & Max & Mdn \\
\hline $\begin{array}{l}\text { B11 (2) } \\
2 \text { reception } \\
\text { desks }\end{array}$ & $5.4 * 2.55$ & 8 & 15 & 11 & 7 & 11 & 9 & 8 & 12 & 10 \\
\hline $\begin{array}{l}\text { B13 (1) } \\
1 \text { reception } \\
\text { desk }\end{array}$ & $5.4 * 2.55$ & 9 & 20 & 13 & 8 & 12 & 10 & 10 & 16 & 11 \\
\hline $\begin{array}{l}\text { B14 (3) } \\
\text { Intersection }\end{array}$ & $2 * 2.55$ & 5 & 9 & 6 & 5 & 9 & 6 & 5 & 11 & 6 \\
\hline $\begin{array}{l}\text { D11 (5) } \\
\text { No specific } \\
\text { function }\end{array}$ & $5.4 * 2.55$ & 4 & 8 & 6 & 4 & 12 & 6 & 4 & 14 & 6 \\
\hline $\begin{array}{l}\text { D13 (5) } \\
\text { No specific } \\
\text { function }\end{array}$ & $5.4 * 2.55$ & 9 & 22 & 14 & 9 & 15 & 10 & 10 & 17 & 11 \\
\hline $\begin{array}{l}\text { F5 (1) } \\
\text { One reception } \\
\text { desk }\end{array}$ & $5.4 * 2.55$ & 9 & 22 & 14 & 9 & 15 & 10 & 10 & 17 & 10 \\
\hline $\begin{array}{l}\text { F16 (4) } \\
\text { Corridor to } \\
\text { psychiatric } \\
\text { centre }\end{array}$ & $5.4 * 2.55$ & 8 & 18 & 12 & 8 & 22 & 12 & 10 & 20 & 12 \\
\hline
\end{tabular}

Min = minimum value of the maximum number of patients; Max = maximum value of the maximum number of patients; $\mathrm{Mdn}=$ median value of the maximum number of patients. 
Table 3.6 Results of experiment 10, 11 and 12. Maximum value of number of people in a segment (100 replications) and the service time at a desk is $T(1.5,2.5,3.5)$ distributed for different schedules with an increased number of patients

\begin{tabular}{|c|c|c|c|c|c|c|c|c|c|c|}
\hline \multirow[b]{3}{*}{$\begin{array}{l}\text { Segment } \\
\text { (category) }\end{array}$} & \multirow[b]{3}{*}{$\begin{array}{l}\text { Dimensions } \\
\text { (meters) }\end{array}$} & \multicolumn{9}{|c|}{ More strictly organised arrival pattern } \\
\hline & & \multicolumn{3}{|c|}{ Schedule A } & \multicolumn{3}{|c|}{ Schedule B } & \multicolumn{3}{|c|}{ Schedule C } \\
\hline & & Min & Max & Mdn & Min & Max & Mdn & Min & Max & Mdn \\
\hline $\begin{array}{l}\text { B11 (2) } \\
2 \text { reception } \\
\text { desks }\end{array}$ & $5.4 * 2.55$ & 9 & 16 & 11 & 7 & 10 & 9 & 8 & 13 & 10 \\
\hline $\begin{array}{l}\text { B13 (1) } \\
1 \text { reception } \\
\text { desk }\end{array}$ & $5.4 * 2.55$ & 11 & 23 & 14 & 9 & 16 & 10 & 9 & 16 & 11 \\
\hline $\begin{array}{l}\text { B14 (3) } \\
\text { Intersection }\end{array}$ & $2 * 2.55$ & 5 & 9 & 6 & 5 & 10 & 6 & 5 & 9 & 6 \\
\hline $\begin{array}{l}\text { D11 (5) } \\
\text { No specific } \\
\text { function }\end{array}$ & $5.4 * 2.55$ & 8 & 14 & 10 & 7 & 13 & 9 & 8 & 16 & 10 \\
\hline $\begin{array}{l}\text { D13 (5) } \\
\text { No specific } \\
\text { function }\end{array}$ & $5.4 * 2.55$ & 4 & 10 & 6 & 4 & 8 & 6 & 4 & 9 & 6 \\
\hline $\begin{array}{l}\text { F5 (1) } \\
\text { One receptior } \\
\text { desk }\end{array}$ & $5.4 * 2.55$ & 12 & 27 & 16 & 9 & 22 & 12 & 7 & 19 & 13 \\
\hline $\begin{array}{l}\text { F16 (4) } \\
\text { Corridor to } \\
\text { psychiatric } \\
\text { centre }\end{array}$ & $5.4 * 2.55$ & 8 & 20 & 12 & 8 & 18 & 12 & 10 & 18 & 12 \\
\hline
\end{tabular}

Min = minimum value of the maximum number of patients; Max = maximum value of the maximum number of patients; $\mathrm{Mdn}=$ median value of the maximum number of patients. 


\subsection{Implications and conclusion}

First the results of the case will be discussed. Then the contribution of the evaluation method for the assessment of the flexibility and fit of building design will be outlined.

\subsubsection{Discussion and conclusion of the case study}

The evaluation method showed that the floor plan design of the outpatient clinic supports the functionality of the system and facilitates expected flows. The results of arrival schedule 1 experiment 1 showed the expected maximum number of persons in the different locations of a hospital building given the proposed logistical concept. Any higher value for the number of people in a certain segment indicates a higher possibility of congestion of the flow. The segments along reception $\operatorname{desk}(\mathrm{s})$ seem the locations which are most sensitive for congestion. But no real problems did occur during the simulation experiments. So the floor plan design can be considered to be functional given the expected situation. The ability to meet future developments is assessed in the twelve experiments. These experiments showed that there is a small difference between the median of the maximum values and the overall maximum value in the three arrival schedules (see Table 3.3). The results from experiment 4-6 and 10-12 indicate that the placement of reception desks directly along the corridors also influences the flow. When the duration of the processes at reception desks (which are directly placed along the corridors) is extended, the maximum values of the number of people in the segments are higher. Experiment 7-12 show us that when the number of patients increases the limitations of and requirements on layout are more evident.

These results show the importance of the evaluation of a floor plan design. In this case the building seems to support the functionality of the system and facilitates expected flows. However, the case study shows that if the flows change in intensity, direction or volume the maximum number of patients in the segments increases and this will lead to congestion. The design does not seem to be flexible enough to deal with variations in the factors mentioned above: used logistical concept, patient mix and technologies. The intended operations management system assumes that patient routings can be standardised and completely controlled once started. According to the hospital management variation in the flow will decrease after the implementation period of ' $21^{\text {st }}$ century airport' concept. The hospital management is taking an enormous risk by constructing a hospital building that allows a limited 
variation in flow. We recommend to increase the flexibility and fit of the building design through the creation of decentralised waiting rooms at the ambulatory departments. Decentralised waiting rooms can counteract the effect of fluctuations in the flow. Besides this, more flexibility can be created through standardisation of rooms, especially consultation rooms. Both the addition of decentralised waiting rooms and standardisation of consultation rooms will reduce the dependency on the used logistical concept and thus increase the flexibility and improve the fit of the building design.

In this case study no waiting times at the ambulatory department were taken into account because of the assumption made by the hospital management that the patients will be directly seen by the medical specialist after their arrival at the ambulatory department. This assumption is an essential part of the operations management concept where patients are paged from a central waiting area to a specific care unit when the medical specialist becomes available ('pull' logistics). The presence of privacy lines before reception desks, which has a reducing effect on available capacity in segments could also not be simulated. These privacy lines would almost certainly have a disturbing effect on the flows. Further, except lunch break, no movements of personnel during office hours are simulated because of unavailability of data. These movements are additional to the movements modelled in the simulation model and therefore will increase the determined maximum values.

\subsubsection{Discussion of the simulation model}

The simulation model provided information about the number of persons in a certain segment. In the simulation model all persons have a constant walking behaviour. We can imagine that people in particular cases slow down or will stop to look around which direction they have to go e.g. when they are approaching a corridor or crossing. This kind of behaviour is not included in the model. Also effects of the use of wheelchairs, rollators, stretchers and buggies have not been taken into account. These movement aids will take more space and progress slower than a single person does, which will disturb the flow with great probability. Enlarging the scope of the simulation model will allow an assessment in greater detail. To extend the simulation model asks for further research. 


\subsubsection{Contribution of the evaluation method}

This research tried to fill the gap between the world of architecture and the world of operational control. Flexibility and fit of a building design implies that the static floor plan, made by the architect, meets the requirements of the dynamics of operational control. The case study shows that discrete event simulation is a useful technique for the evaluation of the flexibility and fit of a building for operations management. Both functionality and the ability to meet future developments of the design can be assessed. When the capacity meets the requirement to deal with the flows in combination with the chosen logistical concept, the building can be considered to be functional. This can be assessed through a simulation study of the expected situation. The ability to meet future developments can be determined through simulation of variations in future developments such as used logistical concept, patient mix and technology. The techniques used in this study are not only useful for evaluation of the new designs. Simulation can also be used for the evaluation of new logistic concepts for care processes in existing buildings. Specific experiments can be designed to assess the implications of the logistical concept. Evaluation of new logistic concepts before introducing them can prevent the occurrence of problems in the overall flow system.

Assessing the flexibility and fit of a building in the design phase is in our opinion of great importance for operations management. In this phase it is still possible to adjust the layout of the building. We illustrated the usefulness of the evaluation method with a case. In this example the building design shows shortcomings regarding the ability to meet future developments. Because of this evaluation, the design of the outpatient clinic can be adjusted in order to reach a higher degree of flexibility and fit for operations management and thus a higher durability. 


\section{References}

1. Liker JK: The Toyota way: 14 management principles from the world's greatest manufacturer. New York [etc.]: McGraw-Hill; 2004.

2. De Vries G, Bertrand JWM, Vissers JMH: Design requirements for health care production control systems. Production Planning \& Control 1999, 10(6):559-569.

3. Van Merode GG, Groothuis S: Hospitals as complexes of queuing systems. In Health Sciences Simulation 2003: January 19-23, 2003 2003; Orlando FL. Edited by Anderson JG, Katzper M. Society for Modeling and Simulation International (SCS); 2003:39-44.

4. Abernethy B, Hanrahan SJ, Kippers V, Mackinnon LT, Pandy MG: The biophysical foundations of human movement. 2nd edition. Champaign, IL etc.: Human Kinetics; 2005.

5. Law AM, Kelton WD: Simulation modelling and analysis. Second edition. New York, USA: McGraw-Hill; 1991.

6. Banks J: Handbook of simulation : principles, methodology, advances, applications, and practice. New York, NY etc.: Wiley; 1998.

7. MedModel homepage [www.promodel.com/products/medmodel]. 


\section{Chapter 4}

\section{Does case-mix based reimbursement stimulate the development of process-oriented care delivery}

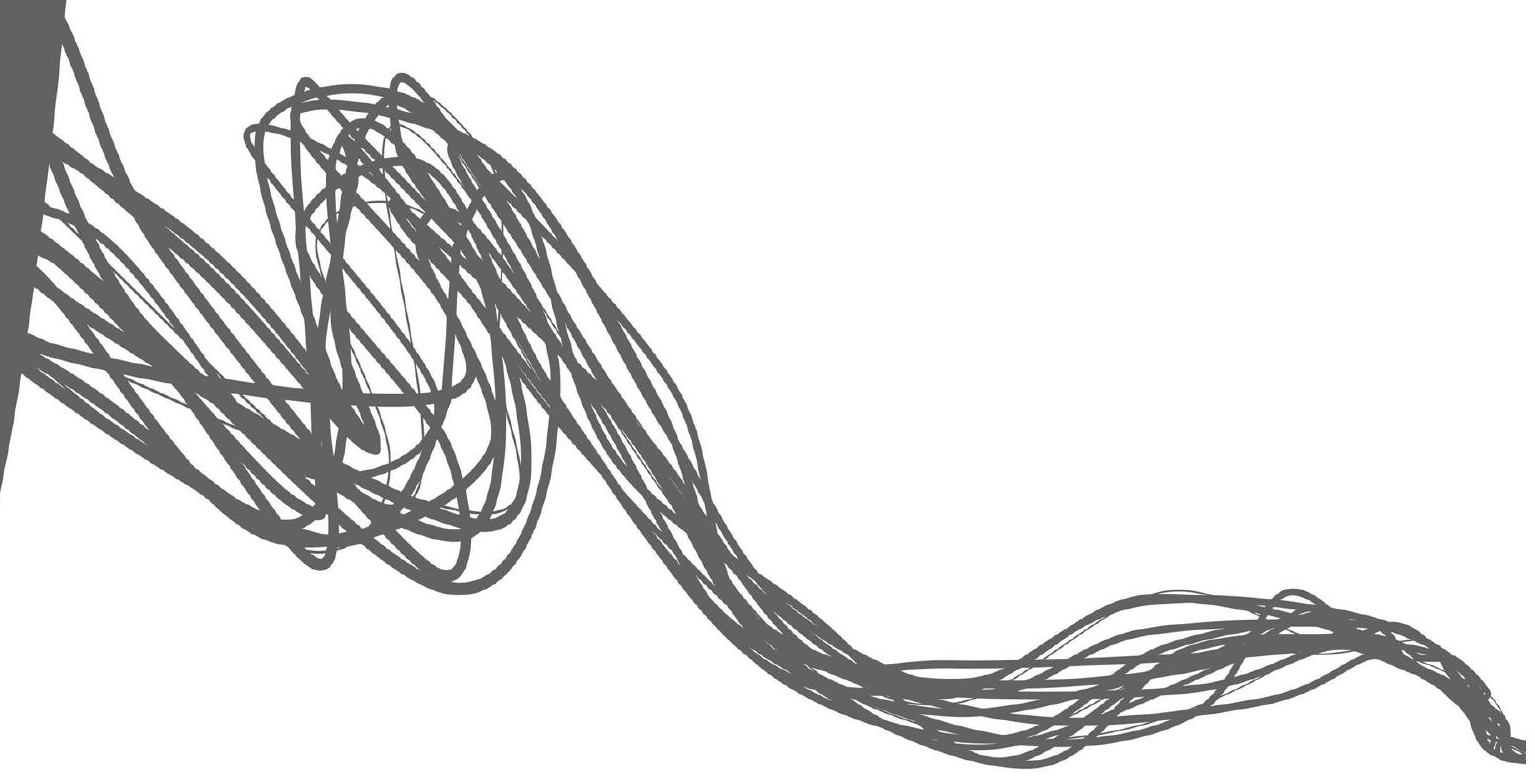

This chapter was accepted for publication as:

Leti Vos, Michel L.A. Dückers, Cordula Wagner, Godefridus G. van Merode. Does case-mix based reimbursement stimulate the development of process-oriented care delivery? Health Policy. 


\subsection{Introduction}

During the last decade, it is believed that fundamental shortcomings in the organisation of hospital care can cause quality problems like long waiting times, waste of resources and poor coordination of care delivery ${ }^{1}$. Traditionally, hospitals are functionally organised into medical (e.g. internal medicine) and facilitating departments (e.g. laboratory), which operate as separate 'silos' with their own goals ${ }^{2,3}$. Each silo is concerned with maximising its own efficiency rather than that of care processes ${ }^{4}$. As a consequence, each care activity within a care process of a patient will be planned on basis of availability of resources, after the previous care activity is completed. This means that activities belonging to a patient's care process are treated as being independent instead of as being connected to a chain of interdependent care activities.

This poor coordination of care delivery is partially due to the use of fee-forservice systems of provider payment ${ }^{4}$. A fee-for-service system rewards the delivery of individual procedures (i.e. hospital admissions, number of in-patient days) and stimulates the overuse of services, duplication of services and use of costly specialised services. One way to stimulate coordination and efficiency of care delivery, is to base reimbursement, in whole or in part, on the total care of a patient during an acute episode of illness ${ }^{5}$. This is in line with the theory of target engineering, which states that external pressures related to reimbursement systems can be used to bridge internal conflicts of interests hampering efficiency and quality 6, 7. Based on this premise, many Western countries introduced Diagnosis Related Groups (DRGs) or similar case-mix based grouping systems for hospital reimbursement. Also in the Netherlands a new reimbursement system was developed and initiated in 2005, that will gradually replace the fee-for-service payment of hospital care ${ }^{8}$. In this new system, hospital budgets are based on the number of delivered Diagnosis Treatment Combinations (DTCs). A DTC consists of all diagnosis- and treatment-related costs incurred by the hospital and the clinician. Thus, it covers the pathway from an initial consultation or examination to the final check-up ${ }^{9}$. Consequently, hospital budgets become dependent upon the efficient and effective delivery of DTCs instead of on individual procedures. However, within this new system hospital budgets are not open-ended. Hospitals negotiate with health care insurers regarding the maximum number of DTCs they may deliver within 1 year.

To actually achieve a better coordinated and more efficient care delivery across hospital department boundaries, hospitals may introduce a more processoriented way of working by the implementation of coordinating structures, 
called care pathways or care programmes (see Figure 4.1 ) $^{3,10}$. Coordinating structures establish the sequence of activities (diagnostics, consultations, treatment) and the professionals' responsibilities in the diagnosis and treatment of homogeneous patient groups. This potentially improves the coordination of care delivery and reduces waiting times and delays within care processes for patients. Hereafter, we refer to these coordinating structures as care programmes.

Figure 4.1 Care delivery in a functional organisation or process-oriented organisation

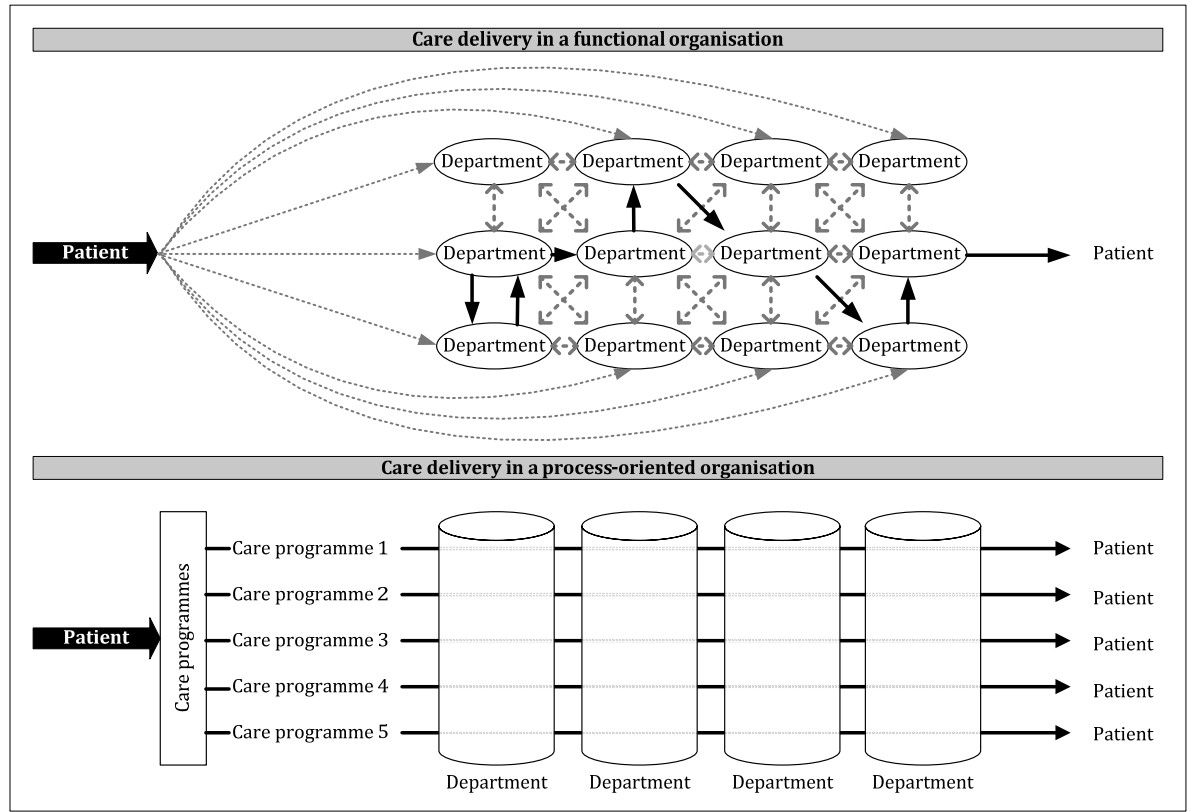

Although the implementation of care programmes is considered a major step, it does not automatically imply that health care professionals adopt a processoriented way of working ${ }^{11}$. To actually change work processes, the implementation of care programmes must be accompanied by:

- A less hierarchical organisation, in which people have more responsibility, increased decision making capabilities, and act more autonomously and flexible ${ }^{12}$;

- $\quad$ Less fragmentation of responsibilities by appointing process owners ${ }^{10,13}$;

- Protocols, that ensure smooth coordination, continuity, and less variation between care processes per patient ${ }^{1,14}$; and

- $\quad$ A process-oriented view held by all employees ${ }^{13}$. 
Davis (2007) ${ }^{5}$ argues that, given the dispersion of care across clinicians and practices, the fragmentation of care delivery and lack of continuity in clinicianpatient relationships, extensive evaluations of new reimbursement methods are needed. A number of studies already evaluated the effect of case-mix based reimbursement on output measures, like the length of stay ${ }^{15-17}$. From these studies, it appears that admissions, the average length of stay and intensity of care, and thus health care costs have, at least initially, decreased as intended ${ }^{18}$. In addition to these intended effects, several dysfunctional effects, such as DRGcreeping ('a deliberate and systematic shift in a hospital's reported case mix in order to improve reimbursement') and DRG-dumping ('an attempt to avoid treating difficult cases'), have been reported ${ }^{18}$. These studies did not examine the effects on the organisation of care delivery, e.g. the coordination between care activities. It is, however, very important to get insight into the effect on care coordination because it is believed that hospital administrators adopt case-mix reimbursement in hospital budgeting systems as a means of showing conformity with institutionalised rules and expectations ${ }^{19}$, but decouple their budgeting systems from the internal operations of the organisation. If that is the case, a better care coordination, which is very important from the patient's point of view, will not be achieved and improvements in efficiency may be only the result of DRG-creeping and dumping. Therefore, we explore in this study whether case-mix based reimbursement stimulates activities to develop care programmes, and eventually a process-oriented way of working.

\subsubsection{Hypothetical model}

On the basis of literature, we constructed a hypothetical model (see Figure 4.2) to demonstrate how case-mix reimbursement should contribute to the establishment of care programmes, with the ultimate goal to become processoriented. To meet the new requirements of case-mix reimbursement, Dutch hospitals have to base the allocation of budgets on processes (the number of delivered DTCs) rather than on individual procedures. In this way hospitals can align the different departmental interests with the organisational goal of maximising the total hospital budget according to the theory of target engineering. Thus, the model starts with the adoption of the new reimbursement system within the hospitals' budgeting process (process-based budgeting) and consists of four hypothesised relations. 
Figure 4.2 Hypothesised relations

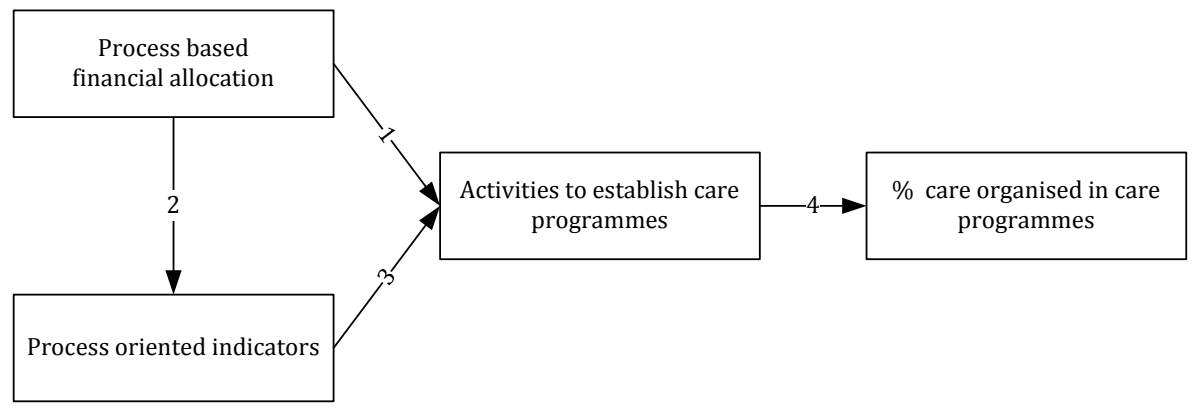

Hypothesis 1: A more process-based budgeting system stimulates activities to establish care programmes.

When financial resources are allocated on basis of care process performance, optimisation of care processes in keeping with certain targets - all of which involve a time factor (e.g. short throughput time) - is more important than high utilisation of departmental resources ${ }^{20}$. Hence, it is assumed that different departments working for the same patient group will undertake more actions to implement care programmes and meet process targets.

Hypothesis 2: A more process-based budgeting system coincides with the use of more process-oriented indicators by clinicians.

For clinicians to assume responsibility for the establishment of 'their' care process, balanced steering information is a prerequisite ${ }^{21}$. Therefore, we hypothesise that process-based budgeting coincides with the use of more process-oriented performance indicators by clinicians.

Hypothesis 3: The use of more process-oriented indicators by clinicians is related to a higher number of activities geared to establishing care programmes.

The information gathered using measurement of process-oriented performance indicators helps to identify areas for improvement ${ }^{22,}{ }^{23}$. Output indicators (e.g. throughput times) tell hospital management and clinicians whether they are reaching targets ${ }^{24}$. Additionally, process measures, like the number of patient handovers between clinicians and physical transfers of patients between departments, gauge the delivered care ${ }^{25}$. The number of physical transfers, for example, informs about the (non)integration of various operations in a care process. An optimal integration of various operations means a better adjustment to patients' needs and minimal delays and waiting times ${ }^{26}$. We therefore assume that use of process-oriented indicators stimulates clinicians to undertake actions to develop and improve care programmes. 


\section{Hypothesis 4: More activities to establish care programmes lead to a higher proportion of care delivery that is organised in care programmes.}

Finally, it seems plausible that hospitals conducting more activities to establish care programmes have higher proportions of care delivery organised in such programmes than hospitals that undertake fewer or no activities. However, when hospitals are at the end of their transition towards a process-oriented way of working, it is likely that they carry out fewer or no activities to establish care programmes but can have a high proportion of care delivery organised in care programmes.

\subsection{Materials and methods}

\subsubsection{Data collection}

To assess the effect of case-mix reimbursement on the development towards process-oriented organisations, we conducted a survey during the winter of $2007 / 2008$. A questionnaire was sent to all Dutch hospitals $(N=96)$, including university $(N=8)$, tertiary teaching $(N=26)$, general $(N=59)$, and specialised hospitals $(N=3)$, followed by a reminder after approximately three weeks. Recipients were hospitals' chief executive officers, who in most instances completed the questionnaire together with quality managers.

Questions included: the extent to which process-based budgeting is applied (interval: completely disagree 0.0 - completely agree 5.0); the use of four different process-oriented performance indicators (dichotomously scaled: yes/no); activities to establish care programmes (ordinally scaled: none, for a single patient group, for several patient groups, hospital wide); the percentage of care delivery that is/can be organised in care programmes (interval: 0100\%); indicators for process-orientation (decision making [interval: completely centralised 0.0 - completely decentralised 5.0]; the establishment of process owners [interval: completely disagree 0.0 - completely agree 5.0]; the employees' view of care delivery as a process [interval: completely disagree 0.0 - completely agree 5.0]; (clinical) protocols for specific diseases [dichotomously scaled: yes/no]; (organisational) protocols for routing of patients [dichotomous scaled: yes/no]); and hospital characteristics (type of hospital, the number of fulltime equivalents (FTEs) employed personnel, and the number of people living in the area the hospitals serve).

This questionnaire is in fact part of a larger survey carried out on a regular basis (at least every 5 years) and aims to assess the developmental stage of a 
hospital's quality management system ${ }^{27}$. However, following developments in the hospital sector, the questions involving the application of process-based budgeting and the percentage of care delivery that is / can be organised in care programmes are introduced in the survey of 2007.

Although several process-oriented indicators exist, we limited ourselves in this questionnaire to: 'length of in-hospital stay', 'throughput times', 'number of physical transfers between departments', and 'number of patient handovers between clinicians'. These indicators are closest related to one of the principles of the establishment of care programmes, which is to simplify the process by reducing the number of interactions and handovers ${ }^{28}$. Besides, these indicators are the known indicators among hospitals and are frequently used within projects that aim to establish care programmes ${ }^{24}$.

\subsubsection{Data analysis}

Descriptive statistics were used to assess the extent to which process-based budgeting is applied, the use of four different process-oriented performance indicators, the number of activities geared to establish care programmes, the percentage of care delivery that is/can be organised in care programmes, and the indicators of process-orientation in hospitals. Next, structural equation modelling (SEM), a statistical technique for testing and estimating relationships using a combination of statistical data and qualitative causal assumptions, was used to assess the hypothesised relations as visualised in Figure 4.2. To apply SEM, all observed variables in the model need to have a normal distribution. Therefore, variables were first assessed for univariate and multivariate normality. Univariate normality was assessed using skewness statistic $\sqrt{ } b_{1}$, kurtosis statistic $b_{2}$, and the D'Agostino \& Pearson $\mathrm{K}^{2}$ omnibus test for normality 29,30 . In addition, Srivistava's and Small's test of multivariate kurtosis and skew, and an omnibus test of multivariate normality based on Small's statistics, were used to check multivariate normality ${ }^{30,31}$. A significant value of one of these statistics $(p<0.05)$ indicates a deviation from normality.

Subsequently, the hypothesised relationships were assessed in two steps: one that tested the hypothetical model and a second test without non-significant relations. Model fit depends on a number of features that need to be examined in addition to the significance of parameter estimates. We limited ourselves to common fit statistics like Chi-square, the Tucker-Lewis Index (TLI), the Confirmative Fit Index (CFI), and the Root Mean Square Error of Approximation (RMSEA). A significant Chi-square represents 'badness of fit'. This test is 
suitable for models with a sample size up to 100 . TLI- and CFI values below 90 indicate that the model can be improved. Values between .90 and .95 are acceptable, and values above .95 are good ${ }^{32}$. Good models, moreover, have an RMSEA value of equal to or lower than .05 , values between .05 and .08 are considered acceptable, values higher than .10 indicate a poor fit ${ }^{33}$, 34. SEM analyses in this study were conducted using AMOS 16.0.

Finally, we assessed whether implementation of care programmes contributed to the transition towards process-orientation. Therefore, Spearman correlation coefficients were computed between the percentage of care in care programmes and the indicators of process-orientation that were measured on an interval scale. Independent sample T-tests were performed for the indicators measured on a dichotomous scale.

\subsection{Results}

Sixty-two hospitals completed and returned the questionnaire (a response rate of $65 \%$ ), including five university, fourteen tertiary teaching, forty general, and three specialised hospitals. On average, university hospitals have the most personnel (in fulltime equivalents) and the highest number of people to serve, followed by tertiary teaching, general, and specialised hospitals.

Table 4.1 gives an overview of the data gathered in the hospital survey. 


\begin{tabular}{|c|c|c|c|c|c|}
\hline & Mean (sd) & $\begin{array}{l}\text { Range } \\
\text { (min-max) }\end{array}$ & $\sqrt{ } b_{1} *(p)$ & $b_{2}^{\wedge}(p)$ & $\begin{array}{l}\text { D'Agostino } \\
\& \text { Pearson } \\
\mathrm{K} \mathrm{sq}^{\#}(p)\end{array}$ \\
\hline \multicolumn{6}{|c|}{ Process-based budgeting within the hospital } \\
\hline Process-based financial allocation & $2.1(1.0)$ & $0-4$ & $-0.22(0.49)$ & $-1.39(0.16)$ & $2.41(0.30)$ \\
\hline \multicolumn{6}{|c|}{ Process-oriented performance indicators } \\
\hline $\begin{array}{l}\text { Use of process-oriented } \\
\text { performance indicators: }\end{array}$ & $1.7(0.8)$ & $0-3$ & $0.38(0.24)$ & $-0.16(0.88)$ & $1.39(0.50)$ \\
\hline $\begin{array}{l}\text { - Indicator for throughput times } \\
(\%,[n])\end{array}$ & $(47.5[29])$ & & & & \\
\hline $\begin{array}{l}\text { - Indicator for length of in- } \\
\text { hospital stay }(\%,[n])\end{array}$ & $(63.9[39])$ & & & & \\
\hline $\begin{array}{l}\text { - Indicator for number of } \\
\text { handovers }(\%,[n])\end{array}$ & $(11.5[7])$ & & & & \\
\hline $\begin{array}{l}\text { - Indicator for number of } \\
\text { transfers }(\%,[n])\end{array}$ & $(9.8[6])$ & & & & \\
\hline \multicolumn{6}{|c|}{ Activities to establish care programmes } \\
\hline $\begin{array}{l}\text { Activities to establish care } \\
\text { programmes: }\end{array}$ & $2.2(0.7)$ & $0-3$ & $-0.10(0.75)$ & $-1.42(0.16)$ & $2.12(0.35)$ \\
\hline - None $(\%,[n])$ & $(1.6[1])$ & & & & \\
\hline - A single project $(\%,[n])$ & $(17.7[11])$ & & & & \\
\hline - Several projects $(\%,[n])$ & $(58.1[36])$ & & & & \\
\hline - Hospital wide $(\%,[n])$ & $(22.6[14])$ & & & & \\
\hline \multicolumn{6}{|c|}{ Percentage of care delivery that is or can be organised in care programmes } \\
\hline $\begin{array}{l}\% \text { of care delivery in care } \\
\text { programmes }\end{array}$ & $33.1(20.1)$ & $10-100$ & $1.23(0.00)$ & $1.89(0.06)$ & $13.70(0.00)$ \\
\hline $\begin{array}{l}\% \text { of care delivery potentially in } \\
\text { care programmes }\end{array}$ & $71.0(14.2)$ & $30-100$ & $-0.37(0.25)$ & $0.77(0.44)$ & $1.92(0.38)$ \\
\hline \multicolumn{6}{|c|}{ Indicators of process-orientation } \\
\hline Decentralised decision making & $2.3(1.0)$ & $0-5$ & $-0.04(0.90)$ & $-0.05(0.96)$ & $0.02(0.99)$ \\
\hline Process view employees & $2.5(1.0)$ & $1-5$ & $0.07(0.83)$ & $-0.46(0.65)$ & $0.26(0.88)$ \\
\hline Process ownership & $3.1(1.0)$ & $1-5$ & $-0.64(0.06)$ & $0.09(0.93)$ & $3.63(0.16)$ \\
\hline $\begin{array}{l}\text { Protocols for routing of patients } \\
(\%,[n])\end{array}$ & (74.2 [46]) & & & & \\
\hline $\begin{array}{l}\text { Protocols for specific patient } \\
\text { groups }(\%,[n])\end{array}$ & $(93.5[58])$ & & & & \\
\hline
\end{tabular}

* Skewness statistic $\sqrt{ } b_{1}$, kurtosis statistic $b_{2 .}$ " D'Agostino \& Pearson $\mathrm{K}^{2}$ omnibus test for normality. 
These data show that:

- $\quad 33.3 \%(n=19)$ of the hospitals allocate financial resources on the basis of care processes to some extent (score > 2.5);

- Clinicians in hospitals generally use two process-oriented performance indicators, namely 'length of in-hospital stay' and 'throughput times', to monitor and adjust the organisation of care processes. The indicators for the number of transfers between departments and patient handovers between clinicians are used by approximately $10 \%$ of the hospitals;

- Most hospitals $(n=50,81 \%)$ undertake several projects to establish care programmes. Only one hospital is not actively involved in establishing care programmes;

- $\quad$ On average, $33.1 \%(s d=20.1$ ) of care delivery was organised in care programmes in the winter of $2007 / 2008$ and $71.0 \%$ ( $\mathrm{sd}=14.2$ ) of care delivery can be organised in care programmes according to the respondents.

Data on process-orientation indicators show that:

- On average, decision making is more centralised than decentralised, as was indicated by one-third of the hospitals $(33.9 \%, n=21)$;

- $\quad 75.4 \%(n=46)$ of the hospitals appoint process owners to care processes (score > 2.5);

- Care delivery is regarded as a series of linked care activities in the minority $(39.3 \%, n=24)$ of the hospitals (score $>2.5)$;

- $\quad 93.5 \%$ of the hospitals has (clinical) protocols for specific diseases and almost 75\% has (organisational) protocols for routing of patients.

Before testing the hypothesised relationships, we first assessed the univariate and multivariate normality of the variables of the hypothetical model (Figure 4.2). Tests for univariate normality indicate that the variables can be regarded as normally distributed except for the variable '\% patients in care programme' (see Table 4.1). To normalise this positively skewed variable, we applied a square root transformation. After this transformation, normality statistics were $\operatorname{good}\left(\sqrt{ } b_{1}=0.52\right.$ [ $p=0.12$ ],$b_{2}=0.15$ [ $p=0.88$ ], D'Agostino \& Pearson $K^{2}=2.50$ $[p=0.29])$. The transformed variable was used in further analysis. In addition, statistics indicate that multivariate normality of the data can be assumed (multivariate kurtosis [Srivistava's test: $\chi=3.85, \mathrm{df}=4, p=0.43$; Small's test: $\mathrm{Q} 1=4.69, \mathrm{df}=4, p=0.43$ ]; multivariate skewness [Srivistava's test: $\chi=2.51, \mathrm{df}$ $=4, p=0.16$; a variant of Small's test: VQ2 $=4.04, \mathrm{df}=4, p=0.40]$; omnibus test of multivariate normality based on Small's statistics [VQ3 $=8.74, \mathrm{df}=8, p=$ $0.37])$. 
Next, the hypothetical model was tested using SEM. It was shown that processbased budgeting does not have a significant effect on activities to establish care programmes (hypothesis $1: \mathrm{b}=0.02 ; p=0.80$ ), but does coincide significantly with the use of process-oriented performance indicators by clinicians (hypothesis $2: b=0.30 ; p=0.02$ ). The use of a higher number of performance measures has in turn a positive relation with activities to establish care programmes (hypothesis 3: $b=0.21 ; p=0.01$ ). Further, an increase in activities to establish care programmes is positively related to the percentage of patients being treated in care programmes (hypothesis $4: b=0.40 ; p=0.00$ ). Fit measures for this model are good: Chi-square 'badness of fit' is not significant (0.96; $p=0.62$ ), the CFI and TLI are almost 1.00 and the RMSEA is close to zero.

In a second test, the non-significant relation between process-based budgeting and activities to establish care programmes was removed (Hypothesis 1). Test results demonstrate that relations 2,3 , and 4 are still significant and estimates are unchanged. Chi-square is not significant $(1.02 ; p=0.80)$. The TLI and CFI are almost 1.00; the RMSEA is close to zero. This means that the model fits of the first and second model are similar. However, because the second model is more restrictive, it is more informative and should thus be preferred.

Statistics show that the presence of more care programmes is not associated with higher scores on indicators for process-orientation: decentralised decision making ( $\rho=-0.11 ; p=0.44)$, agreements about process ownerships $(\rho=-0.02 ; p$ $=0.92)$, hospital employees having a process-oriented view $(\rho=0.06 ; p=0.67)$, availability of protocols for specific patient groups $(t=-0.22 ; p=0.83)$ or for routing of patients $(t=-1.82 ; p=0.08)$.

\subsection{Discussion}

The purpose of this study was to test whether case-mix based reimbursement stimulates activities to develop care programmes, and eventually a processoriented way of working. SEM analysis reveals that the adoption of the case-mix reimbursement system within the hospitals' budgeting process, via a positive effect on the number of process-oriented performance measures used by clinicians, leads to a higher frequency of activities to establish care programmes. Internal process-based budgeting was not confirmed to stimulate these activities directly. It is possible that clinicians need process-oriented performance data before they feel compelled to optimise care processes, to work together, and to establish care programmes. This view is supported by previous research of Lehtonen (2007) ${ }^{18}$ that showed that the implementation 
of case-mix reimbursement in the hospitals' budgeting process is strongly dependent on the involvement of clinicians.

Results on indicators for process-orientation show, however, that implementation of care programmes in the surveyed hospitals has not yet been accompanied by process-orientation. It seems that hospitals do implement protocols for the diagnosis, treatment, and routing of patients, but that employees frequently do not acquire a process-oriented view. The change of focus from function to process, and all additional arrangements (e.g. decentralisation of responsibilities), may require more time. It could be difficult for clinicians, as well as for nurses, to find the appropriate balance between their traditionally strong orientation to professional values and their commitment to develop the power and prestige of their profession ${ }^{3}$; and a more collaborative process-orientation that is needed to effectuate care programmes. The lacking process-orientation can also be related to the low percentage (10\%) of hospitals in which clinicians use process-related performance measures to monitor and adjust the organisation of care delivery (i.e. the number of patient handovers). The use of these kinds of performance indicators by clinicians is important for the development of a process-oriented view, because they provide insight into the process of care (i.e. steps to be taken to diagnose and treat patients) and information about waste (i.e. waiting times, unnecessary consultations).

At the time of this research, only one-third of the hospitals applied internal process-based budgeting to any extent. Because the case-mix-based reimbursement system gradually replaces the fee-for-service system in the Netherlands, it can be expected that more hospitals will apply process-based budgeting and to a greater extent in the future, which in turn will contribute to the development of more care programmes. This expectation is strengthened by the results of a recent longitudinal analysis on the development of Dutch hospital quality management systems. This analysis revealed that financial and non-financial policy measures increased the development levels of Dutch hospital quality management systems since 1995, which includes an increase in the use of protocols for specific patient or diagnosis groups, protocols for the routing of patients from admission to discharge, and management information systems providing periodic overviews of care provision and outcomes ${ }^{27}$. Assuming that this trend continues, we expect that policy measures (like the introduction of case-mix reimbursement) contribute to the further development of process-oriented care delivery via the increased use of processoriented performance indicators and the development of care programmes. This may help to shift the focus from function to process in hospitals, because it 
stimulates health care professionals in different departments to collaborate and to achieve common goals.

Although this study gives a valuable insight in the effect of case-mix reimbursement on the development of a process-oriented way of working, three key limitations in the study should be mentioned. First, we made use of self-reported data gathered using a questionnaire. As a consequence, social desirability bias could have influenced our study results. It is a general limitation of questionnaires that respondents have the tendency to reply in a manner that will be viewed favourably by others. Therefore, some of the results could give a too optimistic picture. Second, the answers chief executives give to questions about issues related to characteristics of decentralised members of the organisation (such as the process-oriented view of employees) reflect their personal, potentially biased, interpretation. Therefore, future research needs to extend the number of questionnaire addressees to decentralised organisational members. The third limitation, which is inherent in SEM, is that a good fit by a model consistent with one causal hypothesis does not rule out an equally good fit by another model consistent with a different causal hypothesis. Care should always be taken when making claims of causality, especially since we did not collect data at multiple time points.

\subsection{Conclusions}

This study demonstrates that hospital management can stimulate the development of care programmes by the adoption of the case-mix reimbursement system within hospitals' budgeting processes. This means that case-mix reimbursement does potentially improve care coordination and that decoupling between hospitals' budgeting systems and internal operations does not take place. Future research is recommended to confirm this finding and to determine whether the establishment of care programmes will in time indeed lead to a more process-oriented view of professionals. 


\section{References}

1. Institute of Medicine. Crossing the quality chasm: a new health system for the 21th century. Washington, DC: National Academy Press; 2001.

2. Lega F, DePietro C: Converging patterns in hospital organization: beyond the professional bureaucracy. Health Policy 2005, 74(3):261-281.

3. Vera A, Kuntz L: Process-based organization design and hospital efficiency. Health Care Management Review 2007, 32(1):55-65.

4. Ludwig M, Van Merode F, Groot W: Principal agent relationships and the efficiency of hospitals. The European Journal of Health Economics 2010, 11(3): 291-304.

5. Davis K: Paying for care episodes and care coordination. New England Journal of Medicine 2007, 356(11):1166-1168.

6. Kaplan RS, Cooper R: Cost and effect: Using integrated cost systems to drive profitability and performance. Boston: Harvard Business School Press; 1997.

7. Van Merode GG: A prelude of 2004 Antwerp quality conference: targets and target values - integrating quality management and costing. Accreditation and Quality Assurance 2004, 9:168-171.

8. Folmer K, Mot E: Diagnosis and treatment combinations in Dutch hospitals. The Hague: CPB Netherlands Bureau for Economic Policy Analysis; 2003.

9. Custers T, Arah OA, Klazinga NS: Is there a business case for quality in The Netherlands? A critical analysis of the recent reforms of the health care system. Health Policy 2007, 82(2):226-239.

10. Gemmel P, Vandeale D, Tambeur W: Hospital Process Orientation (HPO): the development of a measurement tool. Total Quality Management \& Business Excellence 2008, 19(12):1207-1217.

11. Gemmel P, Vandaele D, Tambeur W: Hospital process orientation (HPO): the development of a measurement tool. Gent: Ghent University, Belgium; 2007.

12. Hammer M, Champy J: Reengineering the corporation: A manifesto for business revolution. London: Nicholas Brealey; 1993.

13. McCormack KP, Johnson WC: Business process orientation: gaining the ebusiness competitive advantage. Boca Raton: CRC Press LLC; 2001.

14. Schneller ES, Smeltzer LR: Strategic management of the health care supply chain. San Francisco: Jossey-Bass; 2006.

15. Brock KA, Vale SJ, Cotton SM: The effect of the introduction of a case-mix based funding model of rehabilitation for severe stroke: an Australian experience. Archives of Physical Medicine and Rehabilitation 2007, 88:827-832.

16. Theurl E, Winner H: The impact of hospital financing on the length of stay: evidence of austria. Health Policy 2007, 82:375-389.

17. Forsberg E, Axelsson R, Arnetz B: Financial incentives in health care. The impact of performance-based reimbursement. Health Policy 2001, 58:243-262. 
18. Lehtonen T: DRG-based prospective pricing and case-mix accounting - Exploring mechanisms of successful implementation. Management Accounting Research 2007, 18(367-95).

19. Covaleski MA, Dirsmith MW, Michelman JE: An institutional theory perspective on the DRG framework, case-mix accounting systems and health care organizations. Accounting Organizations and Society 1993:65-80.

20. Vissers JMH, Beech R: Health operations management: patient flow logistics in health care. London: Routledge; 2005.

21. Berg $M$, Schellekens $W$, Bergen C: Bridging the quality chasm: integrating professional and organizational approaches to quality. International Journal for Quality in Health Care 2005, 17(1):75-82.

22. Berwick DM, James B, Coye MJ: Connections between quality measurement and Improvement. Medical Care 2003, 41(1 (suppl)):I30-38.

23. De Vos M, Graafmans W, Kooistra M, Meijboom B, Van Der Voort P, Westert G: Using quality indicators to improve hospital care: a review of the literature. International Journal for Quality in Health Care 2009, 21(2):119-129.

24. Nolan TW, Schall MW, Berwick DM, Roessner J: Reducing delays and waiting times throughout the healthcare system. Boston: Institute for Healthcare Improvement; 1996.

25. Grol R, Wensing M, Eccles M: Improving patient care: the implementation of change in clinical practice. Edinburgh: Elsevier; 2005.

26. Liker JK: The Toyota way: 14 management principles from the world's greatest manufacturer. New York [etc.]: McGraw-Hill; 2004.

27. Dückers MLA, Makai P, Vos L, Groenewegen PP, Wagner C: Longitudinal analysis on the development of hospital quality systems in the Netherlands. International Journal for Quality in Health Care 2009, 21(5):330-340.

28. Plsek PE: Systematic design of healthcare processes. Quality in Health Care 1997, 6:40-48.

29. D'Agostino RB, Belanger A, D'Agostino RB, Jr.: A suggestion for using powerful and informative tests of normality. American Statistician 1990, 44:316-321.

30. DeCarlo LT: On the meaning and use of kurtosis. Psychological Methods 1997, 2(3):292-307.

31. Looney SW: How to use tests for univariate normality to assess multivariate normality. American Statistician 1995, 49:64-70.

32. Bentler PM, Bonett DG: Significance tests and goodness of fit in the analysis of covariance structures. Psychological Bulletin 1980, 88:588-606.

33. Browne MW, Cudeck R: Alternative ways of assessing model fit. In Testing structural equation models. Edited by Bollen KA, Long JS. Newbury Park, CA: SAGE; 1993:136-162.

34. Byrne BM: Structural equation modeling with AMOS. Mahwah, NJ: Lawrence Erlbaum; 2001. 


\section{Chapter 5}

\section{How to implement process-oriented care}

\section{a case study on the implementation of process-oriented in-hospital stroke care}

This chapter was published as:

Leti Vos L, Robert J. van Oostenbrugge, Martien Limburg, Godefridus G. van Merode, Siebren Groothuis. How to implement process-oriented care: a case study on the implementation of process-oriented in-hospital stroke care. Accreditation and quality assurance 2009: 14: 5-13. 


\subsection{Introduction}

Dutch hospitals are currently in the midst of a transition towards processoriented organisation, in order to realise optimal and undisturbed care processes. Hospitals in the Netherlands traditionally have a functional structure. Similar capacities are grouped in departments (units), for example, surgeons in the surgery department, clinical chemistry in laboratories, and so $\mathrm{on}^{1}$. The task differentiation and specialisation of physicians and, to a lesser degree, also nurses, are the main reasons for the typical functional organisational design of hospitals ${ }^{2,3}$. In a functionally organised hospital, each department strives to optimise its level of functioning, but is unable to integrate its services to best meet the needs of patients ${ }^{4}$, i.e. one department is not able to tune its processes to those in other departments. In a process-oriented organisation, processes are mapped so that task responsibilities are described with a focus on processes. In organisations of this type, functional borders are crossed, and all members of different departments are encouraged to collaborate and achieve common goals ${ }^{5}$.

There are two ways to implement process-oriented organisation of care:

A. Implementation of coordination measures (such as care programmes); or

B. Implementation of clinical directorates ${ }^{3,5}$.

In the former, horizontal processes are placed on top of the existing vertical structure, without changing the functional organisation ${ }^{5}$. The implementation of clinical directorates, on the other hand, requires changes in the hospital structure. Clinical directorates are intermediate organisational arrangements through which certain parts of larger hospitals are managed. The hospital organisation is then divided into multidisciplinary organisational units, bringing together physicians, nurses, paramedical, administrative, and clerical staff. These multidisciplinary organisational units handle a business process as comprehensively as possible and have relatively few interdependencies with other clinical directorates. With both strategies, it is necessary to overcome the functional division of labour ${ }^{3,6}$.

Until now, the implementation of process-oriented organisation of care in Dutch hospitals has been limited to the implementation of coordination measures. The implementation of directorates is hampered by, for example:

- Political and ethical obligations, which prevent hospitals from deleting services, and focussing on strategically important services with the same freedom as firms in other industries ${ }^{3}$; and 
- $\quad$ Physicians' strong orientation to professional values and their commitment to developing the power and prestige of their profession, which often conflicts with managerial goals associated with process-based organisation ${ }^{3}$.

The introduction of process-orientation in a functional structure is complex. In a functional structure, the organisation of care delivery traditionally focuses only on certain elements of care rather than the whole care process. The result is a very complex system of flows and queues. There are many interactions between workplaces, and therefore many transfers occur. As a consequence, the throughput times of patient flows are unpredictable, and the quality of care is less than optimal ${ }^{4}$. In order to implement process-oriented care in a functional structure, management and health care professionals must handle an additional focus: besides their focus on optimising unit performance, they also need to focus on the control of care processes across hospital units. To optimise unit performance (utilisation of resources within units), care demand and care delivery have to be adjusted. To maximise the control of care processes, waste in the patient flow over functional borders of separate units must be eliminated. Waste can be considered as all activities, such as waiting and movement of staff and patients, that do not add value to a care process ${ }^{7}$. To maintain focus on both these aspects, management and health care professionals have to find the appropriate trade-off between optimal unit performance (utilisation of resources within units), and the level of service provided to stroke patients (short waiting time for diagnostic tests or consultation with other medical specialties, and throughput times).

In this article, we report on a case study of the implementation of processoriented care using coordination measures for an in-hospital stroke unit.

\subsubsection{Case study: process-oriented in-hospital stroke care}

In 2004 the University Hospital Maastricht (UHM) decided to implement process-orientation for stroke patients in order to adjust their services to the needs of these patients and to optimise the organisation of in-hospital stroke unit care. At that time the average length of hospital stay (LOS) for stroke patients was 12 days, which, according to the management of the department, surpassed the optimal LOS. According to the management of the department, the reason for this was a lack of process-orientation, resulting in poor adjustment of care delivery to the needs of the patients and inefficient use of hospital resources ${ }^{8}$. The importance of well organised stroke care at a stroke 
unit (specialised hospital ward) has been highlighted by several studies ${ }^{9-12}$. Admission to a stroke unit leads to improved health, functional outcomes, and survival $^{9,13}$. In contrast to awareness of the qualitative components of effective stroke unit care, less attention has been paid to the operational management of stroke unit care. Little is known about effective measures that could control the whole care process from a process point of view, simultaneously optimising the efficiency of the departments involved.

In the case of in-hospital stroke care, the hospital is confronted with an acute care demand. Over $70 \%$ of stroke patients are admitted to hospital in the acute phase, resulting in uncertainty about the type and extent of care needed. This requires that the hospital has spare (reactive) capacity. Besides uncertainty over arrival times, the type of care needed by patients at the stroke unit is also complex due to the multitude of co-morbidities, which in turn requires the involvement of several medical specialties and paramedical disciplines. The uncertainty and complexity of care for stroke patients complicate the adjustment between care demand and care delivery. In the case of processorientation this adjustment will also be dependent on the collaboration between several departments, all of which are involved in delivering care to stroke patients (neurologists, diagnostic capacities, and allied health care professionals such as occupational therapists and physiotherapists). The central idea of process-orientation is, after all, the optimisation of patient flow over the functional borders of the separate units involved. In this study, we explored the possibilities of implementing process-orientation using coordination measures.

\subsection{Methods}

In order to implement process-orientation for care in an in-hospital stroke unit, we used a time-series design consisting of four steps:

1. Process-analysis;

2. Identification of bottlenecks;

3. Setting goals for process-oriented care and selection of coordination measures to realise process-oriented care;

4. Implementation of coordination measures and evaluation of effects.

Each of these steps is discussed in more detail below.

\section{Step 1: Process-analysis}

In 2004 we undertook a process-analysis of the stroke care process. Our retrospective analysis was confined to patients admitted to the UHM between 
June and December 2003. These patients were selected retrospectively from the stroke service database of the UHM. Analysis of the existing care process comprised several steps:

- Analysis of the UHM protocol and guidelines of the Dutch Institute for Healthcare Improvement (CBO) for stroke treatment ${ }^{14}$;

- Observation of the care process and structured interviews with the care providers involved;

- Quantitative description of the processes based on the records of stroke patients.

We collected the following demographic data on all included patients: age, sex, stroke type (based on the international statistical classification of diseases 9th revision-ICD-9- $\mathrm{cm}^{15}$ : ischemic stroke [ICD-9-cm 434.9, 435, 436] and intracerebral haemorrhage [ICD-9-cm 431]), length of stay (time period between admission and discharge, in days), ward of admission (stroke unit or other), and discharge destination (home, nursing home, rehabilitation facility). The medical files, the hospital patient information system, and paramedical administrations were checked for the activities listed to determine whether these took place according to protocol. For each diagnostic test or therapeutic activity we determined the day of request and day of performance. We calculated the average time between request and performance. The interrelationship between the day of multidisciplinary meeting and LOS was computed per discharge destination with Spearman's correlation coefficient. We visualised the average care process in a Gantt chart-a graphical representation of the duration of tasks against the progression of these tasks ${ }^{16}$ that aids understanding of the workflow in the stroke care process.

\section{Step 2: Identification of bottlenecks}

The performance of the in-hospital care process of stroke patients before the redesign was determined by comparing treatment protocols according to the UHM protocol and Dutch stroke guidelines ${ }^{14}$ with actual patient treatment schedules obtained from patient records. We also examined whether all required actions were taken, and elucidated time intervals between these actions.

\section{Step 3: Goals for process-oriented care and selection of interventions}

We evaluated the identified bottlenecks with all health care professionals, including allied health workers, with the objective of improving patient flow in in-hospital stroke care in order to deliver optimal care. From an operations management point of view, optimal care can be delivered only with the right trade-off between optimal unit performance (utilisation of resources in 
individual units) and the service level provided to stroke patients (short waiting and throughput times).

\section{Step 4: Implementation of redesign and evaluation of effects}

In January 2006 the redesigned stroke care process to realise process-oriented care was implemented. Process-analysis and selection of interventions took a long time because many different health care professionals were involved in the process and the implementation of the process-orientation meant a shift in responsibilities for some of the professionals involved. Also, staff education was needed, which again took time.

Retrospective analysis to determine the performance after redesign was performed for patients admitted to the stroke unit of the UHM between January and April 2006. The length of this interval was limited to 4 months for practical reasons. Demographic data from all included patients were gathered. First, demographic data (sex, age, and diagnosis) were compared with independent samples by $t$-test. Next, we compared the performance of the care process for stroke patients before and after implementation of process-oriented care. Data concerning the LOS of patients admitted before and after the redesign were compared with the Mann-Whitney $U$ test.

\subsection{Results}

The following sections present the results of the case study according to the four steps of the time-series design.

\section{Step 1: Process-analysis}

We included hundred stroke patients. Table 5.1 shows the demographic data of the population studied. The average age was 74.0 years [standard deviation (sd) $=9.5$ years], 56\% were male, $85 \%$ had an ischemic stroke, and $15 \%$ an intracerebral haemorrhage. The length of stay varied from 3 to 33 days, with the average length of stay being 12.0 days ( $s d=6.3$ days). Due to shortage of capacity on the stroke unit, thirty-one patients were initially admitted to a nonspecialised ward of the UHM and subsequently transferred to the stroke unit.

The frequency of application of diagnostic examinations and consultations is shown in Table 5.2. The care process starts in the emergency unit. After history taking, physical examination, standard blood testing, ECG, and brain CT-scan, patients are usually admitted to the stroke unit but in some cases first to another ward (all within the first $24 \mathrm{~h}$ ). The rehabilitation process, which 
includes mobilisation, physical therapy, occupational therapy, and speech therapy, starts in the following days, and additional examinations take place on average on day 4 , having been requested on day 2 .

Table 5.1 Characteristics of patients included before and after implementation of processorientation

\begin{tabular}{lll}
\hline & $\begin{array}{l}\text { Before } \\
(\mathbf{2 0 0 4 )}\end{array}$ & $\begin{array}{l}\text { After } \\
\mathbf{( 2 0 0 6 )}\end{array}$ \\
\hline Number of patients included: & 100 & 51 \\
- Intracerebral haemorrhage (\%) & $15(15)$ & $7(14)$ \\
- Ischemic stroke (\%) & $85(85)$ & $44(86)$ \\
Sex (number): & & \\
- Male (\%) & $56(56)$ & $25(49)$ \\
- Female (\%) & $44(44)$ & $26(51)$ \\
& & \\
Average age in years (sd) & $74.0(9.5)$ & $73.6(12.9)$ \\
& & \\
Length of hospital stay ${ }^{*}$ (days): & $12.0(6.3)$ & $7.3(5.1)$ \\
- Average (sd) & $3-33$ & $1-30$ \\
- Range &
\end{tabular}

${ }^{*}$ Total duration of hospital stay

The Gantt chart of the existing care process (Figure 5.1) shows at least three days in hospital in which relatively little activity takes place. These are not clinically necessary 'watch and wait' periods. This suggests that the hospital stay could be reduced by at least these three days in the case of stable patients.

Required diagnostic tests-serum, cholesterol, blood testing, and chest X-raywere not performed in $20 \%$ and $34 \%$ of cases, respectively. In the case of chest X-ray, neurologists considered the protocol to be outdated ${ }^{14}$. The duration of the hospital stay of patients discharged to their own home correlated positively with the number of days between day of admission and discussion in a multidisciplinary meeting (Spearman's $\rho=0.33, n=37, p=0.05$ ). Length of hospital stay of patients discharged to other care facilities was not affected by the number of days between admission and discussion in the multidisciplinary meeting. Patients waiting for placement in a rehabilitation facility or nursing home had an extended stay in hospital (3-8 days). The number of days without medical or diagnostic intervention (with the exception of treatments such as occupational therapy) is higher (3-9 days) for the latter patients than for patients who were discharged to home. 


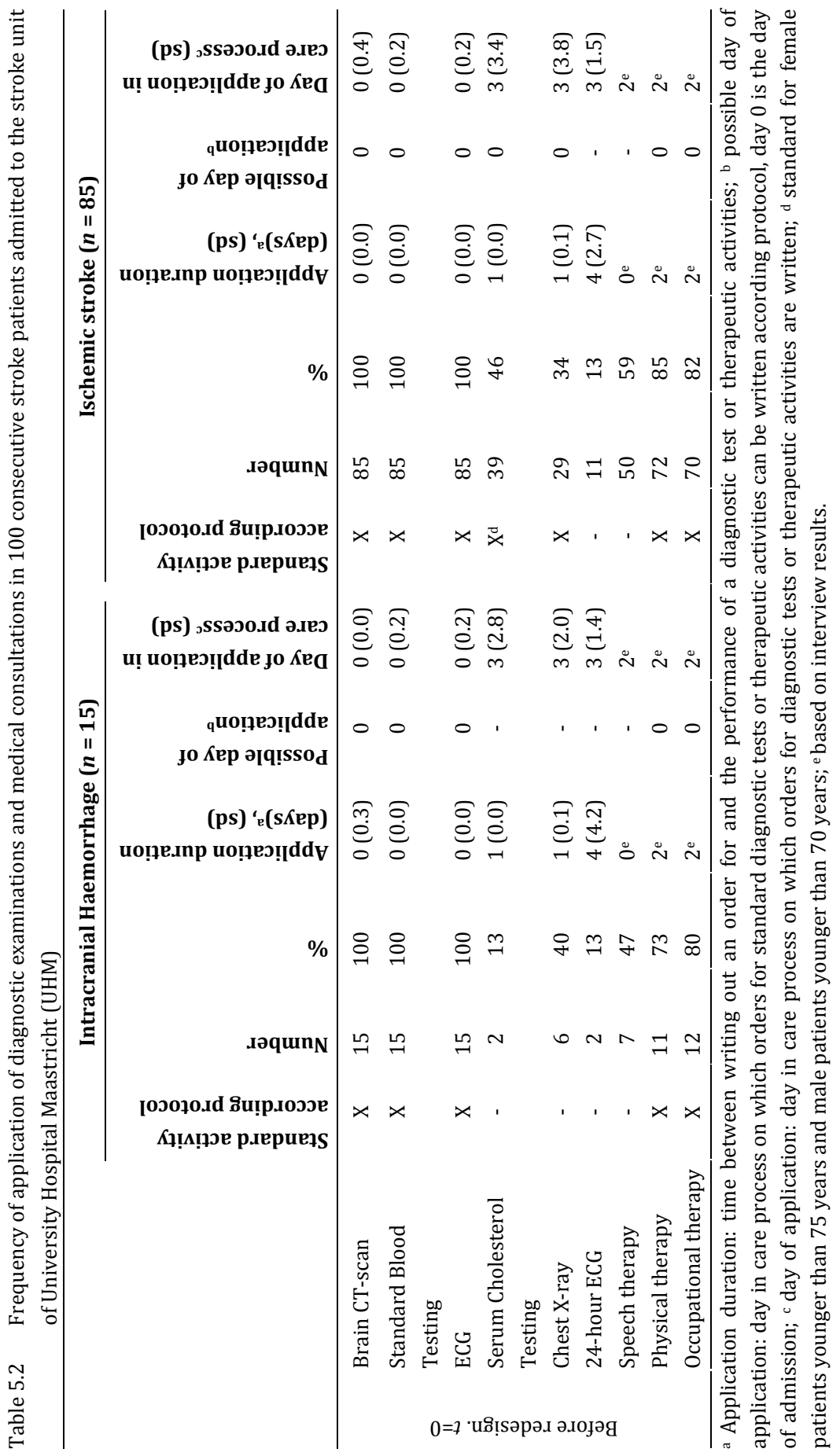




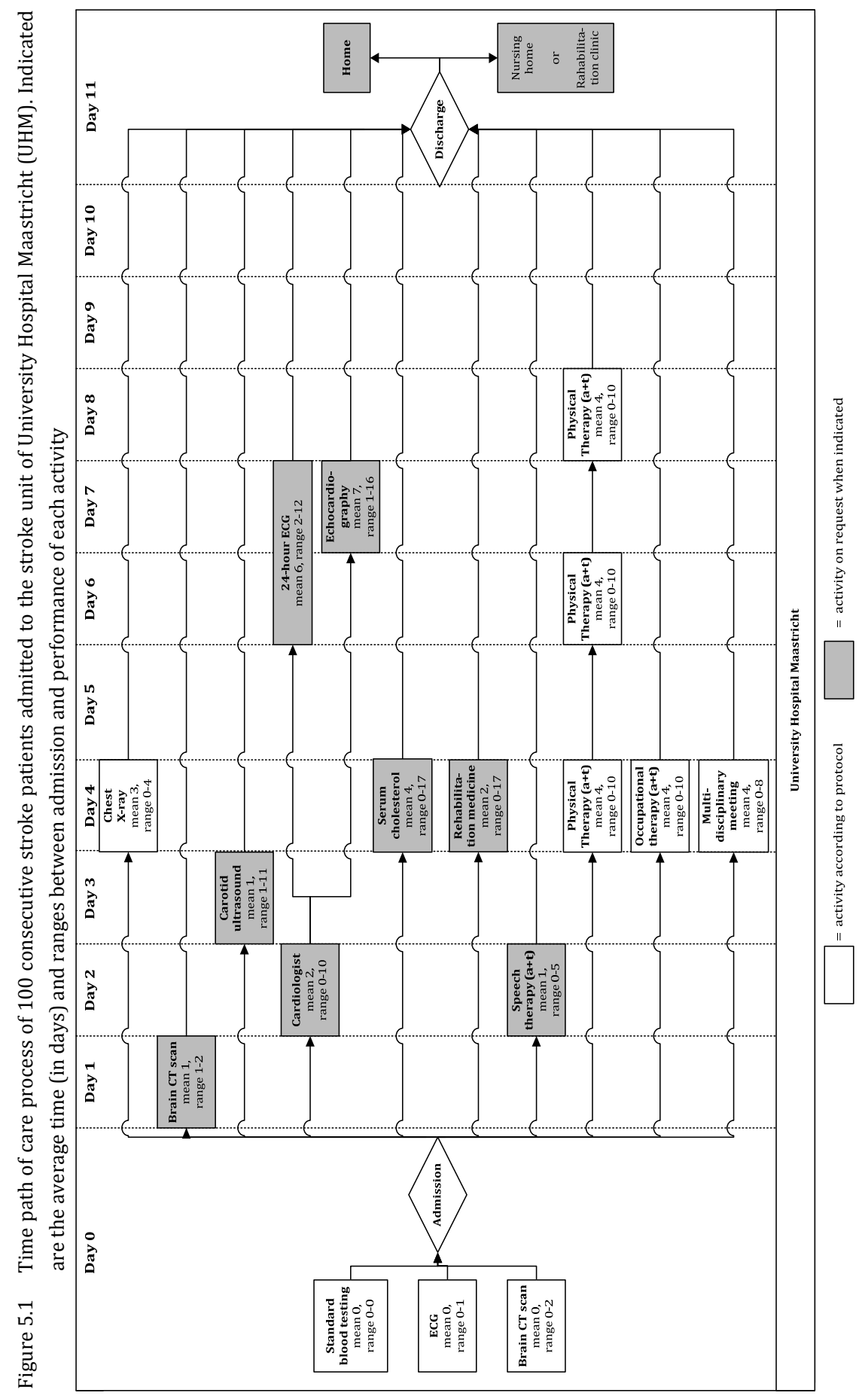




\section{Step 2: Identification of bottlenecks}

Analysis of existing performance helped identify four main bottlenecks for optimal organisation. The first bottleneck is a lack of bed capacity on the stroke unit. One-third of our patients could not be admitted to the stroke unit. Patients spending over five days in a non-specialised ward resided significantly longer in hospital (Mann-Whitney $U$ test: $Z=-2.9, p<0.05$ ). A more efficient organisation of hospital stay in the stroke unit may result in treating more patients at the stroke unit, and so reduce the use of non-specialised wards. Unnecessary delays in requesting orders for diagnostic procedures, and waiting times for diagnostic tests and consultation by allied health professionals form the second bottleneck. When a patient has been admitted, orders for all standard procedures should be written immediately by the neurologist. Yet, in reality, making these requests takes an average of three days. The low frequency of the multidisciplinary meeting (once a week) causes an increase in the length of stay for patients that will be discharged to their homes. Finally, there are waiting times for admission to rehabilitation and nursing facilities.

\section{Step 3: Goals for process-oriented care and identification of coordination measures}

We evaluated the four main bottlenecks with the objective of improving patient flow of in-hospital stroke care in order to deliver optimal care characterised by an appropriate trade-off between optimal unit performance (utilisation of resources in the units) and the level of service provided to stroke patients (short waiting and throughput times). In our case, the bed capacity of the stroke unit was a significant bottleneck. On the other hand, waiting times for diagnostic procedures and nursing facilities increase the LOS in hospital. In order to decrease the LOS and to eliminate waiting times as much as possible, transfer from the hospital to a nursing facility also had to be subject to improvement. The health care professionals involved set the following goals for the implementation of process-orientation:

1. An average LOS in the UHM of five days; and

2. Less than $5 \%$ of all stroke patients having to be admitted to a nonspecialised ward in case of capacity shortage on the stroke unit.

The following coordination measures were selected in order to achieve these goals:

- Use of an updated protocol for patients admitted to the stroke unit, with clear instructions for standard diagnostic procedures and procedures on request. The chest X-ray was dropped as a standard activity, as this procedure is no longer considered best practice; 
- Outsourcing of allied professional assessment to the rehabilitation unit of a nursing facility in order to eliminate waiting times for this assessment and treatment in the UHM, and duplication of care delivery by the UHM and the rehabilitation unit for stroke patients at a nursing facility or rehabilitation centre. As soon as patients are stabilised, they will be transferred to the nursing rehabilitation unit of a nursing facility, in order to begin assessment and rehabilitation as quickly as possible. In the UHM patients receive care of allied health care professionals on demand. In this way patients do not have to wait for placement in a nursing facility, they have direct access;

- Simplification of discharge planning. The weekly multidisciplinary meeting has been removed from the agenda in the UHM because of the delaying effect. After redesign, continuous monitoring of the patient is performed by the neurologist (in consultation with all involved disciplines) to assess the patient's condition and decide on discharge to a rehabilitation unit of a nursing home. Care delivery in the rehabilitation unit is attuned to the needs of the stroke patient. Patients whose condition allows it, will be discharged directly to their home.

The redesign of the care process is illustrated in Figure 5.2. Performance was determined by measuring the outcomes of the care process on the following formulated goals, which acted as proxies for optimal unit performance and the level of service provided to stroke patients:

1. LOS in the UHM; and

2. Percentage of stroke patients initially admitted to a non-specialised ward.

These performance indicators were chosen because they oblige the professionals involved to work together as a group. If they do not cooperate, stroke care will not be optimised and waiting times will not be reduced, and consequently there will be no reduction in LOS. 


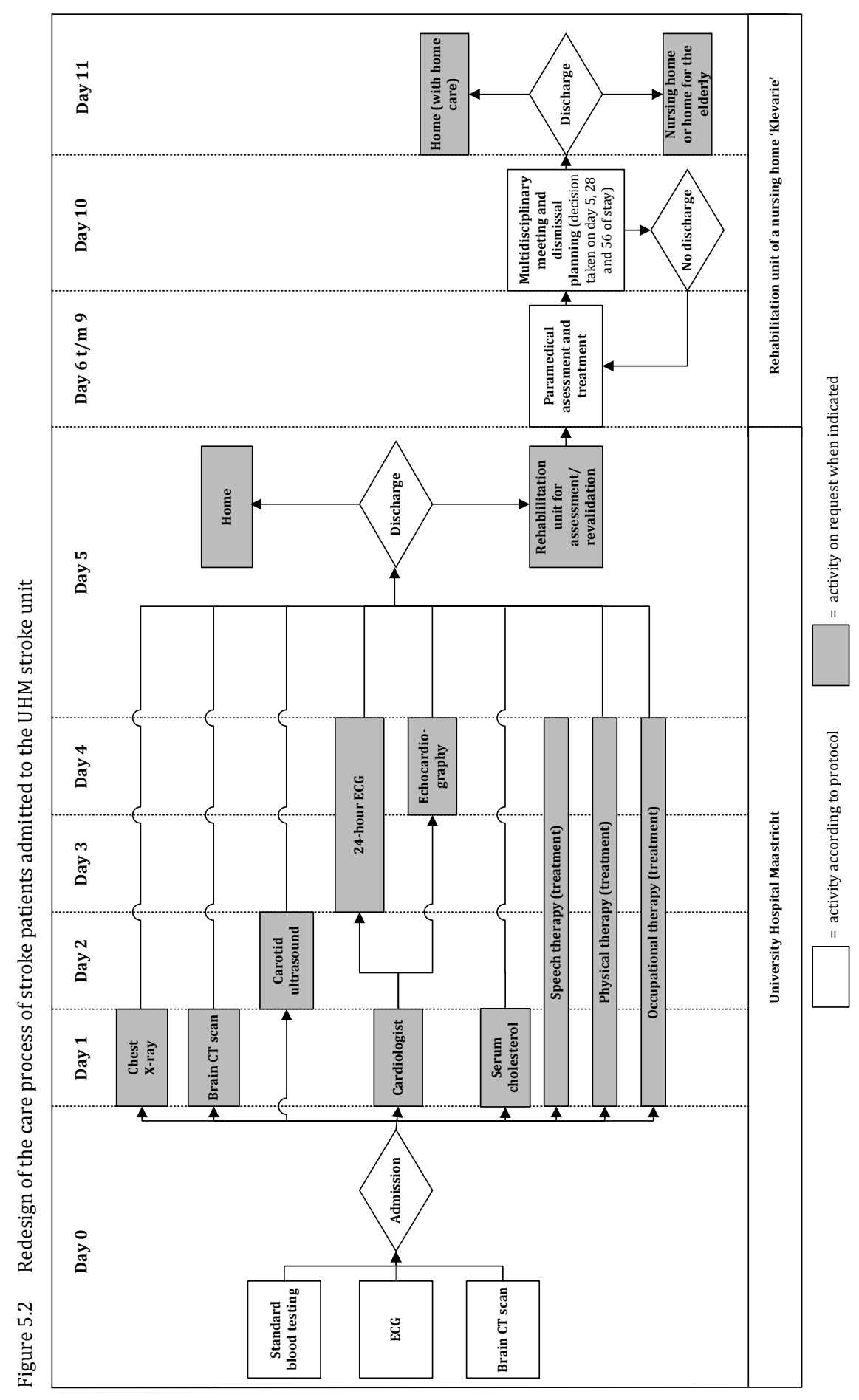




\section{Step 4: Implementation of redesign and evaluation of effects}

Between January and April 2006, fifty-one patients were included in the study to assess the effect of the redesign. The average age was 73.6 years $(\mathrm{sd}=12.9$ years), $49 \%$ of these patients were male, $86 \%$ of the patients suffered an ischemic stroke and $14 \%$ had a intracerebral hemorrhage (Table 5.1). There were no significant differences in demographic data of patient groups in both periods (age, $t$-test: $t=0.22, \mathrm{df}=149, p>0.05$; sex, $t$-test: $t=0.58, \mathrm{df}=149, p>$ 0.05 ; diagnosis, $t$-test: $t=0.21, \mathrm{df}=149, p>0.05$ ).

Table 5.3 shows the results of performance indicators of the care process before and after implementation of the coordination measures. The length of stay of patients admitted after the redesign varied from 1 to 30 days (average 7.3 days, $s d=5.1$ days). After exclusion of three patients that were explicitly indicated for nursing home care, the average length of stay was 6.3 days. The length of stay of patients admitted to the stroke unit was significantly shorter after implementation of the coordination measures (Mann-Whitney $U$ test: $Z=$ $-5.0, p<0.01$ ). Only one patient had to be admitted to another ward because of a lack of capacity on the stroke unit. This was significantly fewer compared to the number of patients admitted to nonspecialised ward before the redesign $(t$ test: $t=8.0, d f=149, p<0.01$ ).

Table 5.3 Performance of stroke care process in the UHM before and after implementation of process-orientation

\begin{tabular}{llll}
\hline & $\begin{array}{l}\text { Before } \\
\mathbf{( 2 0 0 4 )}\end{array}$ & $\begin{array}{l}\text { After } \\
(\mathbf{2 0 0 6 )}\end{array}$ & Sig. \\
\hline $\begin{array}{l}\text { Average length of stay (sd) in days } \\
\begin{array}{l}\text { Percentage of patients admitted to a } \\
\text { non specialised ward }\end{array}\end{array}$ & $31 \%$ & $7.3 \pm 5.1$ days & $p<0.01$ \\
\hline
\end{tabular}

\subsection{Discussion}

In this study we explored the possibilities of implementing process-orientation for care in an in-hospital stroke unit using coordination measures. In processoriented care, the performance of the whole care process is reviewed. To maximise performance of a care process from the point of view of processoriented care, waste (defined as unnecessary steps in the care process) had to be eliminated ${ }^{4,7}$. Besides optimising the level of service provided (short waiting and throughput times), we also needed to take the unit performance into account, since process-oriented care was to be implemented in a functionally organised hospital. In this case study, implementation of coordination 
measures led to better performance of in-hospital stroke unit care in terms of LOS (throughput time) and the number of patients that could be admitted to the stroke unit. Although the chosen process performance indicators (LOS, number of patients admitted to non-specialised wards) are perhaps not the best proxies for process-orientation, we conclude that the coordination measures applied here were useful in coordinating the activities of the stroke care unit from a process point of view for several reasons.

Firstly, standardisation of the in-hospital stroke care process facilitated the decision-making process by making clear which medical and diagnostic procedures were required by each patient and by whom these had to be performed in the care process. This led to better control of the in-hospital stroke care process in time. As a consequence, less flexibility in terms of spare capacity was needed, thus optimising unit performance.

Secondly, the transfer of allied professional assessment and treatment to the rehabilitation unit of a nursing facility reduced waste caused by duplication of work and unnecessary waiting times for allied professional assessment and treatment in the UHM. Besides the reduction of waste, it simplified the planning process and made clear which aspects of care were the responsibility of the specialist services.

In addition, the fact that the number of patients that could be admitted directly to the stroke unit increased after implementation reduced the complexity of planning of the care process and increased the quality of care, since admission to a stroke unit leads to improved health, functional outcomes and survival. ${ }^{9}$ The reduction in the number of patients admitted to non-specialised wards also eliminated waste from the process because professionals no longer had to walk to the other side of the hospital to care for their patients. We showed that application of the described coordination measures contributed to both the adjustment of care demand and care delivery, as streamlining of the process reduced uncertainty and complexity. Uncertainty and, as a consequence, the need for flexibility are reduced by making the process more transparent. Complexity is reduced by standardisation and reducing waste. Care activities are now delivered in a more integrated manner. Furthermore, it would appear that all involved professionals now see their care delivery as part of a care process. This means that they have shifted their focus from optimisation of performance of their unit to improving process performance overall.

Although this study was quite time-consuming, all steps taken were considered essential. Visualising the care process in Gantt charts creates a sense of urgency 
among the involved professionals to streamline processes because they can actually see what is happening with the patient during their hospital stay.

Limitations of our study include the fact that the process-analysis and evaluation of effects did not take place at the same time of year. Seasonal factors could have influenced our results. Also, the fact that the time span between process-analysis and evaluation of effects was quite long for organisational reasons could mean that changes in hospital personnel or other changes in hospital practice could have taken place and influenced our results. However, we do not consider that these limitations biased our results as we described the process in both periods in detail and were not aware of any changes in the hospital process other than those initiated by our study.

\subsection{Conclusion}

The present case study demonstrates that process-orientation using coordination measures can be implemented for in-hospital stroke unit care, and can improve performance by reducing the uncertainty and complexity of this type of care. The method used to decide which coordination measures are needed could be applied to other patient groups. The coordination measures that the UHM has taken to optimise in-hospital stroke care will not be automatically applicable to other care processes because of the specific components of each care process. However, the general principles of visual representation, bottleneck reduction, and elimination of waste and uncertainty would be very useful in many settings. 


\section{References}

1. Van Merode GG: A prelude of 2004 Antwerp quality conference: targets and target values - integrating quality management and costing. Accreditation and Quality Assurance 2004, 9:168-171.

2. Braithwaite J: Strategic management and organisational structure: Transformational processes at work in hospitals. Australian Health Review 1993, 16:383-404.

3. Vera A, Kuntz L: Process-based organization design and hospital efficiency. Health Care Management Review 2007, 32(1):55-65.

4. Van Merode F, Molema H, Goldschmidt H: GUM and six sigma approaches positioned as deterministic tools in quality target engineering. Accreditation and Quality Assurance 2004, 10:32-36.

5. Gemmel P, Vandeale D, Tambeur W: Hospital process orientation (HPO): the development of a measurement tool. Total Quality Management \& Business Excellence 2008, 19(12):1207-1217.

6. Vanhaverbeke W, Torremans H: Organizational structure in process-based organizations. Knowledge and Process Management 1999, 6(1):41-52.

7. Liker JK: The Toyota way: 14 management principles from the world's greatest manufacturer. New York [etc.]: McGraw-Hill; 2004.

8. Limburg M, Vos L, Van Oostenbrugge R, Van Merode GG, Groothuis S: Causes of inefficient stroke unit -bed use- possibilities for freeing up capacity. Cerebrovascular Diseases 2005, 19(supplement 2):114-115.

9. Stroke Unit Trialists' Collaboration. Organised inpatient (stroke unit) care for stroke. The Cochrane Database of Systematic Reviews 2001, Issue 3.

10. Kjellström T, Norrving B, A. S: Helsingborg declaration 2006 on European stroke strategies. Cerebrovascular Diseases 2007, 23:229-241.

11. Langhorne P, Pollock A: What are the components of effective stroke unit care? Age and Ageing 2002, 31(5):365-371.

12. Leys D, Ringelstein B, Kaste M, Hack W: The main components of stroke unit care: result of a European expert survey. Cerebrovascular Diseases 2007, 2007(23):344-352.

13. Brainin M, Olsen TS, Chamorro A, Diener HC, Ferro J, Hennerici MG, Langhorne P, Sivenius J: Organization of stroke care: education, referral, emergency management and imaging, stroke units and rehabilitation. Cerebrovascular Diseases 2004, 17(suppl. 2):1-14.

14. Limburg M, Tuut MK: CBO-guideline 'Stroke' (in Dutch). Nederlands Tijdschrift voor Geneeskunde 2000, 144(22):1058-1062. 
15. Manual of the international statistical classification of diseases, injuries, and causes of death: based on the recommendations of the ninth revision conference, 1975, and adopted by the 29th World Health Assembly. World Health Organization, Geneva (1977-1978).

16. Ozcan YA: Quantitative methods in health care management: techniques and applications. San Francisco: Jossey-Bass; 2005. 


\section{Chapter 6}

\section{Applying the quality improvement collaborative method to process redesign}

a multiple case study

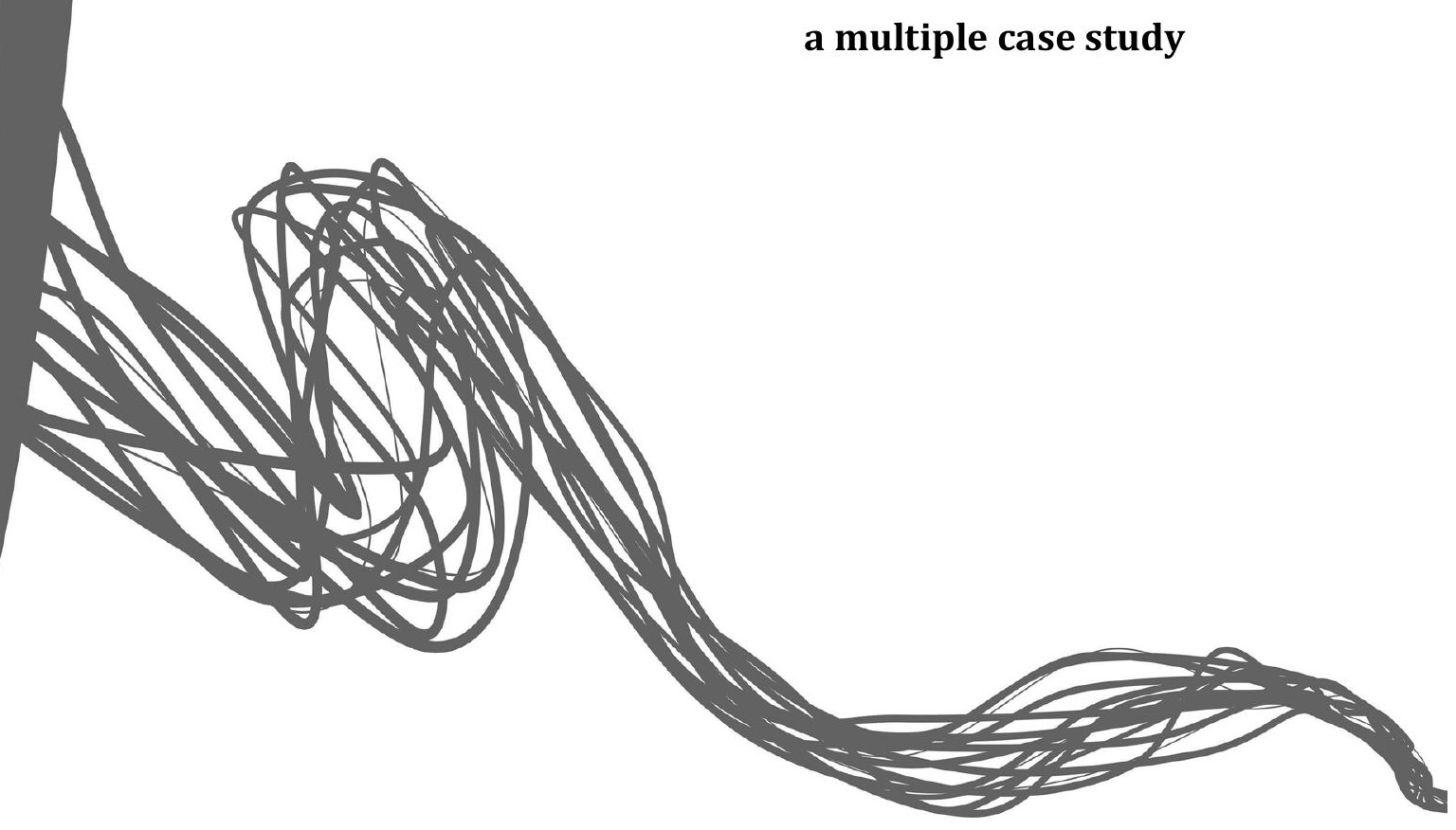

This chapter was published as:

Leti Vos, Michel L.A. Dückers, Cordula Wagner, Godefridus G. Van Merode. Applying the quality improvement collaborative method to process redesign: a multiple case study. Implementation Science 2010, 5(1):19. 


\subsection{Background}

Quality improvement collaboratives (QICs) are used increasingly in many countries to achieve large-scale improvements in performance and to provide specific remedies to overcome the typically slow diffusion of medical and health care innovations ${ }^{1-3}$. A QIC is a multifaceted method that seeks to implement evidence-based practice through sharing knowledge with others in a similar setting over a short period of time ${ }^{4}$. Within the QIC method, external change agents provide collaborative project teams from different health care departments or organisations with a clear vision for ideal care in the topic area and a set of specific changes that may improve system performance significantly ${ }^{5}$. . Project teams also learn from the external change agent about the model for improvement. The model for improvement incorporates four key elements ${ }^{6}$ : specific and measurable aims; measures of improvement that are tracked over time; key changes that will result in the desired improvement; and series of parallel testing plan-do-study-act (PDSA) cycles. Each series involves a test of one change idea (Figure 6.1, part A) ${ }^{7}$. On the basis of the results of the first test of one series, a project team can decide to refine the change idea (in case the change idea works in their context) or to start a new test series of a new change idea (in case the test did not lead to the desired result). These PDSA cycles should be short but significant, testing a big change idea in a short timeframe so that a team can identify ways to improve or change the idea ${ }^{8}$. In Figure 6.2, an example is given to illustrate the model for improvement.

In addition to the relatively efficient use of external change agent support and the exchange of change ideas as well as the model for improvement, the strength of the QIC method seems to be that collaborative project teams share experiences of making changes, which accelerates the rate of improvement (peer stimulus) ${ }^{3}$.

However, despite the widespread use of QICs, a recent review on their impact indicates that evidence is positive but limited, and the effects cannot be predicted with certainty ${ }^{5}$. This apparent inconsistency requires a deeper understanding of how and why QICs work. Therefore it is necessary to explore the 'black box' of the intervention and to study the determinants of success or failure of the QIC method ${ }^{5}$ 9. In this article, we contribute to this by assessing the applicability of this quality improvement method to process redesign. Process redesign aims to improve the organisation of care delivery in terms of waiting times in a patient's care trajectory. From other studies it is already known that the QIC method can be successfully applied to improve the organisation of care delivery in specific departments, such as emergency and 
surgery departments ${ }^{8,10}$. But, to our knowledge, it is unknown whether the QIC method itself is applicable for implementing complex process redesigns, which aim to change patterns of interaction between departments in order to achieve speedy and effective care from a patient's perspective ${ }^{11}$. Therefore, we explored in this study whether the QIC method was applied to complex process redesign projects in a process redesign collaborative in the Netherlands.

Figure 6.1 Testing and implementing changes using PDSA cycles

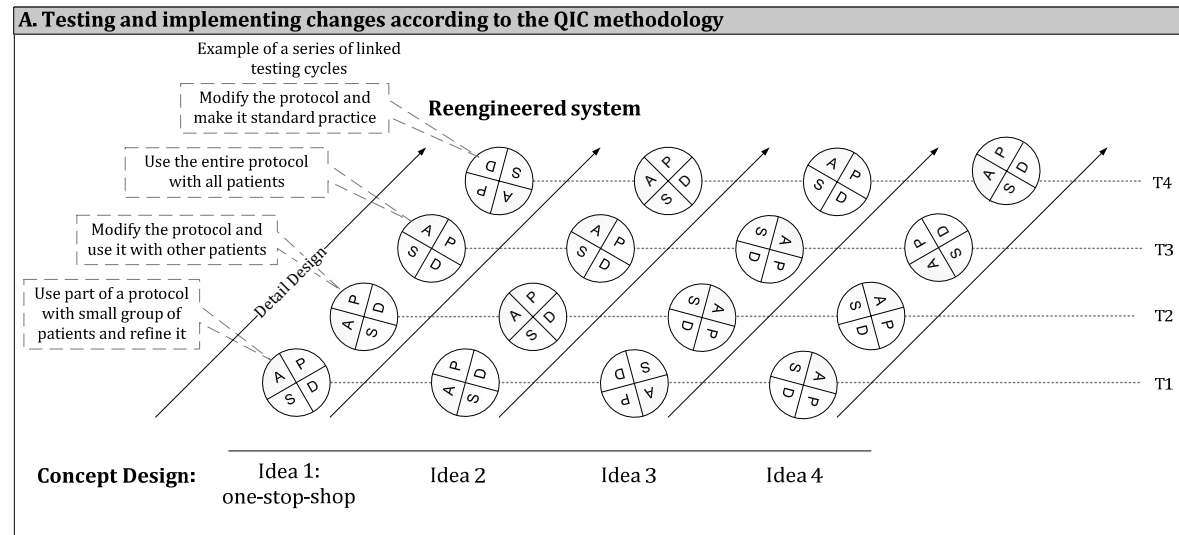

Source original figure: Langley GJ et al. (19967

B. Testing and implementing changes according to the advised method in the evaluated collaborative

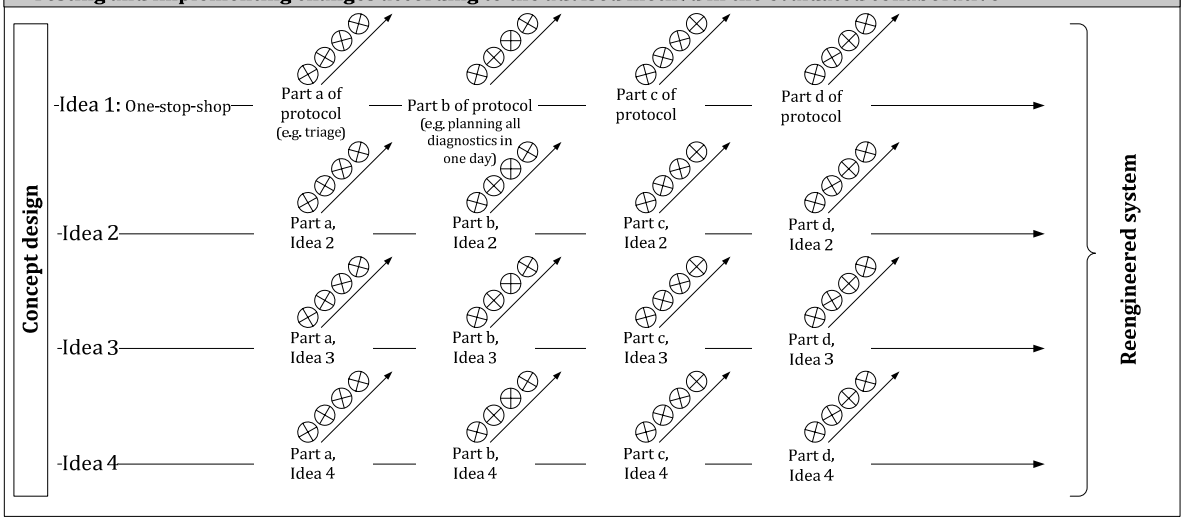


Figure 6.2 Applying the model for improvement, an example

Reducing waiting times for patients within the waiting room of medical specialists

1. Aim: To start $90 \%$ of the planned patient consultations with medical specialists at the time they are planned for during each day.

2. Measure of improvement:

Number of consultations started on time at day X

Total number of consultations at day X

3. Change idea: Medical specialists hand in their pagers during consultation hours to reduce disruptions during consultation with patients.

4. Series of parallel testing plan-do-study-act (PDSA) cycles: Medical specialists test during one day whether the handing in of their pagers reduces disruptions of their consultations, and thus prevents delays of their consultations with patients. Based on the results of a first PDSA-cycle (testing whether 'handing in pagers' works or not), a project team can decide to refine the change idea (if 'handing in pagers' in this context seems to work) or to replace the change idea by another one (if 'handing in pagers' did not increase the number of consultations that started on time and if it is unlikely that it ever will).

\subsection{Methods}

The collaborative described in this paper was part of the Dutch national quality improvement programme 'Sneller Beter' ('Better Faster'), which began in 2004 as an initiative from the Ministry of Health and the Dutch Hospital Association. 'Sneller Beter' aimed to realise substantial and appealing performance improvements in three groups of eight Dutch hospitals in the areas of patient logistics and safety. These twenty-four hospitals were enrolled in the programme by a selection procedure that assessed the organisational support, commitment for participation, availability of personnel, time to realise improvements, and experience with improvement projects. Each group of eight hospitals joined the programme for 2 years (2004 to 2006, 2005 to 2007, or 2006 to 2008) and participated in several QICs on different topics (e.g., pressure ulcers, process redesign) ${ }^{12}$.

The process redesign collaborative evaluated in this study represented the third group of eight hospitals. The overall aim of this collaborative was to reduce the time between the first visit to the outpatients' clinic and the start of treatment and/or to reduce the length of in-hospital stay by $30 \%$ for selected 
patient groups ${ }^{13}$. Eighteen project teams from the eight participating hospitals joined this collaborative, which started in October 2006. Seventeen of these teams agreed to participate in our independent evaluation. The enrolment of project teams within the evaluated QIC differed per hospital. Project teams took part on their own initiative or were enrolled by the hospital board, but always in agreement with the external change agent.

\subsubsection{Process redesign collaborative}

The evaluated collaborative used a step-by-step guide, which included the model for improvement (see Figure 6.3). This step-by-step guide was provided by the external change agent. Next to this, the external change agent organised five collaborative meetings to inform teams about the step-by-step guide as well as about changes that have worked at other sites. The presented evidence for improvement focused mainly on the introduction of a one-stop-shop, in which various visits per patient (diagnostic examinations, consultations, and preoperative screening) are planned for a single day, with the aim of reducing the throughput time of the diagnostic trajectory. Examples of other process redesign change ideas that were provided are: the standardisation of care processes in order to reduce variation, the reduction of the number of unnecessary steps in care processes (do not provide care for which there is no evidence of efficacy), the reduction of the number of planning moments or handovers in a care process so that fewer health care workers are involved in the process, and that each worker is involved only once per iteration of a process. The change agent also provided a website enabling project teams to share information.

Although it is recommended for QICs to test a big change idea in one series of testing cycles ${ }^{8}$, the external change agent advised splitting up every planned change into smaller ones that could be tested instantaneously in a series of testing cycles based on the experiences of other collaboratives (Figure 6.1, part B). By doing so, the external change agent tried to ensure that teams spent their initial resources on testing changes instead of dealing with barriers and resistance to change. 


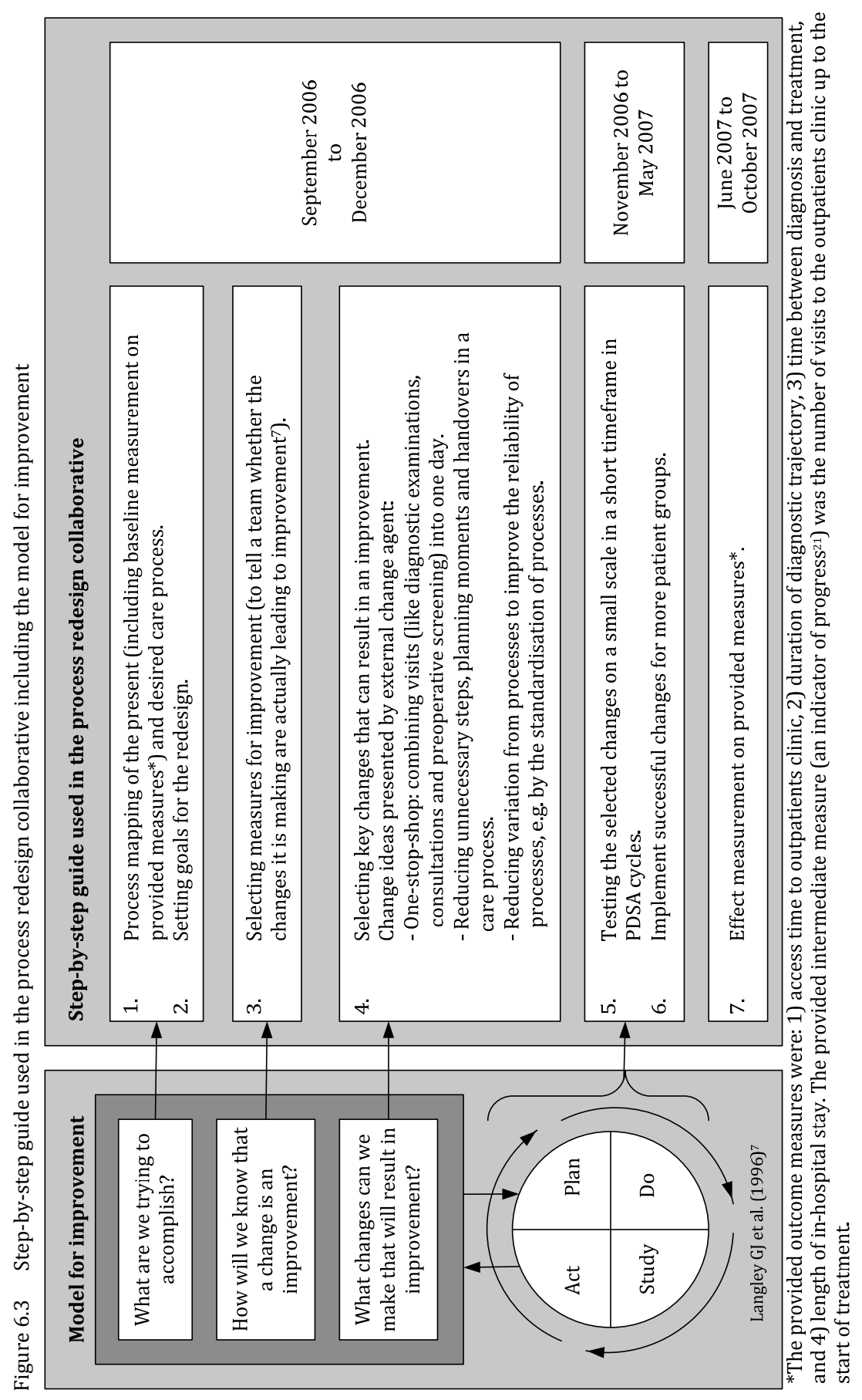




\subsubsection{Data collection}

To explore the applicability of the QIC method, we evaluated the process redesign collaborative in a multiple case study design ${ }^{14}$ using complementary qualitative data collection methods.

We analysed the process redesign team education manual to learn more about the provided change ideas and step-by-step guide. Further, we held a survey among hospital staff members who took part in the project implementations (project staff members) $(n=17)$ and among project leaders $(n=17)$ to gather data on project characteristics and aims, composition of the project teams, and project plans (including (planned) changes, project progress, and the application of the model for improvement). The surveys also included questions about team organisation (including a clear task division, self responsibility for progress, good compliance to arrangements, good communication and coordination, be in charge of implementation), organisational support (including support of strategic management, organisational willingness to change) and external change agent support (including sufficient support and supply of instruments, transfer of valuable insights), because it is known from literature that these are preconditions for successful use of the QIC method ${ }^{12,15}$, 16. In the survey among project leaders, we included a validated questionnaire to assess these three preconditions ${ }^{15}$. Project staff members were asked to rate the amount of organisational support and external change agent support on a scale of 0 to 10 . Questionnaires were sent to respondents 1 year after the start of the collaborative (September 2007), and sixteen project staff members (response $=94 \%$ ) and eleven project leaders (response $=65 \%$ ) completed and returned them.

We also interviewed all project staff members $(n=17)$ after they returned the questionnaire between October and December 2007. Interview themes were: change agent support (provided best practices, change concepts, and quality improvement methods), shared experiences between teams, and applicability of the model for improvement.

In addition, we observed the guidance and training offered by the external change agent during meetings and training sessions of the process redesign collaborative. The observations provided us with context for the analysis of the questionnaires and interviews.

Finally, we analysed the results reported on the outcome and intermediate measures set by the external change agent, who collected these results in a 
'Sneller Beter' database and, at our request, provided us with these data (December 2007).

All gathered information was used to describe the collaborative process and to assess the applicability of the QIC method to process redesign. Additional information about the preconditions was gathered to evaluate whether these could have influenced the results.

\subsection{Results}

\subsubsection{Characteristics of the process redesign projects within the collaborative}

Table 6.1 gives an overview of the characteristics of the process redesign projects. Fifteen project teams chose to redesign an elective care process. Eight of those projects involved care for cancer patients. Two project teams chose to redesign an acute care process.

All project teams intended to make improvements in waiting times and delays, but in different areas (access times, throughput times of diagnostic trajectories, and/or length of stay) and for different types of patient groups. The median value of the volume of the involved patient groups was 150 patients a year (range 17 to 1,000). The number of medical departments involved in the redesigned care process was on average three and varied per project from one to eight departments. In seven instances, not all medical departments involved participated in the project team. 


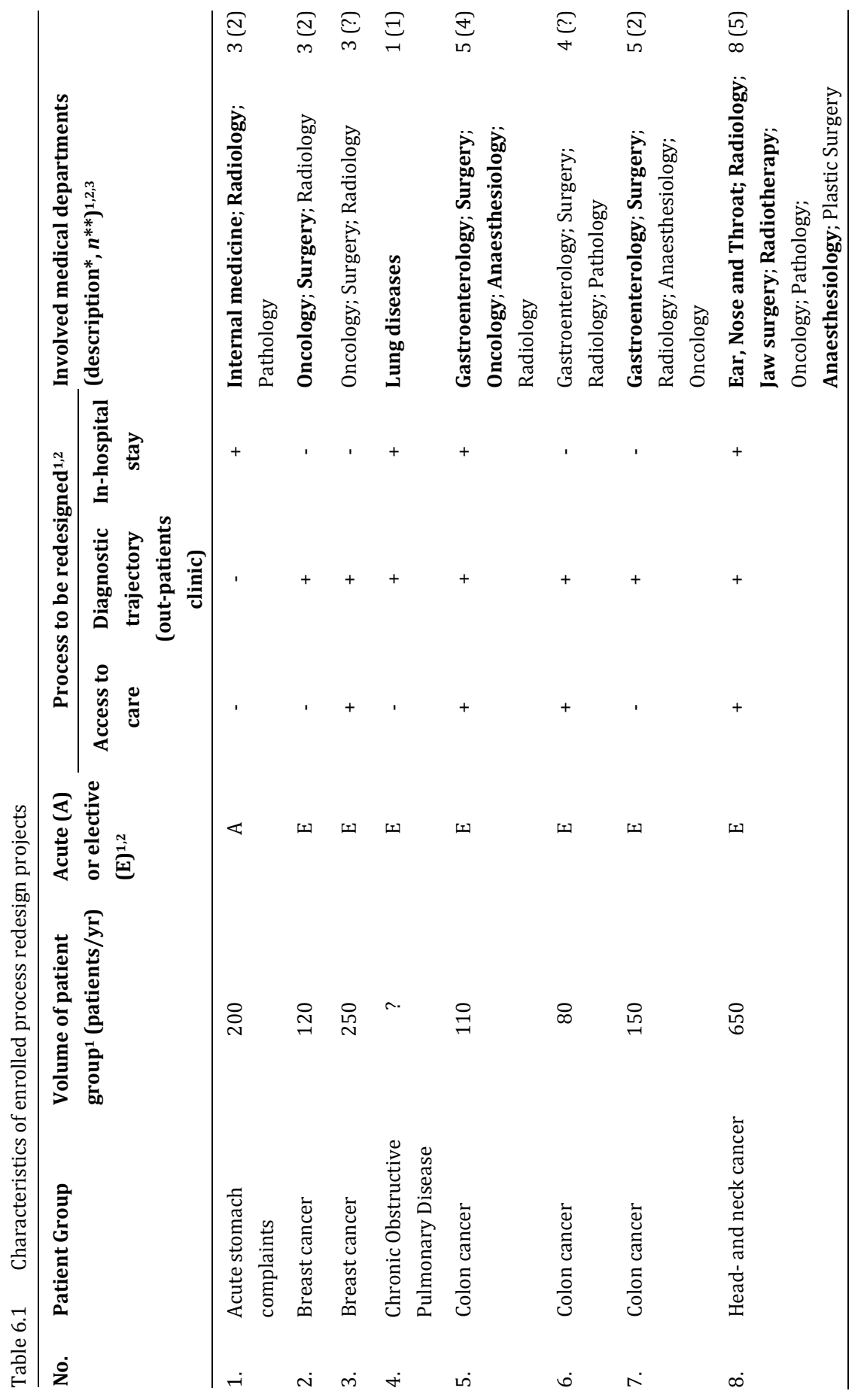




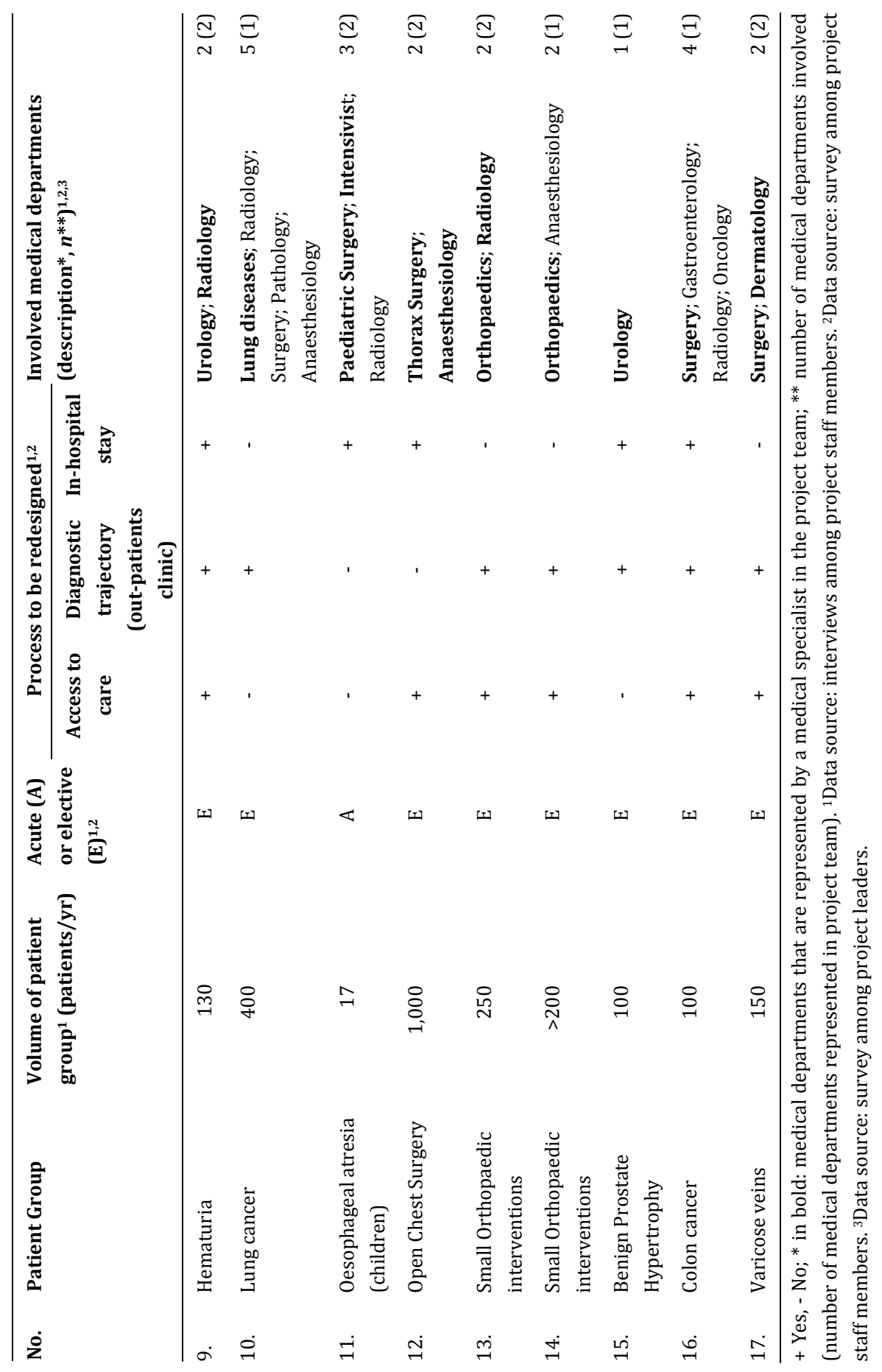




\subsubsection{Presence of preconditions for successful use of the QIC method}

The project leaders and project staff members of six project teams shared the opinion that preconditions for successful use of the QIC method - i.e., 'team organisation', 'organisational support', and 'external change agent support' were sufficiently present (project no. 1, 4, 6, 10,16, and 17). The remaining project teams show a diverse picture of the presence of the preconditions. In general, almost all project teams were positive about the organisation of their project team. One-half of the project teams had the opinion that support from their organisation and/or external change agent support was lacking.

\subsubsection{Evaluation of the collaborative process}

This section describes the collaborative process according to the step-by-step guide provided to the process redesign collaborative (see Figure 6.3).

\section{Step 1: Process mapping of the present care process}

All projects started with a process analysis of the existing care process. Sixteen of the seventeen projects performed a baseline measurement.

\section{Step 2: Setting goals for the redesign}

The baseline measurement and ideas about the desired care process formed the input for the project aims and changes that needed to be implemented. Although all project teams formulated project aims, only fourteen formulated at least one specific and measurable aim (range 0 to 7, average 2) (see Table 6.2).

\section{Step 3: Selecting measures for improvement}

After setting aims, the next step was to establish measures that would indicate whether a change led to an improvement. With one exception, all project teams made use of one or more of the outcome measures provided for the effect measurement. The provided intermediate measure was used by eleven project teams (Table 6.2). For three teams, this measure (number of visits to outpatient clinic) was not applicable because these projects involved only the redesign of in-hospital stay. For two project teams, the provided intermediate measure was not applicable because it was not related to the project aims: namely, the project did not strive to reduce the number of visits.

Eight project teams established additional outcome measures: for example, time between several diagnostic examinations within the diagnostic trajectory. Six project teams appointed intermediate and/or process measures to establish 
whether a process change was accomplished, for instance: Is the date of surgery planned directly after setting the diagnosis, yes or no? Five projects used no additional intermediate or process measure at all. Reasons for not using project-specific measures were that teams thought the provided measures gave enough insight to know whether a change is an improvement or because their project aims were not considered measurable (e.g., qualitative aims such as a standardised discharge planning, or appointing one contact person for the patient during the whole care process).

\section{Step 4: Selecting change ideas}

The main change idea, the one-stop-shop, presented in the collaborative meetings was applicable for eleven project teams (Table 6.2). Two of them did not succeed in combining the visits in one day due to organisational characteristics, the nature of the needed diagnostics, and/or the burden of the diagnostics to the patients. Six project teams thought the evidence was not applicable because they already combined all visits in the diagnostic trajectory into one; they did not redesign a diagnostic trajectory at the outpatients' clinic; or the long throughput time was not a result of many visits but of a long waiting list for one specific diagnostic examination. All project teams applied one or more of the other provided change concepts to redesign their care processes. Application of these change ideas required that project teams first investigated the causes of waiting times and delays in the redesigned process and then tailored the change ideas to their own setting. However, according to the project staff, tailoring change ideas proved more difficult in care processes in which more medical departments were involved, and accordingly more disagreement existed between the involved medical departments about the changes that had to be made.

\section{Steps 5 and 6: Testing and implementing changes}

During the interviews, project staff members were asked whether they had applied the PDSA cycle for change. Five confirmed that their project team used or was going to use the PDSA cycle. However, these five project teams did not split up every planned change in smaller changes as the change agent suggested. Further, staff members of these five project teams indicated that the PDSA cycle was not or would not be performed in a rapid cyclical mode because both the preparation for the test as well as the test of the change itself was time consuming. Because the patient groups were relatively small, a testing cycle took considerable time even when the number of patients per testing period was scaled down. The use of the PDSA cycle was also hampered by the fact that hospital information systems proved unable to generate data on the appointed 
measures when more hospital departments were involved. As a consequence, project teams had to gather data by hand, which was time consuming.

The teams that did not use or were not going to use PDSA for implementation ( $n=10$ ) chose to change the organisation of the care process radically by implementing their 'newly designed process' at once without first testing the individual changes. According to these project teams, testing change ideas within a short timeframe was not applicable to their situation because of the number of medical departments involved and/or the small number of patients involved in their redesign. Another reason for not testing in rapid cycles was the feeling that a test could fail due to non-optimal conditions when supporting processes were not optimised. For example, the team implementing changes in the care for open chest surgery patients considered it impossible to test a new operating room planning process. Changing the planning system for the operating room would necessitate adjusting all the supporting processes, including the working hours of the teams and how the rooms were prepared. Any testing before the altering of supporting processes would be massively disruptive.

\section{Step 7: Effect measurement}

Three project teams performed an effect measurement and reached collaborative goals (Table 6.2). The other project teams, including those that used the PDSA cycle, had not yet measured any interim results by December 2007 (1 year after the start of the QIC). Therefore it is unknown whether they reached the collaborative goals. 


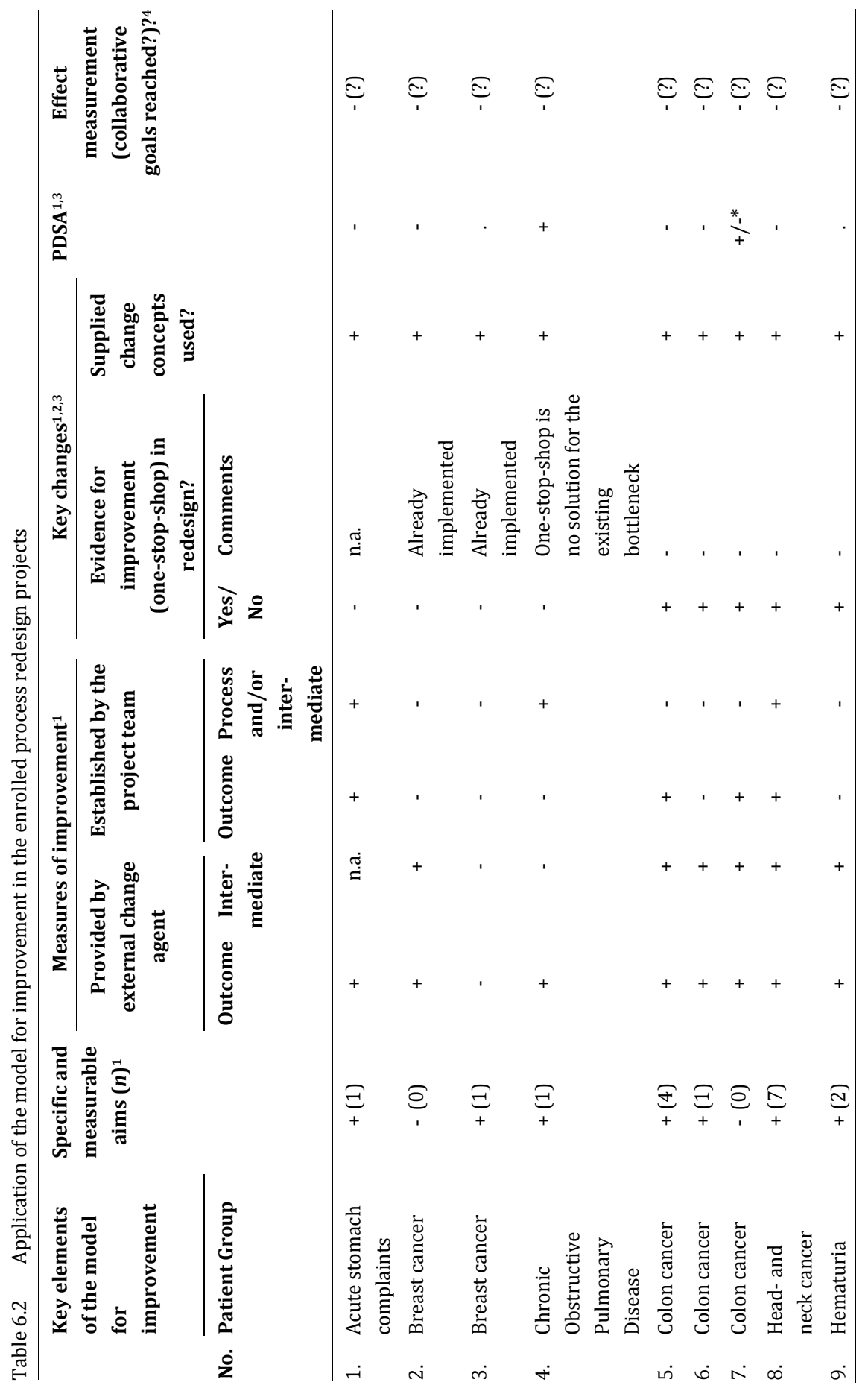




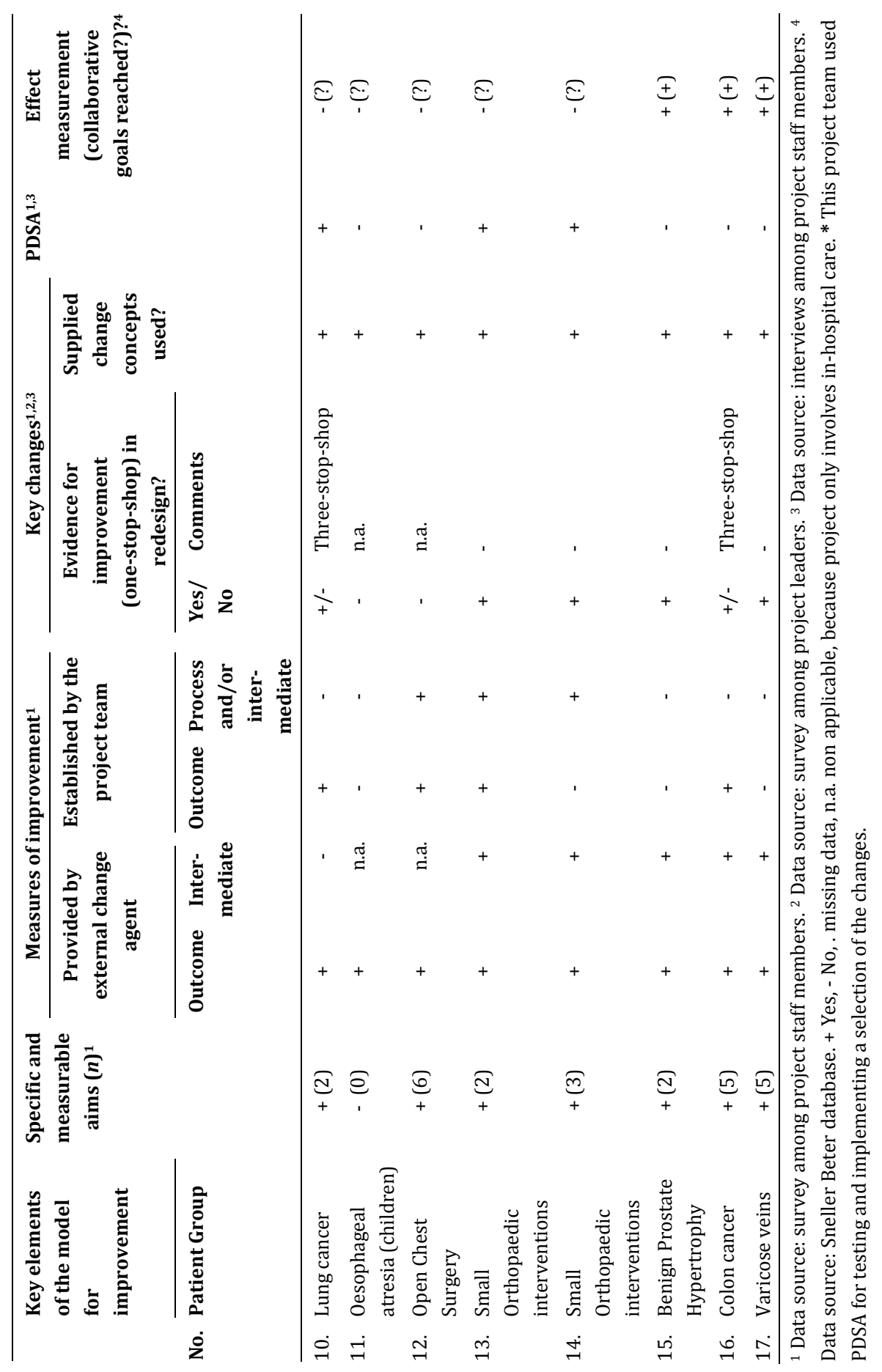


From this description of the collaborative process we can identify several difficulties experienced by the project teams in applying the QIC method to process redesign. First, the adoption of change ideas and the accompanying measures provided by the external change agent, appeared not (directly) applicable for these collaborative project teams. Project teams had to tailor change ideas to their own context or could not use the provided change ideas at all.

Second, the adoption of the model for improvement by the project teams was hampered. Project teams were not capable of testing change ideas within a short time frame using PDSA cycles due to: the need for tailoring change ideas to their own context, and the complexity of aligning several interests of involved medical departments; the small volumes of the involved patient groups; and hospital information systems that proved unable to generate data on the appointed measures.

Third, project teams did not experience peer stimulus. All collaborative project teams intended to make improvements on an administrative subject, but in different parts of care processes (access times, throughput times of diagnostic trajectories, and/or length of stay) for different types of patient groups. As a consequence, project teams saw few similarities between their projects, rarely shared experiences, and demonstrated no competitive behaviour.

Further, a number of project teams perceived a lack of organisational support and external change agent support. However, the project teams that succeeded in implementing changes (projects 15, 16, and 17) shared the opinion that preconditions for successful use of the QIC method - i.e., 'team organisation', 'organisational support', and 'external change agent support' - were in general sufficiently present. Only organisational support lacked in one of the three project teams (project 15).

\subsection{Discussion}

From the results it seems that in the evaluated collaborative the QIC method was not used. Apparently, it did not empower project teams to implement their process redesign in a short timeframe. As a consequence, this study could not show whether the QIC method can effectively contribute to process redesign, if used. The description of the collaborative process provides us with valuable information about the difficulties experienced by the project teams in applying the QIC method to process redesign. In this section, we will discuss 
explanations for these difficulties, which concentrate on a lack of fit between the QIC method and process redesign, a non-optimal application of the QIC method, and non-optimal conditions for using the QIC method.

\subsubsection{Non-optimal fit between the QIC method and process redesign}

First, a lot of the project teams needed customised solutions for their process redesign, while the QIC method aims to spread standardised evidence-based practices or change ideas to serve many teams at the same time with a limited number of external change agents. According to the QIC method collaborative project teams should benefit of the exchange of the standardised change ideas in such a way that they can eliminate much of the investigative work on problem analysis and change ideas in comparison with traditional quality project teams ${ }^{3}$. For example, in a QIC for pressure ulcers, an external change agent can provide concrete best practices from pressure ulcer guidelines to perfect the elements of care, such as 'minimise skin pressure through the use of a positioning schedule for clients with an identified risk for pressure ulcer development'. This best practice can then be tested and, if it works, be implemented directly in every setting. Process redesign, however, calls for customised solutions because project teams need to handle context-specific causes of waiting times and delays in care processes determined by the existing interaction patterns between departments in their hospital. Project teams can therefore not test the standard change ideas provided by the change agent within a short time frame but have to investigate the causes of waiting times and delays and to tailor change ideas to their own setting. As a consequence, the collaborative cannot eliminate the investigative work on problem analysis and profit from standard change ideas provided by the external change agent as the QIC method prescribes.

Second, the model for improvement, and especially the PDSA cycle, seemed inappropriate to test intended changes within a short timeframe. The QIC method assumes that testing one big change idea lowers the resistance to a change because clinicians are more likely to be reassured that the change is effective $^{8}, 17$. This assumption ignores the fact that testing changes that affect several departments may lead to more consultation before testing a change and thus to an increased possibility of resistance to a change. This happened in the hospitals involved as result of their functional structure, in which every department has its own responsibilities and tries to optimise its own functioning. These functional boundaries hampered, for example, the adjustment of the department schedules needed to realise a 'one-stop-shop'. 
After all, more relationships are affected, and more different interests play a role. As a result, project teams could only start testing after a buy-in or political solution. In this study, the complexity of aligning department schedules and interests became more apparent when the number of departments involved in a care process increased. The project teams might have improved the collaboration across boundaries if they had included in their team a medical specialist from all medical department(s) involved. However, the need for buyin solutions before testing a change could also be due to the fact that the external change agent advised splitting up every planned change into smaller changes. Although smaller changes can reduce the risk of failure, it also lowers the expectations of the benefits of a change. Unclear or smaller benefits do not stimulate medical departments to invest in making changes.

Difficulties in using the PDSA cycle meant that most teams decided to implement changes without testing them. Subsequently, teams did not get feedback on the work they were doing and did not experience a momentum of change ${ }^{18}$. It is known from previous studies that consistent ongoing measurement is required to tell whether changes being made are leading to an improvement, and to provide basis for continued action ${ }^{19}, 20$. Because of this lack of feedback, teams were not stimulated to adapt another change idea for improvement, which in turn slowed down the implementation of changes.

Although the difficulties with the use of the PDSA cycle are (almost) inevitable in process redesign projects in functionally organised hospitals, the use of the PDSA could be improved by taking care of some preconditions. First, hospital information systems should be able to generate data on the appointed measures. Second, the number of patients involved in the care process that need to be redesigned has to be big enough to test a change idea within a number of days.

\subsubsection{Non-optimal application of the QIC method}

Next to the non-optimal fit between the QIC method and process redesign, difficulties can also be due to the selection process of the collaborative project teams. The external change agent included project teams in the collaborative that worked on different parts of care processes (access times, throughput times of diagnostic trajectories, and/or length of stay) for different types of patient groups, while the QIC method aims to implement evidence-based practice through sharing knowledge with others in a similar setting ${ }^{4}$. Probably, the external change agent could have provided peer stimulus if it had selected 
project teams that worked on comparable process redesign projects with comparable goals. Nevertheless, lack of peer stimulus can also occur between comparable redesign projects because of the existence of context-specific causes of delays and waiting times.

\subsubsection{Non-optimal conditions for using the QIC method}

Next to hospital information systems to generate data on outcome, intermediate and process measures, complex process redesign projects need support to change interaction patterns between involved departments. A number of project teams perceived a lack of organisational and external change agent support, despite the facts that all project teams received external change agent support and the participating hospitals were enrolled in the 'Sneller Beter' programme by a selection procedure that assessed the organisational support. Unfortunately, we could not identify factors that contributed to this perceived lack of organisational and external change agent support.

\subsubsection{Limitations}

This study aimed to assess the applicability of the QIC method for process redesign. Although we think the findings of this study provide useful information for future collaboratives, the results need to be interpreted with caution. The findings of this evaluation could be influenced negatively by the selection process of both the collaborative project teams and the care processes to be redesigned. For instance, not all teams participated in the collaborative on a voluntary basis. Unfortunately, we could not determine with certainty to which project teams this applied and how this influenced the collaborative process.

Another limitation is that the gathered data are not complete. However, observations during meetings and training sessions of the process redesign collaborative showed us that the missing data of project leaders and project staff members are not related to poor performing project teams and/or organisational support. The poor availability of effect measurements on collaborative goals can be contributed to the fact that it is not feasible for many project teams to redesign, implement, and perform an effect measurement within a year, and to the non-optimal fit between the principles of the used QIC method and process redesign. 


\subsection{Conclusion}

This study showed that the need for tailoring standard change ideas to the context of collaborative project teams, and the complexity of aligning several interests of involved medical departments, hampered the use of the QIC method for process redesign. We cannot determine whether the QIC method is appropriate for process redesign. As result of the selection process for participation of project teams by the external change agent peer stimulus was non-optimal. Further project teams felt that preconditions for successful use of the QIC method were lacking. Therefore, additional research into the applicability of the QIC method for process redesign is needed. 


\section{References}

1. Baker GR: Collaborating for improvement: The institute for healthcare improvement's breakthrough series. New Medicine 1997, 1:5-8.

2. Lindenauer PK: Effects of quality improvement collaboratives. BMJ 2008, 336(7659):1448-1449.

3. Øvretveit J, Bate P, Cleary P, Cretin S, Gustafson D, McInnes K, McLeod H, Molfenter T, Plsek P, Robert G et al: Quality collaboratives: lessons from research. Quality and Safety in Health Care 2002, 11(4):345-351.

4. Newton PJ, Halcomb EJ, Davidson PM, Denniss AR: Barriers and facilitators to the implementation of the collaborative method: reflections from a single site. Quality and Safety in Health Care 2007, 16(6):409-414.

5. Schouten LM, Hulscher ME, Van Everdingen JJ, Huijsman R, Grol RP: Evidence for the impact of quality improvement collaboratives: systematic review. BMJ 2008, 336(7659):1491-1494.

6. The breakthrough series: IHI's collaborative model for achieving breakthrough improvement. IHI innovation series white paper. Boston: Institute for Healthcare Improvement; 2003 (Available on www.IHI.org).

7. Langley GJ, Nolan KM, Nolan TW, Norman CL, Provost LP: The improvement guide: a practical approach to enhancing organizational performance. San Francisco: Jossey-Bass; 1996.

8. Nolan TW, Schall MW, Berwick DM, Roessner J: Reducing delays and waiting times throughout the healthcare system. Boston: Institute for Healthcare Improvement; 1996.

9. Mittman BS: Creating the evidence base for quality improvement collaboratives. Annals of Internal Medicine 2004, 140:897-901.

10. Kerr D, Bevan H, Gowland B, Penny J, Berwick D: Redesigning cancer care. BMJ 2002, 324(7330):164-166.

11. Locock L: Health care redesign: meaning, origins and application. Quality and Safety in Health Care 2003, 12(1):53-57.

12. Dückers MLA, Spreeuwenberg P, Wagner C, Groenewegen PP: Exploring the black box of quality improvement collaboratives: modelling relations between conditions, applied changes and outcomes. Implementation Science 2009, 4(1):74.

13. Rouppe van der Voort M, Stoffer M, Zuiderent-Jerak T, Janssen S, Berg M: Breakthrough process redesign III: 2006-2007 Better Faster pillar 3, T2S2 en T3S1 (in Dutch). Utrecht/Rotterdam/Utrecht: Quality Institute for Health Care CBO, Institute of Health Policy and Management of the Erasmus University Rotterdam, Order of Medical Specialists; 2006.

14. Yin RK: Case study research: design and methods. 3rd edition. Thousand Oaks, CA (etc.): Sage; 2003. 
15. Dückers ML, Wagner C, Groenewegen PP: Developing and testing an instrument to measure the presence of conditions for successful implementation of quality improvement collaboratives. BMC Health Services Research 2008, 8:172.

16. Dückers MLA, Wagner C, Groenewegen PP: Conditions for a sector wide, knowledge based, improvement programme in the Dutch hospital care (in Dutch). Acta Hospitalia 2005, 45(3):37-54.

17. Resar R: Why we need to learn standardisation. Australian Family Physician 2005, 34(1-2):67-68.

18. Plsek PE: Quality improvement methods in clinical medicine. Pediatrics 1999, 103(1 Suppl E):203-214.

19. Berwick DM: Developing and testing changes in delivery of care. Annals of Internal Medicine 1998, 128(8):651-656.

20. Leape LL, Rogers G, Hanna D, Griswold P, Federico F, Fenn CA, Bates DW, Kirle L, Clarridge BR: Developing and implementing new safe practices: voluntary adoption through statewide collaboratives. Quality and Safety in Health Care 2006, 15(4):289-295.

21. Gaucher EJ, Coffey RJ: Breakthrough performance: accelerating the transformation of health care organizations. San Francisco: Jossey-Bass; 2000. 


\section{Chapter 7}

General discussion and conclusion 


\subsection{Introduction}

Traditionally, hospitals have a functional organisation structure. Within this structure, organisational departments are built around the skills and knowledge of their professionals, like internal medicine, radiology, and so on ${ }^{1-3}$. These departments frequently operate as separate 'silos' with their own goals, and do not exchange information for the planning and control of patient flow (functional operating control system) ${ }^{1,2}$. As a consequence, each care activity within a chain of care activities for the diagnosis and treatment of a patient will be planned on the basis of availability of resources, after the previous care activity is completed. This has led to quality problems like waiting times, poor coordination of care, and a waste of resources.

National and international attention to these quality problems has made hospital management and medical specialists aware that the way care is delivered needs to be reorganised. However, little is known about how to improve the organisation of care delivery in terms of quality and efficiency. In addition, it is not known how new ways of organising care delivery should be introduced into a hospital organisation. Until now, many of the ideas for improvements of coordination and process control have been derived from research in industry, including the successful concept referred to as 'business process orientation'. This concept's breakthrough occurred at the beginning of the 1990s under the name 'Business Process Reengineering'4. Successful examples of the application of business process orientation for the organisation of care delivery to specific patient groups are known, for instance, from the Dutch programme 'Better Faster'5, from Australia's 'Redesigning Hospital Care'6, and from the United States' 'Reducing delays and waiting times throughout the system'7. It is unknown, however, whether business process orientation or process-oriented care delivery can also be applied successfully at hospital level.

Therefore, this thesis aimed to test the hypothesis that the implementation of process-oriented care delivery leads to better outcomes in terms of quality and efficiency at hospital level. In order to test the central hypothesis of this thesis, the overall research question is:

'Is the implementation of a process-oriented logistical concept effective for improving quality and efficiency of care delivery at hospital level?'

In the studies described in the previous chapters, the following sub-questions were addressed: 
1. 'Which process-oriented logistical concepts do hospitals implement to deliver process-oriented care, and how effective are these in improving the quality and efficiency of care delivery?'

2. 'Does evaluation of the flexibility of hospital building layout contribute to the implementation of a new logistical concept?'

3. 'Do process-based payments contribute to the implementation of a processoriented logistical concept?'

4. 'Do improvement and innovation methods contribute to the implementation of a process-oriented logistical concept?'

The first sub-question assessed which process-oriented logistical concepts hospitals implement to deliver process-oriented care, and the effectiveness of these logistical concepts in improving the quality and efficiency of care delivery. Sub-questions 2-4 examined ways to introduce process-oriented logistical concepts effectively into a hospital organisation.

In this chapter, the main findings on these sub-questions are presented first. Next, the meaning of these findings with regard to the general research question is discussed. Subsequently, the general research question is answered. The chapter ends with recommendations for future research and for the implementation of process-oriented organisation of care delivery.

\subsection{Main findings}

1. 'Which process-oriented logistical concepts do hospitals implement to deliver process-oriented care, and how effective are these in improving the quality and efficiency of care delivery?'

The literature review in Chapter 2 reported and discussed the experiences of five hospitals with respect to implementing a process-oriented logistical concept at organisational level. This literature review showed that hospitals chose between two main approaches to improve the integration of functions around care processes and to become process-oriented organisations:

A. The implementation of a process-oriented operational control system without changing the hospitals' basic structure; and

B. The implementation of a process-oriented basic structure, in which the composition of hospital departments is based on the needs of specific patient groups instead of on the type of medical specialties. 
On the basis of the results, it seems that under preconditions the adoption of either approach to become process-oriented can possibly lead to improved quality and efficiency of care delivery. First, the implementation of each approach has to focus on logistically homogeneous patient groups. Bottom-up knowledge on the part of medical professionals is essential to identify these patient groups. The review showed that, ultimately, hospitals with an initial focus on overarching processing steps with respect to patients' medical diagnosis and treatment mainly implemented improvements in departmental processes instead of improvements that made the patient flow smoother. Second, the implementation has to be accompanied by a committed process management to change previous patterns relating to the functional division of tasks.

The literature review also provided insight into factors that hampered the implementation of both approaches. An effective implementation of a processoriented operational control system (A) requires that department managers and medical specialists both give priority to the coordination of care delivery between departments above the capacity utilisation of each department. This proved difficult, since medical departments in functional organisations have to maximise their own output. An effective implementation of a process-oriented basic structure based on multidisciplinary patient-focused departments (B) requires that hospitals focus on strategically important services. However, the characteristics of hospital care make this difficult because political and ethical obligations prevent hospitals from refusing to deliver services to groups of patients from within their service area.

Unfortunately, we were not able to judge which of the two approaches (implementation of a process-oriented operational control system or implementation of a process-oriented basic structure) delivers the best results and under what circumstances. For such an assessment, more specific studies are needed.

\section{2. 'Does evaluation of the flexibility of hospital building layout contribute to the} implementation of a new logistical concept?'

Chapter 3 described an evaluation method for the assessment of hospital building layout, and its contribution to the implementation of new logistical concepts is tested in a case study. Using computer simulation techniques, the described evaluation method assessed hospital building layout from the viewpoint of operations management. The aim of such an evaluation is to ensure that the building layout supports the efficient and effective operating of current and future care processes. In the case study, a newly designed hospital 
layout was assessed on its flexibility to meet future requirements of new logistical concepts and changes in patient mix. The results showed that a change in intensity, direction, or volume of the flow as a result of a new logistical concept or a changed patient mix led to congestions in the patient flow. In other words, the design of the hospital building layout was not flexible enough to deal with the changes. In this case, however, the layout of the building could easily be adjusted because it was still in the design phase.

The evaluation of a building layout in the design phase is of great importance from the perspective of operations management. In this phase, it is still possible to adjust the layout to make it more flexible to meet future requirements of new logistical concepts and changes in patient mix, and it therefore contributes to an effective implementation of future logistical concepts. In addition, the evaluation method can also be used to assess the implications of new logistical concepts in existing hospital buildings. Ex-ante evaluation of new logistical concepts can prevent the occurrence of congestions in the overall patient flow, which affect waiting and throughput times, and thus the quality and efficiency of care delivery.

We conclude that an evaluation of the flexibility of a hospital building layout using simulation techniques contributes to an effective implementation of new logistical concepts, and prevents the occurrence of conflicts.

3. 'Do process-based payments contribute to the implementation of a processoriented logistical concept?'

Chapter 4 tested whether the use of process-based payments - process-based internal hospital budgeting - contributes to the implementation of processoriented logistical concepts, and more specifically to the implementation of a process-oriented operational control system. Analyses of data involving Dutch hospitals demonstrated that process-based budgeting - the allocation of financial means on the basis of the total care of a patient during an acute episode of illness - stimulated medical professionals to use process-oriented performance measures, which in turn had a positive effect on the number of activities to develop process-oriented operational control systems. Although process-based budgeting did not stimulate directly the implementation of a process-oriented logistical concept, it seems that it is a valuable tool to bridge internal conflicts of interests concerning departments and medical professionals, which hamper collaboration across departmental boundaries. It stimulated cooperation between departments and medical professionals to organise care delivery in a process-oriented way, even though the implementation was not yet accompanied by adapted internal organisational 
activities: for instance, more decentralised decision-making, agreements about process ownerships, and a process-oriented view on the part of medical professionals.

The results of this study show that process-based payments contribute to the implementation of process-oriented logistical concepts, and they also help to align the interests of departments and medical professionals with top management's wish to implement a process-oriented concept.

4. 'Do improvement and innovation methods contribute to the implementation of a process-oriented logistical concept?'

Chapters 5 and 6 assessed the effects of two types of redesign methods on the implementation of process-oriented logistical concepts at process level. Chapter 5 dealt with a process innovation method: that is, one intended to radically redesign and improve work processes. This method is used to change the traditionally functional operating system of in-hospital care for stroke patients towards a process-oriented operating system, the aim of which is to improve the quality and efficiency of care delivery. The method consisted of four steps: process analysis, identification of bottlenecks, design of the processoriented operating system, and implementation of the system. Results indicate that implementation of the process-oriented operating system led to a significantly shorter length of hospital stay. As a result, more stroke patients could be admitted to the specialised ward.

Chapter 6 concerned the applicability of the Quality Improvement Collaborative (QIC) method for the redesign of work processes. With the help of external facilitators and peer stimulus, this method is intended to change a functional operating system incrementally to a process-oriented operating system for specific patient groups. The method was assessed in a multiple case study design. Within the evaluated QIC, external change agents provided eighteen collaborative project teams from various hospitals with a clear vision for the redesign of their operating system, along with a set of specific changes that could significantly improve the patient flow. Results of the evaluation showed that - for several reasons - this application of the QIC method did not succeed in empowering project teams to implement a redesign in a short time frame. First, there seems to be a non-optimal fit between the QIC method and the redesign of work processes. While the QIC method aims to serve as many teams as possible with standardised change ideas, the redesign of work processes calls for customised solutions, because project teams need to handle contextspecific causes of waiting times and delays in care processes determined by the existing interaction patterns between departments. Second, the QIC method 
was not optimally applied. The external change agent included project teams in the collaborative that worked on different aspects of care processes (access times, throughput times of diagnostic trajectories, and/or length of stay) for various types of patient groups and different patient volumes, while the QIC method aims to implement evidence-based practice through sharing knowledge with other teams that have similar goals. Third, project teams were confronted with non-optimal conditions for applying the QIC method: for instance, a number of project teams perceived a lack of organisational and external change agent support. These results show that the need to tailor standard change ideas to the context of collaborative project teams, plus the complexity of aligning interests of involved departments, hamper the use of the QIC method for process redesign. To conclude, due to the non-optimal application of the QIC method and the non-optimal conditions for using the QIC method, we cannot determine whether the QIC method is appropriate for the process redesign of care processes in hospitals.

From the results of the two studies described in Chapters 5 and 6, it seems that process innovation methods contributed more than the evaluated process improvement method (QIC) to the implementation of a process-oriented logistical concept. This is probably because the implementation requires customised solutions that fit context-specific causes of waiting times and delays. While the thorough process analysis as part of the process innovation method resulted in the implementation of customised interventions to change the pattern of interaction between professionals and to redesign the overall work flow, the process improvement method tried to implement standard change ideas that worked for others. Moreover, hospitals that used the process improvement method frequently focused on parts (e.g. the diagnostic or treatment trajectory) rather than on whole care processes. In the decision as to what form work processes should take, the process innovation method described gave involved medical professionals more autonomy than did the QIC method. Therefore, the process innovation method used seems also more able to deal with possible conflicts between the autonomy of medical professionals and the requirements of a process-oriented logistical concept.

\subsection{Discussion of the findings}

There are successful examples of the application of the business process orientation concept for the organisation of care delivery to specific patient groups. This thesis examined whether process-orientation can also be applied 
successfully at hospital level, and explored ways to introduce process-oriented care delivery.

The research reconfirms that the implementation of process-oriented logistical concepts can reduce throughput times for specific patient groups (Chapters 1, 5, and 6), which leads to a gain in quality for patients and to efficiency for specific care processes. These patient groups will not only have shorter waiting times between examination and treatment but their conditions will be treated timely and adequately, and with fewer resources (e.g. number of bed days) ${ }^{8}$. Similar benefits of process-oriented logistical concepts could not be determined at hospital level. The literature review in Chapter 2 was unable to identify enough high-quality studies that assessed the implementation of processoriented logistical concepts. Therefore, we intended to test the effects of the implementation of process-oriented delivery empirically by evaluating the results of the national quality improvement programme 'Better Faster' with regard to its aim to accelerate the transition towards process-oriented care delivery in participating hospitals ${ }^{9}$. Data on outcomes were provided by programme officers of 'Better Faster'. These data proved to be incomplete, however, and it was thus not possible to assess effects. The incomplete data are probably due to implementation failures and to the fact that hospitals needed more time to implement process-oriented logistical concepts. The limited scientific foundation of underlying assumptions of 'Better Faster'9 may have contributed to the implementation failures. Nevertheless, on the basis of available data and additional research, this thesis was able to identify certain suboptimal applications of process-orientated logistical concepts and introductory strategies that may hinder an effective implementation of processoriented care delivery.

\subsubsection{Suboptimal application of process-oriented logistical concepts}

\section{No system view}

On the basis of this research, it seems that hospitals do not acquire a systems view when they try to become process-oriented organisations. Most hospitals work towards this goal by means of the gradual or partial implementation of process-oriented control systems or care programmes (Chapter 2). These programmes help hospitals to overcome the functional division of labour and to improve collaboration between departments. However, this approach ignores the importance of an optimal performance of the separate departments, which incorporates a risk for sub-optimisation of the entire hospital system. This potential sub-optimising effect is, for example, caused by the fact that when 
introducing care programmes, hospitals often reserve slots for specific patient groups in the planning of scarce resources ${ }^{10}$, like CT, MRI, and PET scans, and in the planning of outpatients' clinics. Although the use of these 'priority lanes' reduces throughput and waiting times for specific patient groups, it may lead to an inefficient use of resources and more waiting times and delays for other patients: first, because a higher number of waiting lines increases the time and energy needed to control them; and second, because the waiting lines are more sensitive to fluctuations in the demand for specific places ${ }^{11}$. However, an information exchange between medical professionals - one that is enabled by process-oriented control mechanisms (care programmes) in a functional basic structure or by the implementation of a process-oriented basic structure (multidisciplinary departments) - could provide departments with information about what capacities are needed at what time. They could use this information to optimise the organisation of departments. A precondition then is that hospitals be capable of a twofold focus: one on the optimisation of care processes and the other on the optimisation of departments ${ }^{12}$.

We conclude that solutions chosen by the hospitals are a trade-off between the optimisation of care processes and that of department efficiency. Hospitals tried to optimise care processes by optimising parts of processes and the coordination of transfer points in the chain of care. The coordination of transfer points frequently requires the reservation of specific places. This in turn suboptimised the planning of departments. Therefore, in our view it seems more fruitful to prevent this trade-off, which means focusing the entire hospital structure on patient processes and deleting transfer points.

\section{Too little attention to contingency factors}

Further, our research shows that hospitals do not take contingency factors into account consistently in applying process-oriented logistical concepts. It is known from operations management literature that contingency factors may affect the success of interventions that attempt to improve the management of operations ${ }^{13}$, 14 . According to Hall $(1999)^{15}$ and Donaldson $(2001)^{16}$, the most important contingency factors of a logistical concept are strategy, size, task uncertainty, and technology. Each hospital has a unique combination of contingency factors, and thus of opportunities and limitations. In agreement with Hall (1999) ${ }^{15}$ and Donaldson (2001) ${ }^{16}$, the success of process-oriented care delivery for a single patient group is dependent on the organisational goals and on ways to reach these goals (strategy), the volume of a patient group (size), the certainty that steps that are mostly taken or that should be taken in a care process for a specific patient group can be predicted (task certainty), and the technology of hospital care. 
However, hospitals do not carefully consider the fit between process-oriented logistical concepts and these contingency factors. For example, in Chapter 6 we saw that hospitals tried to implement process-oriented care delivery for very small patient groups. We know from the literature, however, that due to the high level of standardisation and the dedicated investment, the effective operating of a process-oriented logistical concept calls for a high volume of patients who require the same chain of services to answer their health care needs ${ }^{17}$. In addition, it is difficult for a general hospital to maintain a group of medical professionals specialised in care delivery for only a small group of patients. The increasing specialisation within medical disciplines during the last decennia due to the rapid increase in medical knowledge and therapeutic options has made this problem worse ${ }^{18}$. It has resulted in medical professionals having a limited work area, meaning they can only deliver subtasks within a care process. Thus, if high volumes are not reached, the organisational investment will be higher than the return.

In conclusion, the importance of the fit between logistical concepts and contingency factors means that process-oriented logistical concepts are no panacea for a hospital under all circumstances. There are circumstances in which the use of a functional logistical concept is more effective than that of a process-oriented logistical concept. After all, disparities in the environment are likely to call for different responses in the design of a logistical concept ${ }^{19}$. As a consequence, different logistical concepts would remain among hospitals, and there would not be a 'one-size-fits-all' solution.

\subsubsection{Suboptimal strategies to implement process-oriented logistical concepts}

It became apparent in several chapters of this thesis that the implementation of process-oriented logistical concepts in hospitals is not accompanied by an appropriate ex-ante hospital management analysis of the consequences of a change of logistical system and the unintended effects for the different components of the hospital system (top management, divisions/departments, medical professionals within a hospital building). This prevented hospital management from handling the conflicts that emerged between components. As a consequence, the implementation of process-oriented logistical concepts was obstructed. 


\section{Hospital building layout and process-oriented logistical concepts}

Chapter 3 showed that the implementation of process-oriented logistical concepts can be hampered by the physical layout of a building. Changes in the intensity, direction, or volume of patient flow as a result of a new logistical concept led to congestions of the patient flow within the designed hospital building. Experts have noted that it is extremely hard to achieve a situation in which the physical layout supports the functionality of a new logistical concept in pre-existing buildings ${ }^{20}$. During the life of a hospital building, changes in the hospital environment occur that influence its strategy, which in turn affects the logistical concept with regard to planning and to controlling patient flow. Therefore, it seems important to create flexibility in the physical layout when hospital buildings are designed: for example, by the standardisation of consultation rooms or the introduction of single patient rooms ${ }^{21}$. After all, the running of hospital buildings is extremely expensive due to the investments in needed technology, and buildings need to last for many years. The layout can only be changed if major investments are made. This underlines the importance of a flexible building layout to enable hospitals to respond to change. Chapter 3 of this thesis demonstrated that simulation techniques can be very helpful to assess a building design in terms of its flexibility with regard to handling future changes in patient flow.

\section{Goals of departments and of process-oriented logistical concepts}

In Chapters 1 and 6, it appeared that the implementation of process-oriented logistical concepts was hampered because departmental goals (i.e. maximising department output) were not adjusted accordingly (i.e. maximising performance of care processes in terms of waiting times and delays). After all, it was not in the interests of the departments and medical professionals to improve care coordination and waiting times and delays, since they are only responsible for and benefit from the output of their own departments. Chapter 4 showed that the introduction of process-based budgeting - the allocation of financial means on the basis of the total care of a patient during an acute episode of illness - can stimulate departments and medical professionals to use process-oriented outcome measures, which in turn encourages them to implement process-oriented logistical concepts. From this, it seems important that hospital management also adapts reward- and information systems to the new logistical concept. This can be related to the fact that a change needs to be seen by all involved parties as an improvement in the existing practice ${ }^{22,23}$. In general, a new logistical concept will only be effectively implemented if it seems to offer advantages. Benefits can include better health care outcomes, financial benefits, work pleasure, or an increase in status for people who adopt the new working methods. At an early stage, when selecting and developing a logistical 
concept, it is important to consider these factors and the possible responses of the target group in order to increase the likelihood of a successful implementation ${ }^{23}$. Hence, the implementation of a process-oriented logistical concept has to be accompanied by sufficient incentives for involved departments and staff.

\section{Routines of medical professionals and process-oriented logistical concepts}

Chapter 4 showed that although many Dutch hospitals have implemented protocols for the diagnosis, treatment, and routing of patients, these are not yet accompanied by decentralised decision-making, agreements about process ownerships, and a process-oriented view on the part of medical professionals. Thus, formal structures - protocols - have been created, but internal organisational activities - routines of medical professionals - have not been adjusted. It is known from literature that implementation of innovations like process-oriented care logistical concepts do not run smoothly, no matter how great the advantages, if the innovation is not consistent with existing norms and values, or with the experiences of professionals who have to adjust their work processes ${ }^{22,23}$.

Due to the strong institutionalisation of the health care sector in the Netherlands, it is difficult to alter the routines of medical professionals, since responsibilities and competences of doctors, nurses, and allied health care professionals are bound by law ${ }^{24}$. As a consequence, only limited possibilities exist to change the responsibilities of involved medical professionals within care processes. Improving the organisation of care delivery requires a change in work processes, modifying the interaction between departments and medical professionals ${ }^{25}$, which includes changes in the division of responsibilities and decision-making capabilities. This is not always compatible with existing rules. The law impedes the introduction of workforce flexibility: for instance, nurses cannot take over the tasks of medical doctors with the same freedom that employees switch tasks in industry. However, workforce flexibility could reduce the need for transfers and care coordination between medical professionals in hospitals ${ }^{26}$.

An additional barrier to changing existing routines is that there are no readymade solutions that describe exactly what form processes for a specific patient group in a specific context should take ${ }^{23}$. Because improvements in work processes cannot be derived from guidelines, protocols, and procedures, a thorough problem analysis is needed to tailor changes to the specific context (Chapter 5). Formulating the change itself thus forms part of the 
implementation process, and this enables a process of bottom-up learning instead of top-down implementation. Medical professionals need to engage in formulating the change, so that they support the new logistical concept and help ensure that it will be accepted. Realisation of the implementation process must, however, be a joint effort on the part of medical professionals and management. Medical professionals frequently lack experience in applying process innovation methods, and they already face huge demands on their time; hence, justifiably, they may not always be willing to prioritise timeconsuming process redesign over spending time with patients.

\subsubsection{Reflections}

We found that hospitals cannot or do not fully implement the process-oriented logistical concepts: they lack a system view, which in turn leads to a trade-off between process and department optimisation; they do not take contingency factors into account, which in turn leads to a suboptimal fit between logistical concept and hospital environment; and they do not accompany the implementation with an appropriate adaptation of internal organisational activities (i.e. reward- and information systems, routines of medical professionals), which subsequently leads to conflicts that hamper the successful implementation of logistical concepts. Possible explanations can be found in the institutional hospital environment and in the characteristics of hospital care.

\section{The institutional hospital environment}

The optimal implementation of process-oriented logistical concepts is obstructed by the need for hospitals to obtain institutional legitimacy, upon which the support of normative authorities, the approval of legal bodies, and the survival chances of hospitals depend 27 . This legitimacy is contingent on how the hospital complies with three institutional pressures ${ }^{27,28}$ : cultural-cognitive isomorphic ('Everyone else in the hospital sector is doing it'), regulative isomorphic ('Government enforces it by rules and regulations, backed by sanctions and enforcement agencies'), and normative isomorphic ('It has become a prevailing standard in hospital practice, and is thus expected from hospitals'). As a consequence, the implementation of process-oriented logistical concepts by hospitals is not necessarily motivated by their contribution to effectiveness, but rather by their contribution to legitimacy ${ }^{29}$. This means that hospitals sometimes make suboptimal choices that do not automatically lead to more efficient and qualitative care delivery: instead of looking at what is best for the hospital itself, they conform to institutional pressures. This can lead to 
isomorphism of hospitals, although it is known from the contingency theory that there is no best way to organise, that any way of organising is not equally effective, and that the best way to organise depends on the nature of the environment to which the organisation relates ${ }^{30}$. This means that hospitals should have different customised logistical concepts dependent on the hospitals' strategy, size, volume, and technology. In addition, there exists a risk of decoupling between the formal structures created by hospitals to comply symbolically with institutional forces like the creation of care programmes and the internal organisational activities. Thus, hospitals may formally establish care programmes while departments and medical professionals do not change their working methods.

The aforementioned situation means that hospitals do frequently not implement process-oriented logistical concepts thoroughly, although it does not mean that these concepts cannot be fully applied. Due to institutional pressures to become process-oriented organisations, hospitals start improvement projects without first acquiring a system view. As a consequence, hospitals try to perfect individual care processes by optimising parts of processes and by coordinating transfer points. These transfer points cause breakdowns in the coordination of care processes ${ }^{31}$ : namely, coordination of transfer points offers a solution for one patient group, but may cause the situation for other patient groups to deteriorate. As such, the transfer points present obstacles to the successful implementation of process-oriented care delivery at hospital level. Thus, from a system point of view it is better to eliminate transfer points. However, hospitals have difficulties gaining an insight into the operating of their entire hospital system, which is needed to effectively reduce transfer points. Therefore, future research should focus on methods that achieve a clear view of the complexity of a hospital system and of the possibilities to reduce transfer points within care processes.

\section{Hospital care characteristics}

It seems that the specific characteristics of hospital care prevent hospitals from optimally implementing process-oriented logistical concepts. The organisation of service delivery in hospitals is complex. Due to the number of different illnesses, treatments, and preferences of patients and their medical professionals, hospital care incorporates much more variation than industrial processes. In addition, many patients have more than one problem ${ }^{32}$, 33, which calls for different kinds of services, and sometimes at the same time ${ }^{34}$. Furthermore, there exists considerable medical practice variation or interdoctor variation ${ }^{35}$. Medical practice variations are systematic differences in the standardised incidence rate of clinical procedures in a specific population ${ }^{36}$. 
These variations can also have an effect on the allocation of resources, and can result from different approaches to the same clinical problem or from inappropriate clinical decision-making.

Although much of the variation can be eliminated by, for example, an aggregation of the needs of patients and elimination of avoidable practice variation, the amount of variation still exceeds that of industry. A thorough elimination of variation requires the standardisation of medical practice and doing away with patient groups ${ }^{37}$. However, hospitals experience political and ethical obligations that prevent them from dropping certain services and from focusing on strategically important ones ${ }^{2}$. At the same time, the geographical service area of hospitals is restricted by norms for accessibility of care. Thus, because of their limited service area, hospitals are prevented from serving high volumes of patients who need the same care; at the same time, to work efficiently, hospitals need high volumes of patients who require the same chain of services ${ }^{17}$. In addition, hospitals wishing to standardise medical practice experience resistance from medical professionals, and lack effective methods to counteract it. Recent research has shown, for example, that the introduction of uniform guidelines did not reduce practice variation ${ }^{38}$.

This variation in hospital care hinders the prediction of the demand for services, which in turn prevents departments from adjusting their capacity planning on actual needs. As a consequence, it is more efficient for departments to create waiting lines, since in that way they can maximise their capacity use of the departments. Another problem caused by the variation is that hospitals have to deal with patients that need standard care and those that need customised care. It is already known from operations management theory that the delivery of standard and customised care is hard to combine within one organisation with one culture, one set of norms, staff, incentives, and operating systems, since the repetitive work of care delivery to standard patients and the creation of one-of-a-kind services are such different operations ${ }^{34}$. Medical professionals delivering customised care need to be highly skilled, and often possess tacit knowledge that is difficult to transfer. Tacit knowledge is less important when process steps are known ahead of time.

Under the present circumstances, full application of process-oriented logistical concepts does not seem to be feasible. To apply the concepts successfully, hospitals have to negotiate ethical and political obligations, eliminate services, reduce variation in medical practice, enlarge the geographical services area, and focus care delivery on a limited number of groups of standard patients who 
need a specific treatment, or on a limited number of multidisciplinary patient groups.

If a hospital focuses on the care delivery to patients needing a specific procedure, it can choose to implement process-oriented control systems that establish the sequence of care activities and the responsibilities of professionals involved in the diagnosis and treatment. An example of a hospital that decided to serve only a limited segment of a total population needing a specific procedure is the Shouldice Hernia Centre in Canada. In a hospital like Shouldice, only patients who fit the highly standardised care process are offered treatment; all others are rejected ${ }^{34}$. For example, inguinal hernia patients seeking a repair at Shouldice fill out a preadmission form that helps to identify those who do not fit in the segment served. Those not suitable for Shouldice's highly standardised process are counselled to seek treatment elsewhere: for instance, in hospitals that focus on care delivery to customised patients. This selection makes it possible to standardise the care process to a high degree.

If a hospital decides to focus on care delivery to specific groups of multidisciplinary patients, the implementation of a process-oriented basic structure - a hospital structure that is focused towards patient processes - is probably more appropriate. After all, patients from multidisciplinary groups may need standard as well as customised care. A health care process is then crafted for each patient by linking a set of standard processes together after an initial evaluation ${ }^{34}$. Each standard process may be provided by the same or separate professionals. What makes the care uniquely suited to each patient is the combination of the components; the role of the medical professional who performs the initial assessment is then that of a designer. The need for transfers and care coordination can be reduced if medical professionals are flexible: namely, when they can perform different types of activities ${ }^{26}$. Moreover, flexibility also increases performance, since it enables hospitals to balance and distribute the workload effectively because staff can be switched 39,40 . Collaboration of medical professionals and coordination of care delivery is facilitated by the elimination of departmental borders between the medical professionals ${ }^{2}$.

It should be noted that institutional circumstances in the Netherlands are not all in favour of specialisation. On one hand, regulative pressures enforce hospitals to specialise in order to reach high quality health care delivery. The Health Care Inspectorate (IGZ) ${ }^{41}$, for example, sets standards for the minimum number of procedures that a hospital has to perform to keep its license for 
certain procedures. On the other hand, opposing forces exist in the institutional context. Hospitals need, for example, to comply with the Dutch Competition Act, which is enforced by Netherlands Competition Authority (NMA). According to the Dutch Competition Act, hospitals may not participate in cartels, for example, by making price agreements, sharing markets, and restricting production ${ }^{42}$. From this, it seems that hospitals are obliged to treat all patients regardless of their care demand, and cannot restrict themselves to the delivery of certain procedures or to care delivery to specific patient groups. Until this dilemma between pressures to specialise and the pressure to compete is resolved, Dutch hospitals are de facto limited in their development towards specialised hospitals, and thus in effective implementation of process-oriented logistical concepts.

\subsection{Conclusion}

On the basis of the findings, we cannot confirm the central hypothesis that process-oriented care delivery leads to better outcomes in terms of the quality and efficiency of care delivery at hospital level. More research is needed to identify the circumstances under which the implementation of processoriented care delivery is or is not effective. However, our research did provide indications that an effective implementation of process-oriented care delivery requires a 'product' focus of hospitals: namely, restricting care delivery to a limited number of groups of standard patients who need a specific procedure or on a limited number of specific multidisciplinary patient groups, to prevent hospitals from needing to trade-off process and department optimisation. In this respect, hospitals are faced with two dilemmas:

1. They are expected to provide care for every patient, but at the same time they must provide care efficiently, which calls for specialisation;

2. Care must be accessible within a reasonable distance and time, but at the same time hospitals need a sufficient volume of the same type of patients, which calls for a larger service area.

To enable this, it might be necessary that hospitals negotiate with their institutional environment expectations and ethical obligations, redefine their service area, and cooperate with other hospitals. As soon as and insofar as institutional circumstances allow it, hospitals can effectively implement process-oriented care delivery. A condition for success is that hospitals make an appropriate analysis of the consequences of a changed logistical system for the different components of the hospital system, followed by actions that align internal organisational activities and interests with the process-oriented logistical concept. 


\subsection{Recommendations}

The main findings of this thesis provide an insight into the effectiveness of the implementation of process-oriented logistical concepts and supporting measures for the quality and efficiency of care delivery. Based on the findings, several recommendations can be made with regard to future research on logistical concepts for care delivery in hospitals as well as with regard to the implementation of process orientation.

\subsubsection{Future research}

This thesis focused mainly on the evaluation of existing initiatives to implement process-oriented care delivery. As a result of the research, doubts have arisen about the applicability of this type of concept for hospitals that serve a heterogeneous patient population.

Future research should therefore first focus on the preconditions for an effective application of process-oriented logistical concepts in health care to ensure appropriate application at a later date. Alternatively, for hospitals that serve a heterogeneous patient population, it would be interesting to explore the applicability of other logistical concepts such as task or care component standardisation for an improvement in their quality and efficiency.

It also seems important to develop methods that provide an insight into the complexity of a hospital system and into the effects of changes in logistical concepts for the efficient and effective operating of care processes. A visualisation of the complexity of systems gives hospitals better opportunities to take appropriate actions for process optimisation. Simulation techniques may be helpful, because they can estimate effects of changes on interrelated activities. This can prevent the occurrence of unexpected and undesirable effects during the real-life implementation of changes in logistical concepts ${ }^{43}$.

Next, research is needed into possibilities to reduce transfer points in hospitals, because these make it difficult to maintain the streaming of processes in an efficient and optimal way ${ }^{17}$. As described, the diversity in the chain of care prevents hospitals from reducing transfer points when a process-oriented logistical concept is implemented.

Further, research is needed to establish whether process-oriented care delivery can be implemented more effectively if a group of hospitals cooperates. After 
all, a group of hospitals has a larger service area, which increases the chance of standardised care delivery to all patients.

Finally, future research has to take into account patient preferences and the medical outcomes of care delivery. It is assumed within this thesis that a reduction in waiting and throughput times, coupled with collaboration between medical professionals, increases the quality of care delivery. However, faster care delivery may not always be better. In some cases, for example when cancer is diagnosed, a too-short throughput time between diagnosis and treatment is not desirable because of the psychological impact on patients. Moreover, we did not investigate the medical outcomes of care delivery itself. Although we expect that the medical outcomes of care delivery will be positively affected as the result of a better organisation of care delivery, future research needs to confirm this.

\subsubsection{Hospital practice}

Despite a lack of evidence on the effectiveness of process-oriented care delivery, several programmes have been initiated worldwide during the last decennium to help hospitals make their organisation of care delivery more process-oriented. This study has attempted to fill the gap between evidence and practice. On the basis of the results, we can offer the following recommendations.

It seems obvious from our research that not all hospitals can benefit equally from the implementation of process-oriented logistical concepts. The effectiveness depends on the fit that can be reached between characteristics of the environment and the concept that is applied. The challenge is to find the best match. Therefore, we recommend that hospitals carefully consider the fit between process-oriented logistical concepts and their environmental factors: these include the possibility to focus on a limited number of groups of standard patients who need a specific treatment or on a limited number of multidisciplinary patient groups; the volume of the served patient groups; and the predictability of the care processes. An effective implementation of processoriented logistical concepts seems to require the specialisation in the delivery of care to a limited number of groups of standard patients who need a specific procedure, or to a limited number of specific multidisciplinary patient groups. From a geographical point of view, specialisation appears to be a feasible option. The demand for specialised hospitals seems big enough in the Netherlands, with its approximately 17 million inhabitants who live in close 
proximity to one another. The good infrastructure in the Netherlands also favours the specialisation of hospitals.

For an effective implementation of process-oriented logistical concepts, hospitals need a system view of their own organisation. Specific conditions and contingencies require customised implementation in such a way that conflicts between hospital system components are prevented. To increase the likelihood of successful implementation, we recommend the use of a balanced set of incentives, such as reward- and information systems.

Hospitals must determine for themselves the institutional requirements that may prevent them from specialising. At the moment, hospitals are being encouraged to specialise, but at the same time are obliged by the Netherlands Competition Authority to treat all patients regardless of their care demand. Hospitals need to resolve this dilemma. 


\section{References}

1. Lega F, DePietro C: Converging patterns in hospital organization: beyond the professional bureaucracy. Health Policy 2005, 74(3):261-281.

2. Vera A, Kuntz L: Process-based organization design and hospital efficiency. Health Care Management Review 2007, 32(1):55-65.

3. Van Merode GG: A prelude of 2004 Antwerp quality conference: targets and target values - integrating quality management and costing. Accreditation and Quality Assurance 2004, 9:168-171.

4. Hammer M, Champy J: Reengineering the corporation: a manifesto for business revolution. London: Nicholas Brealey; 1993.

5. Consortium Better Faster pillar 3. National strategy Better Faster pillar 3 (in Dutch). Utrecht/Rotterdam/Utrecht: Quality Institute for Health Care CBO, Institute of Health Policy and Management of the Erasmus University Rotterdam, Order of Medical Specialists; 2004.

6. McGrath KM, Bennett DM, Ben Tovim DI, Boyages SC, Lyons NJ, O'Connell TJ: Implementing and sustaining transformational change in health care: lessons learnt about clinical process redesign. Medical Journal of Australia 2008, 188(6 Suppl):S32-35.

7. Nolan TW, Schall MW, Berwick DM, Roessner J: Reducing delays and waiting times throughout the healthcare system. Boston: Institute for Healthcare Improvement; 1996.

8. Berg M, Schellekens W, Bergen C: Bridging the quality chasm: integrating professional and organizational approaches to quality. International Journal for Quality in Health Care 2005, 17(1):75-82.

9. Vos L, Dückers M, De Bruijn M, Wagner C, Groenewegen PP, Van Merode F: To a process-oriented hospital: desired effects of a logistic improvement programme (in Dutch). Tijdschrift voor Gezondheidswetenschappen 2008, 86(4):207-215.

10. Rouppe van der Voort M, Stoffer M, Zuiderent-Jerak T, Janssen S, Berg M: Breakthrough process redesign III: 2006-2007 Better Faster pillar 3, T2S2 en T3S1 (in Dutch). Utrecht/Rotterdam/Utrecht: Quality Institute for Health Care CBO, Institute of Health Policy and Management of the Erasmus University Rotterdam, Order of Medical Specialists; 2006.

11. Vermeulen IB, Bohte SM, Elkhuizen SG, Lameris JS, Bakker PJM, La Poutré JA: Adaptive optimisation of hospital resource planning. In Proceedings 11th Conference on Artificial Intelligence in Medicine in Europe, AIME 2007.

12. De Vries G, Van Tuijl H (Eds.): Health care under pressure: vital tension in the middle of organisations, a business approach (in Dutch). Houten: Bohn Stafleu van Loghum; 2006.

13. Lawrence P, Lorsch J: Differentiation and integration in complex organisations. Administrative Science Quarterly 1967, 12:1-30. 
14. Sousa R, Voss CA: Contingency research in operations management practices. Journal of Operations Management 2008, 26(6):697-713.

15. Hall RH: Organizations: structures, processes and outcomes. New Jersey: Prentice Hall; 1999.

16. Donaldson L: The contingency theory of organizations. Thousand Oaks: Sage; 2001.

17. Van Merode F, Molema H, Goldschmidt H: GUM and six sigma approaches positioned as deterministic tools in quality target engineering. Accreditation and Quality Assurance 2004, 10:32-36.

18. Lee KH: The hospital movement - a complex adaptive response to fragmentation of care in hospitals. Annals Academy of Medicine Singapore 2008, 37(2).

19. Mintzberg H: The structuring of organizations: a synthesis of research. Englewood Cliffs, N.J.: Prentice-Hall; 1979.

20. Bevan H, Glenn R, Bate P, Maher L, Wells J: Using a design approach to assist large-scale organizational change: '10 high impact changes' to improve the national health service in England. The Journal of Applied Behavioral Science 2007, 43(1):135-152.

21. Van Merode GG, Verreusel R, Vrieze KOJ, Zeemering S: Constructing new hospitals: the effects of innovative care organization. In Health Sciences Simulation Conference Proceedings: 2004; San Diego; 2004:25-28.

22. Dückers MLA, Wagner C, Groenewegen PP: Conditions for a sector wide, knowledge based, improvement programme in the Dutch hospital care (in Dutch). Acta Hospitalia 2005, 45(3):37-54.

23. Grol R, Wensing M, Eccles M: Improving patient care: the implementation of change in clinical practice. Edinburgh: Elsevier; 2005.

24. Ministry of Health, Welfare and Sport: The individual health care professions act: International Publication Series Health, Welfare and Sport nr. 10. The Hague; 2001.

25. Berwick DM, Nolan TW: Physicians as leaders in improving health care: a new series in annals of internal medicine. Annals of Internal Medicine 1998, 128:289292.

26. Desombre T, Kelliher C, Macfarlane F, Ozbilgin M: Re-organizing work roles in health care: evidence from the implementation of functional flexibility. British Journal of Management 2006, 17:139-151.

27. Scott WR, Ruef M, Mendel PJ, Caronna CA: Institutional change and healthcare organizations: from professional dominance to managed care. London: University of Chicago Press; 2000.

28. Powell WW, DiMaggio PJ: The new institutionalism in organizational analysis. Chicago, IL: The University of Chicago Press; 1991. 
29. Kenis P: Waiting lists in Dutch health care: an analysis from an organization theoretical perspective. Journal of Health, Organization and Management 2006, 20(4):294-308.

30. Scott WR: Organisations: rational, natural and open systems. New Yersey: Upper Saddle River; 2003.

31. Tavena S, Grote G, Easty A, Plattner B: Decoding the perioperative process breakdowns: a theoretical model and implications for system design. International Journal of Medical Informatics 2010, 79(1):14-30.

32. Schellevis FG: Multimorbidity in general practice (in Dutch). Bijblijven 2009, 25(3):25-30.

33. Wagner EM: Meeting the needs of chronically ill people. BMJ 2001, 323:945-946.

34. Bohmer RMJ: Medicine's service challenge: blending custom and standard care. Health Care Management Review 2005, 30(4):322-330.

35. Westert GP, Groenewegen PP, Boshuizen HC, Spreeuwenberg PM, Steultjens MP: Medical practice variations in hospital care; time trends of a spatial phenomenon. Health \& Place 2004, 10(3):215-220.

36. Fernandez LA, Martin JM, del Castillo JD, Gaspar OS, Millan JI, Lozano MJ, Keenoy ED: Sources of influence on medical practice. Journal of Epidemiology and Community Health 2000, 54(8):623-630.

37. Morton A, Cornwell J: What's the difference between a hospital and a bottling factory? BMJ 2009, 339:428-430.

38. De Jong JD, Groenewegen PP, Spreeuwenberg P, Schellevis F, Westert GP: Do guidelines create uniformity in medical practice? Social Sciences \& Medicine 2010, 70(2):209-216.

39. Li LLX, King BE: A healthcare staff decision model considering the effects of staff cross-training. Health Care Management Science 1999, 2(1):53-61.

40. Molema JJW: Hospital system design: creating supply flexibility to match demand variability. Maastricht University, Health Organization, Policy and Economics; 2009.

41. The Health Care Inspectorate: http://www.igz.nl/english/(accessed at 6 March 2010)

42. The Netherlands Competition Authority: http://www.nma.nl/engels/home/ index.asp (accessed at 6 March 2010)

43. Groothuis S: Simulation in health care: lessons learned. PhD Thesis. Maastricht University; 2002. 


\section{Summary}

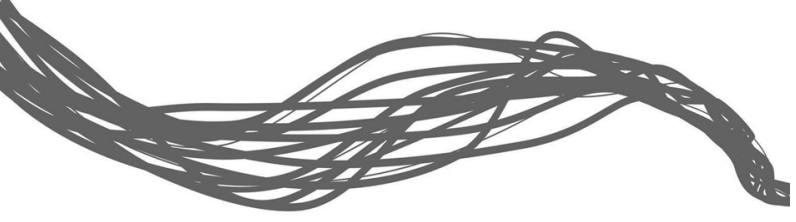




\section{'Towards process-oriented care delivery in hospitals'}

Patients frequently have to wait for long periods before they are seen by medical specialists; they then need to wait again for diagnostic examinations or treatment. Problems with regard to quality, such as waiting times and poor coordination of care often occur because hospital departments operate as separated 'silos', each with its own goals, and do not exchange information for the planning and control of patient flow. National and international attention to these quality problems has made hospital management and medical specialists aware that the way in which care is delivered needs to be reorganised. However, little is known about how to improve the organisation of care delivery in terms of quality and efficiency. It is also not known how new ways of structuring care delivery need to be introduced into a hospital organisation.

Until now, many of the ideas for improvements in coordination and process control have been derived from industry, including the successful concept referred to as 'business process orientation'. The concept's breakthrough took place at the beginning of the 1990s under the name 'Business Process Reengineering'. Successful examples of the application of business process orientation for the organisation of care delivery to specific patient groups are known, for instance, from the Dutch programme 'Better Faster', from Australia's 'Redesigning Hospital Care', and from the United States' 'Reducing delays and waiting times throughout the system'. It is unknown, however, whether this process-oriented care delivery can also be applied successfully at hospital level. Therefore, this thesis aims to test the hypothesis that the implementation of process-oriented care delivery leads to better outcomes in terms of quality and efficiency at hospital level.

Chapter 1 describes the background of this thesis and lists the main research questions. To assess the effectiveness of process-oriented care delivery at hospital level in terms of quality and efficiency, we first performed a literature review; this review is presented in Chapter 2. The review discusses hospitals' experiences with implementing a process-oriented logistical concept. It shows that hospitals choose between two main approaches:

A. Implementation of a process-oriented operational control system without changing the hospital's existing functional basic structure; and

B. Implementation of a process-oriented basic structure, in which the composition of departments is based on the needs of specific patient groups instead of on the type of medical specialties.

The review pointed out that an effective implementation of a process-oriented operational control system (A) requires that both department managers and 
medical specialists give priority to the coordination of care delivery between departments above the capacity utilisation of each department. This proved difficult, however, since medical departments in functional organisations have to maximise their own output. An effective implementation of a processoriented basic structure based on multidisciplinary patient-focused departments (B) requires that hospitals focus on strategically important services. Unfortunately, this literature review could not identify studies of sufficient quality to determine which of the two approaches (A or B) delivers the best results and under what circumstances.

Following on from the assessment of the effectiveness of process-oriented care delivery at hospital level, Chapters 3-6 of this thesis focus on ways to introduce process-oriented logistical concepts into a hospital organisation.

Chapter 3 describes an evaluation method to assess the fit between hospital building layout and a process-oriented logistical concept. Its contribution to the implementation of new logistical concepts is tested in a case study. The described method aims to ensure that top management's wish to implement process-oriented care delivery is not hampered by a conflict between the building layout and specifics of the new logistical concepts. Using computer simulation techniques, the evaluation method assesses hospital building layout from the viewpoint of operations management. The aim of such an evaluation is to ensure that the building layout currently supports the efficient and effective operating of care processes, and will do so in the future. In the case study, a newly designed hospital layout was assessed on its flexibility to meet future requirements of new logistical concepts and changes in patient mix. The results of the case study showed that a change in intensity, direction, or volume of the flow as a result of a new logistical concept or a changed patient mix led to congestions in the patient flow. In other words, the design of the hospital building layout was not flexible enough to deal with a new logistical concept or a changed patient mix. In this case, however, the layout of the building could easily be adjusted because it was still in the design phase.

Chapter 4 tests whether the use of process-based payments - process-based internal hospital budgeting - contributes to the implementation of processoriented logistical concepts. Process-based budgeting - the allocation of financial means on the basis of performance of care processes - aims to ensure that the coordination of care delivery between departments is not obstructed by responsibilities at division or department level. Analyses of data involving Dutch hospitals demonstrated that process-based budgeting stimulated medical professionals to use process-oriented performance measures, which in 
turn had a positive effect on the number of activities to develop processoriented operational control systems. Although process-based budgeting did not directly stimulate the implementation of a process-oriented logistical concept, it seems that it is a valuable tool to bridge those internal conflicts of interests between departments and medical professionals that hamper collaboration across departmental boundaries. It stimulated cooperation between departments and medical professionals to organise care delivery in a process-oriented way, even though the implementation was not yet accompanied by adapted internal organisational activities: for instance, more decentralised decision-making, agreements about process ownerships, and a process-oriented view on the part of medical professionals.

In Chapter 5 and Chapter 6 of this thesis, the effects of two types of redesign methods on the implementation of process-oriented logistical concepts at process level are assessed. These redesign methods aim to change patterns of interactions between professionals in order to develop and implement new routines that fit process-oriented logistical concepts.

Chapter 5 applies a process innovation method - intended to radically redesign and improve work processes - to change the traditionally functional operating system of in-hospital care for stroke patients towards a processoriented operating system with the aim to improve the quality and efficiency of care delivery. This method includes four steps: process analysis, identification of bottlenecks, design of the process-oriented operating system, and implementation of the system. Results indicate that implementation led to a significantly shorter length of hospital stay. As a result, more stroke patients could be admitted to the specialised ward.

Chapter 6 uses the Quality Improvement Collaborative (QIC) method for the redesign of work processes to change a functional operating system incrementally towards a process-oriented operating system for specific patient groups with the help of external facilitators and peer stimulus. This method was assessed in a multiple case study design. Within the evaluated QIC, external change agents provided eighteen collaborative project teams from various hospitals with a clear vision for the redesign of their operating system, along with a set of specific changes that could significantly improve patient flow. Results of the multiple case study showed that the perceived need to tailor standard change ideas to local contexts and the complexity of aligning the interests of involved departments hampered use of the QIC method for process redesign by the project teams. As result of the selection process for the participation of project teams by the external change agent, peer stimulus was 
non-optimal. The external change agent included project teams in the evaluated collaborative that worked on different aspects of care processes for various types of patient groups and different patient volumes, while the QIC methodology aimed to implement evidence-based practice through sharing knowledge with other teams having similar goals. Further, project teams felt that preconditions for the successful use of the QIC method were lacking. Therefore, additional research into the applicability of the QIC method for process redesign is needed.

Chapter 7 summarises the main findings of the studies presented in this thesis, and takes the findings into consideration. The research reconfirms that implementation of process-oriented logistical concepts can reduce throughput times for specific patient groups, which leads to a gain in quality care for patients and to efficiency for specific care processes. Not only will these patient groups have shorter waiting times between examination and treatment but their conditions will be treated timely and adequately, and will require fewer resources (e.g. number of bed days). Similar benefits of process-oriented logistical concepts could not be determined at hospital level. The literature review in Chapter 2 was unable to identify enough high-quality studies that assessed the implementation of process-oriented logistical concepts, and an empirical assessment failed due to the limited availability of data. However, the research showed that hospitals cannot or do not fully implement the processoriented logistical concepts: they lack a system view, which in turn leads to a trade-off between process and department optimisation; they do not take into account the fit between contingency factors (strategy, volume, task certainty, and technology) and process-oriented logistical concepts when deciding to implement a process-oriented care delivery (process-oriented logistical concepts are no panacea for hospitals under all circumstances); and they do not accompany the implementation with an appropriate adaptation of internal organisational activities (i.e. reward- and information systems, routines of medical professionals), which in turn leads to conflicts that hamper successful implementation of logistical concepts. Possible explanations can be found in the institutional hospital environment and in the characteristics of hospital care. The institutional environment forces hospitals to comply with culturalcognitive ('Everyone else in the hospital sector is doing it'), regulative ('Government enforces hospitals to do it by regulations and legalisation, backed by sanctions and enforcement agencies'), and normative ('It has become a prevailing standard in hospital practice and thus expected from hospitals') pressures to obtain institutional legitimacy. As a consequence, the implementation of process-oriented logistical concepts by hospitals is not necessarily motivated by their contribution to effectiveness, but rather by their 
contribution to legitimacy. This means that hospitals sometimes make suboptimal choices that do not automatically lead to more efficient and qualitative care delivery: instead of looking at what is best for the hospital itself, they conform to institutional pressures. This can lead to isomorphism of hospitals and to decoupling between the implementation of logistical concepts and adaptation of internal organisational activities. Isomorphism is not desired, since it is known from the contingency theory that hospitals need to customise their logistical concept to their environment. Decoupling leads to ineffectiveness of the introduced logistical concept. In addition to the institutional environment, current hospital care characteristics also limit the implementation of process-oriented logistical concepts. Ethical and political obligations and resistance to standardising medical practice prevent hospitals from focusing on a limited number of groups of standard patients who require a specific procedure, or on a limited number of groups of specific multidisciplinary patients.

On the basis of the findings, we cannot confirm the central hypothesis of this thesis that process-oriented care delivery leads to better outcomes in terms of the quality and efficiency of care delivery at hospital level. More research is needed to identify the circumstances under which the implementation of processoriented care delivery is or is not effective. However, our research did provide indications that an effective implementation of process-oriented care delivery requires a 'product' focus of hospitals: namely, restricting care delivery to a limited number of groups of standard patients who need a specific procedure or to a limited number of groups of specific multidisciplinary patients, to prevent hospitals from needing to trade-off process and department optimisation. In this respect, hospitals are faced with two dilemmas:

1. They are expected to provide care for every patient, but at the same time they must provide care efficiently, which calls for specialisation;

2. Care must be accessible within a reasonable distance and time, but at the same time hospitals need a sufficient volume of the same type of patients, which calls for a larger service area.

To enable this, it might be necessary that hospitals negotiate with their institutional environment expectations and ethical obligations, redefine their service area, and cooperate with other hospitals. As soon as and insofar as institutional circumstances allow it, hospitals can effectively implement process-oriented care delivery. A condition for success is that hospitals make an appropriate analysis of the consequences of a changed logistical system for the different components of the hospital system, followed by actions that align internal organisational activities and interests with the process-oriented logistical concept. 


\section{Samenvatting}




\section{'Naar een procesgerichte organisatie van ziekenhuiszorg'}

Patiënten moeten regelmatig lang wachten op een afspraak bij de specialist, op diagnostisch onderzoek en op behandeling. Deze wachttijden en de slechte afstemming tussen betrokken zorgverleners in een zorgproces van de patiënt treden vaak op omdat Nederlandse ziekenhuizen van oudsher functioneel georganiseerd zijn. In een functionele structuur staat niet de zorgvraag van een patiënt maar het zorgaanbod, georganiseerd in specialistische afdelingen, centraal. Informatie-uitwisseling over de planning en beheersing van patiëntenstromen tussen verschillende specialistische afdelingen is in een dergelijke functionele ziekenhuisstructuur beperkt. Nationale en internationale aandacht voor kortere wachttijden en zorgcoördinatie heeft specialisten en ziekenhuismanagement er bewust van gemaakt dat de zorgverlening anders moet worden ingericht. Er is echter weinig bekend over mogelijkheden om de kwaliteit en doelmatigheid van de organisatie van zorg te verbeteren. Ook bestaat er slechts beperkte kennis over de wijze waarop nieuwe manieren van zorgorganisatie het beste kunnen worden ingevoerd in de dagelijkse zorgpraktijk.

Tot nu toe komen veel van de ideeën ter verbetering van de organisatie van zorg uit de industrie, zoals het 'business process orientation' concept. De doorbraak van dit concept vond plaats in het begin van de jaren 90 onder de naam 'Business process reengineering'. Succesvolle voorbeelden van de toepassing van dit concept op de inrichting van zorg voor specifieke patiëntengroepen zijn bekend uit het Nederlandse verbeterprogramma 'Sneller Beter', uit het Australische 'Redesigning Hospital Care', en uit het Amerikaanse 'Reducing delays and waiting times throughout the system'. Maar het is niet bekend of dit concept, het procesgericht organiseren van zorg, met succes kan worden toegepast op het niveau van een heel ziekenhuis. Daarom beoogt dit proefschrift de volgende centrale hypothese te toetsen: 'de invoering van een procesgerichte organisatie van zorg leidt op ziekenhuisniveau tot betere resultaten op het gebied van kwaliteit en doelmatigheid'.

Hoofdstuk 1 beschrijft de achtergrond van het proefschrift en de onderzoeksvragen. Om inzicht te krijgen in de effectiviteit van een procesgerichte organisatie van zorg op ziekenhuisniveau is een literatuurstudie uitgevoerd. De resultaten van deze literatuurstudie zijn beschreven in hoofdstuk 2. De literatuurstudie laat zien dat ziekenhuizen op twee verschillende manieren toewerken naar een procesgerichte organisatie van zorg: 
A. Door de invoering van procesgerichte besturingssystemen, zoals zorgpaden, binnen de bestaande functionele ziekenhuisstructuur; en

B. Door de invoering van een procesgerichte ziekenhuisstructuur, waarin de afdelingen zijn samengesteld op basis van de behoeften van specifieke patiëntengroepen in plaats van op medische specialismen.

Uit de literatuurstudie bleek dat een effectieve invoering van procesgerichte besturingssystemen (A) vereist dat managers en medisch specialisten meer prioriteit geven aan een goede coördinatie van zorg aan patiënten in plaats van aan een optimaal capaciteitsgebruik van hun afdeling. Moeilijkheid hierbij is dat specialistische afdelingen in functionele ziekenhuisorganisaties afgerekend worden op hun productie. Voor een effectieve invoering van een procesgerichte ziekenhuisstructuur (B) bleek een focus op strategisch belangrijke patiëntengroepen essentieel. De literatuurstudie kon niet genoeg valide en betrouwbare studies vinden om vast te stellen welke van de twee benaderingen (A of B) de beste resultaten onder welke omstandigheden levert.

In aansluiting op deze evaluatie van de effectiviteit van een procesgerichte organisatie van zorg op ziekenhuisniveau, onderzoeken de hoofdstukken 3-6 van dit proefschrift de toegevoegde waarde van ondersteunende maatregelen bij de introductie van een procesgerichte organisatie van zorg in een ziekenhuisorganisatie.

Hoofdstuk 3 beschrijft en test een evaluatiemethode die nagaat of de wens tot het invoeren van een procesgerichte organisatie van zorg wordt ondersteund door de lay-out van het gebouw. Bovendien toetst de methode de bruikbaarheid van het gebouw in de toekomst. Het nut van deze evaluatiemethode bij de invoering van nieuwe logistieke concepten is getest in een casestudie. De casestudie evalueerde de flexibiliteit van een nieuw ziekenhuisontwerp ten aanzien van nieuwe eisen van toekomstige logistieke concepten en van veranderingen in de samenstelling van de patiëntenpopulatie. De casestudie toonde aan dat een verandering in de intensiteit, de richting of het volume van de patiëntenstroom als gevolg van een nieuw logistiek concept of van een verandering van de patiëntenpopulatie tot opstoppingen in het ziekenhuis leidde. Het ontwerp van het ziekenhuis was dus niet flexibel genoeg. Op basis van de uitkomsten van de evaluatie kon het ziekenhuisontwerp nog makkelijk worden aangepast en het optreden van opstoppingen worden voorkomen.

Hoofdstuk 4 gaat na of de toekenning van financiële middelen per zorgproces procesgerichte budgettering - binnen het ziekenhuis bijdraagt aan de invoering van procesgerichte logistieke concepten. Met procesgerichte budgettering wil men bereiken dat de coördinatie van zorg niet wordt gehinderd door 
verantwoordelijkheid van divisies en specialistische afdelingen om door productie hun budget veilig te stellen. De analyse van Nederlandse ziekenhuisdata toonde aan dat procesgerichte budgettering medische professionals stimuleerde om procesgerichte prestatie-indicatoren te gebruiken. Het gebruik van procesgerichte presentatie-indicatoren bevorderde vervolgens weer activiteiten gericht op het realiseren van procesgerichte besturingssystemen. Ondanks dat procesgerichte budgettering dus niet direct bijdraagt aan de invoering van procesgerichte besturingssystemen, lijkt het een waardevol instrument om interne belangenconflicten tussen specialistische afdelingen te overbruggen. Het stimuleert de samenwerking tussen afdelingen die nodig is om de zorg procesgericht te organiseren.

Hoofdstuk 5 en 6 beschrijven de toegevoegde waarde van twee methoden voor herontwerp van zorgprocessen van specifieke patiëntengroepen. Deze methoden beogen interactiepatronen tussen medische professionals te veranderen zodat nieuwe routines ontstaan die passen bij procesgerichte logistieke concepten.

Hoofdstuk 5 toetst het effect van een procesinnovatie methode, die werkprocessen opnieuw ontwerpt, op de kwaliteit en doelmatigheid van de ziekenhuiszorg voor CVA-patiënten. Deze methode bevat vier stappen: procesanalyse, identificatie van knelpunten, ontwerp van een procesgericht besturingssysteem en de implementatie hiervan. De toepassing van deze methode leidde tot een significant korter ziekenhuisverblijf. Gevolg hiervan was dat meer patiënten toegang konden krijgen tot de gespecialiseerde CVA afdeling.

Hoofdstuk 6 evalueert de stapsgewijze verandering van een functioneel besturingssysteem naar een procesgericht besturingssysteem voor specifieke patiëntengroepen met behulp van de Doorbraak methode. Dit is een methode waarin teams met professionals van verschillende organisaties een gezamenlijke training volgen om specifieke probleemgebieden aan te pakken. Doorbraakprojecten maken gebruik van een kort cyclische verbetermethode gebaseerd op het formuleren van concrete doelen (plan), het toepassen van specifieke interventies (do) en het aanhoudend meten en bestuderen van de stand van zaken aan de hand van prestatie-indicatoren (study) om te bepalen waar bijsturing wenselijk is (act). In het geëvalueerde doorbraakproject adviseerden externe veranderagenten achttien deelnemende teams over het herontwerp van zorgprocessen voor verschillende patiëntengroepen en voorzagen zij de teams van gerichte veranderideeën. Deze methode werd geëvalueerd in een multiple casestudie. De multiple casestudie liet zien dat het 
gebruik van de Doorbraakmethode werd belemmerd door de noodzaak van de teams om de aangereikte veranderideeën aan te passen aan hun eigen situatie en door de belangenafweging van betrokken specialistische afdelingen. Bovendien bleef de uitwisseling van ervaringen tussen de teams beperkt doordat de teams werkten aan verschillende zorgprocessen voor verschillende patiëntengroepen van verschillende volumes, terwijl de Doorbraakmethode uitgaat van kennisuitwisseling tussen teams met vergelijkbare doelen. Daarnaast ontbraken volgens projectteams voorwaarden voor een succesvol gebruik van de Doorbraakmethode. Hierdoor kunnen op basis van dit doorbraakproject niet met zekerheid uitspraken worden gedaan over de waarde ervan. Daarom is additioneel onderzoek nodig om de toepasbaarheid van de Doorbraakmethode voor procesherontwerp te bevestigen.

Hoofdstuk 7 geeft een overzicht van de bevindingen van de verschillende studies uit dit proefschrift en bediscussieert deze in het licht van de centrale hypothese. Het onderzoek bevestigt opnieuw dat de invoering van een procesgerichte organisatie kan leiden tot kwaliteitswinst voor patiënten en tot doelmatigheidswinst voor specifieke zorgprocessen. Als gevolg van de procesgerichte organisatie zijn wachttijden tussen diagnostisch onderzoek en behandeling korter en worden patiënten tijdig en adequaat behandeld bij een kleinere inzet van middelen, bijvoorbeeld door een reductie in het aantal ligdagen. Op ziekenhuisniveau konden vergelijkbare voordelen niet worden vastgesteld. De literatuurstudie kon niet genoeg studies van goede kwaliteit hierover vinden. Daarnaast faalde een empirisch onderzoek naar de invoering van een procesgerichte organisatie van zorg door gebrekkige data. Wel kwam naar voren dat ziekenhuizen procesgerichte logistieke concepten niet volledig willen of kunnen invoeren. Allereerst missen de ziekenhuizen een systeemvisie, wat leidt tot een compromis tussen de optimalisatie van processen en afdelingen. Ook besteden de ziekenhuizen geen of te weinig aandacht aan de relatie tussen contingentiefactoren (zoals strategie, volume, taakzekerheid en technologie) en procesgerichte logistieke concepten wanneer zij overgaan tot de invoering van een procesgerichte organisatie van zorg (procesgerichte logistieke concepten kunnen immers alleen werken onder bepaalde voorwaarden). Tenslotte combineren ziekenhuizen de invoering van procesgerichte logistieke concepten niet met een aanpassing van de interne organisatie (beloningsstructuren, informatiesystemen en medische routines), wat leidt tot conflicten die de succesvolle invoering van de logistieke concepten belemmeren. Mogelijke verklaringen hiervoor kunnen gevonden worden in de institutionele omgeving van het ziekenhuis en de kenmerken van ziekenhuiszorg. De institutionele omgeving dwingt ziekenhuizen te voldoen aan cultureel-cognitieve ('iedereen doet het'), regulatieve ('wet- en regelgeving 
vereist het') en normatieve ('het is standaard ziekenhuispraktijk') druk voor het verkrijgen van institutionele legitimiteit. De invoering van procesgerichte logistieke concepten wordt daardoor niet noodzakelijkerwijs ingegeven door de bijdrage aan de effectiviteit maar eerder door de bijdrage aan de institutionele legitimiteit. Dit betekent dat ziekenhuizen soms suboptimale keuzen maken die niet automatisch leiden tot grotere doelmatigheid en betere kwaliteit van de organisatie van zorg: ziekenhuizen conformeren zich aan institutionele druk in plaats van dat zij kiezen wat het beste is voor het ziekenhuis zelf. Dit kan leiden tot isomorfisme van ziekenhuizen en tot ontkoppeling tussen de invoering van logistieke concepten en aanpassing van de interne ziekenhuisorganisatie. Isomorfisme is ongewenst omdat het uit de contingentietheorie bekend is dat ziekenhuizen hun logistieke concept moeten aanpassen aan hun omgeving. Ontkoppeling leidt tot ineffectiviteit van het geïntroduceerde logistieke concept. De invoering van procesgerichte logistieke concepten wordt niet alleen beperkt door de institutionele omgeving, maar ook door de kenmerken van de huidige ziekenhuiszorg. Ethische en politieke verplichtingen en weerstand tegen het standaardiseren van de medische praktijk verhinderen dat ziekenhuizen zich richten op een beperkt aantal groepen standaard patiënten die een specifieke procedure nodig hebben of op een beperkt aantal groepen van specifieke multidisciplinaire patiënten.

Op grond van de bevindingen kunnen we de centrale hypothese van dit proefschrift 'de invoering van een procesgerichte organisatie van zorg leidt tot betere resultaten op het gebied van kwaliteit en doelmatigheid op ziekenhuisniveau' niet bevestigen. $\mathrm{Er}$ is meer onderzoek nodig om de omstandigheden, waaronder de invoering van een procesgerichte organisatie van zorg al of niet effectief is, te identificeren. In ons onderzoek zijn indicaties gevonden dat een effectieve invoering van een procesgerichte organisatie van zorg vraagt om een 'product' focus van ziekenhuizen: dat wil zeggen, het beperken van de zorgverlening tot een beperkt aantal groepen standaard patiënten die een specifieke procedure nodig hebben of op een beperkt aantal groepen van specifieke multidisciplinaire patiënten, om te voorkomen dat ziekenhuizen een compromis moeten sluiten tussen de optimalisatie van processen en de optimalisatie van afdelingen. In dit opzicht worden ziekenhuizen geconfronteerd met twee dilemma's:

1. De maatschappij verwacht dat ziekenhuizen zorg verlenen aan iedere patiënt maar tegelijkertijd moet deze zorg efficiënt verleend worden, wat vraagt om specialisatie;

2. Zorg moet beschikbaar zijn binnen redelijke afstand en tijd maar tegelijkertijd hebben ziekenhuizen een voldoende volume van hetzelfde soort patiënten nodig, wat vraagt om een groter verzorgingsgebied. 
Om dit mogelijk te maken kan het nodig zijn dat ziekenhuizen met hun institutionele omgeving onderhandelen over verwachtingen en ethische verplichtingen, hun verzorgingsgebied opnieuw bepalen, en samenwerken met andere ziekenhuizen. Wanneer en voor zover institutionele omstandigheden dit toestaan kunnen ziekenhuizen effectief een procesgerichte organisatie van zorg invoeren. Voorwaarde voor succes is dat ziekenhuizen een gedegen analyse van de gevolgen van een veranderd logistiek system maken voor de verschillende componenten van het ziekenhuissysteem, gevolgd door acties die de interne organisatieactiviteiten en belangen in overeenstemming brengen met het procesgerichte logistieke concept. 


\section{Dankwoord}

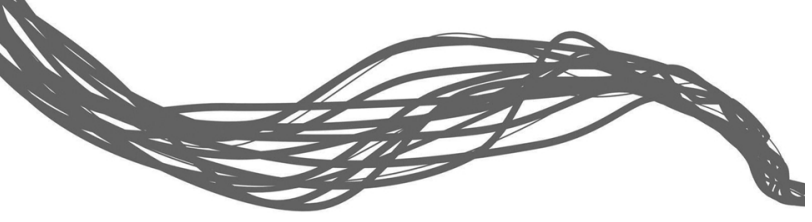


Dit proefschrift is tot stand gekomen met hulp en steun van heel veel mensen uit mijn professionele omgeving, familie en vriendenkring; een aantal van hen wil ik hier in het bijzonder noemen.

Frits: Je vertrouwen in mij tijdens het schrijven heb ik enorm gewaardeerd. De fysieke afstand tussen Maastricht en Den Haag heeft een goede samenwerking niet in de weg gestaan; jij stond te allen tijde voor mijn vragen klaar en beantwoordde die altijd super snel. Je vele suggesties en kritische vragen hebben mij steeds, tot aan het einde toe, aan het denken gezet. Ik heb veel van je geleerd.

Cordula en Peter: Ik heb het zeer gewaardeerd dat ik van het NIVEL de kans heb gekregen aan mijn proefschrift te werken en ook af te ronden. Hartelijk dank voor jullie adviezen en de ruimte die ik kreeg om mijn eigen ideeën voor dit proefschrift uit te werken.

Beoordelingscommissie: Graag wil ik op deze plek ook een woord van dank aan uitspreken aan Prof. dr. C. Spreeuwenberg, Prof. dr. H.J.J.M. Berden, Prof. dr. J. van Engelshoven, Prof. dr. J.A.M. Maarse en Prof. dr. J. de Vries voor de beoordeling van mijn proefschrift.

Paranimfen: Michel en Olga, onze gezellige tijd bij het NIVEL zal ik niet snel vergeten. Michel, mijn 'Sneller Beter' collega, het was een feest om met je samen te werken. Olga, ik heb goede herinneringen aan onze gesprekken tijdens de laatste fase van onze promotietrajecten. Fantastisch dat jullie mijn paranimfen willen zijn.

Coauteurs: Jullie hulp bij de analyses en kritische revisies van mijn artikelen waren zeer welkom. Siebren, jouw interesse in mijn promotie en verdere loopbaan heb ik als bijzonder ervaren.

'Vormgevers' van mijn proefschrift: Christel, dankzij jouw ruime ervaring en oog voor detail ziet de opmaak van mijn proefschrift er prachtig uit. Marc, bedankt voor het mooie ontwerp van de kaft van mijn proefschrift.

NIVEL en LUMC collega's: Jullie morele steun, de gezelligheid tussen onze werkzaamheden door, en jullie belangstelling voor mijn promotietraject heb ik heel prettig gevonden.

Vriend(inn)en, Elfjes, Hans en Ria, en familie: Hartelijk dank voor jullie vriendschap, interesse in mijn werk en vooral ook de afleiding van mijn werk. 
Juul: Mam, jouw en papa's onvoorwaardelijke steun, aanmoediging en betrokkenheid, van begin tot het eind, hebben ongelooflijk veel voor mij betekend. Helaas kunnen we niet meer samen met papa van dit moment genieten.

Rob: Meer dan drie jaar lang heb jij mij gesteund, ook al betekende dat voor jou dat ik in de weekenden heel vaak achter mijn laptop zat. Dank voor je eindeloze geduld en goede zorgen.

\section{Ceri}




\section{Curriculum Vitae}


Leti Vos was born on 22 March 1980 in Leidschendam, the Netherlands. After finishing Grammar School in 1998, she studied Health Sciences at Maastricht University in the Netherlands. In August 2004 she graduated with specialisations in Health Policy and Administration and Movement Sciences. After graduating, Leti worked as a researcher in the Faculty of Health, Medicine, and Life Sciences at Maastricht University Medical Centre+, and at NIVEL, the Netherlands Institute for Health Services Research. Her research concentrated on operations management in hospitals. Leti was involved in several projects, including research on the improvement of care processes for stroke patients; the relation between hospital building layout and logistical concepts for controlling patient flow; and the evaluation of a national quality improvement programme for improving patient safety and logistics in hospitals. In addition to her research activities, during the period from October 2005 until June 2007, Leti worked as programme assistant for the Health Care Efficiency Research Programme at the Netherlands Organisation for Health Research and Development (ZonMw).

In January 2010, Leti was appointed Implementation Fellow in the Department of Medical Decision Making at the University Medical Centre in Leiden. 


\section{List of publications}




\section{Articles and abstracts}

Leti Vos, Judith D. de Jong, Peter Spreeuwenberg, Emile C. Curfs, Peter P. Groenewegen. Patients' use of and preferences for primary and secondary care: a multinomial multilevel regression model (revised version submitted for publication).

Leti Vos, Sarah E. Chalmers, Michel L. A. Dückers, Peter P. Groenewegen, Cordula Wagner, Godefridus G. van Merode. Towards an organisation-wide process-oriented organisation of care: a literature review (revised version submitted for publication).

Michel L.A. Dückers, Cordula Wagner, Leti Vos and Peter P. Groenewegen. Organisational development, sustainability, and diffusion of innovations within hospitals participating in a multilevel quality collaborative (revised version submitted for publication).

Leti Vos, Michel L. A. Dückers, Cordula Wagner, Godefridus G. van Merode. Does case-mix based reimbursement stimulate the development of process-oriented care delivery? Health Policy (accepted for publication).

Arno van Raak, Siebren Groothuis, Robert van der Aa, Martien Limburg, Leti Vos. Shifting stroke care from the hospital to the nursing home: explaining the outcomes of a Dutch case. Journal of Evaluation in Clinical Practice (accepted for publication).

Leti Vos, Michel L.A. Dückers, Cordula Wagner, Godefridus G. van Merode. Applying the quality improvement collaborative method to process redesign: a multiple case study. Implementation Science 2010, 5 (1):19.

Cordula Wagner, Michel L.A. Dückers, Peter Makai P, Leti Vos, Peter P. Groenewegen. National policy changes and evolving hospital quality management systems. ISQua's (The International Society for Quality in Health Care) 26th International Conference 2009; Dublin, Ireland, October 11-14.

Leti Vos, Michel Dückers, Cordula Wagner. Blijft het vliegwiel draaien? Resultaten van een follow-up meting. Best Practices Zorg 2009: 2: 35-40. 
Michel L.A. Dückers, Peter Makai, Leti Vos, Peter P. Groenewegen, C. Wagner. Longitudinal analysis on the development of hospital quality management systems in the Netherlands. International Journal for Quality in Health Care 2009: 21(5):330-340.

Leti Vos, Robert J. van Oostenbrugge, Martien Limburg, Godefridus G. van Merode, Siebren Groothuis. How to implement process-oriented care: a case study on the implementation of process-oriented in-hospital stroke care. Accreditation and quality assurance 2009: 14: 5-13.

Leti Vos, Michel L.A. Dückers, Cordula Wagner, Godefridus G. van Merode. A breakthrough collaborative for process redesign: does it work? ISQua's (The International Society for Quality in Health Care) 25th International Conference 2008; Copenhagen, Denmark, October 20-22.

Michel L.A. Dückers, Cordula Wagner, Leti Vos, Peter P. Groenewegen. Organization development, sustainability and dissemination of innovations within hospitals. ISQua's (The International Society for Quality in Health Care) 25th International Conference 2008; Copenhagen, Denmark, October 20-22.

Leti Vos, Michel Dückers, Cordula Wagner. Sneller Beter, wat kunnen we ervan leren? Kwaliteit in Zorg 2008:6:10-14.

Leti Vos, Michel L.A. Dückers, Monique de Bruijn, Cordula Wagner, Peter P. Groenewegen, Godefridus G. van Merode. Naar een procesgestuurd ziekenhuis: beoogde effecten van een logistiek verbeterprogramma. Tijdschrift voor Gezondheidswetenschappen 2008 (86): 4: 207-215.

Leti Vos, Siebren Groothuis, Godefridus G. van Merode. Evaluating hospital redesign from an operations management perspective. Health Care Management Science 2007: 10: 357-64.

Leti Vos, Jessika van Kammen, Karen van Liere, Carolien Bouma, Jetty Hoeksema. Knowledge synthesis for use of PET research: variety of interests, one view? Health Technology Assessment International (HTAi) 2007; Barcelona, Spain, 17- 20 June 2007.

Jessika van Kammen, Leti Vos and Jetty Hoeksema. Knowledge synthesis: from informing to involving. Health Technology Assessment International (HTAi) 2007; Barcelona, Spain, 17- 20 June 2007. 
Siebren Groothuis, Leti Vos, Godefridus G. van Merode. A new hospital layout analysed using simulation. The Society for Modeling and Simulation International SCS, 2007 Western MultiConference WMC; San Francisco, California, USA, 22-26 January 2007.

Martien Limburg, Leti Vos, Robert J. van Oostenbrugge, Godefridus G. van Merode, Siebren Groothuis. Causes of inefficient stroke-unit-bed use possibilities for freeing up capacity. Cerebrovascular Diseases 2005; 19 (Suppl. 2) 114-115.

\section{Factsheets and reports}

Leti Vos, Judith D. de Jong. Percentage overstappers van zorgverzekeraar 3\%: Ouderen wisselen nauwelijks van zorgverzekeraar. Utrecht: NIVEL, 2009.

Leti Vos, Michel Dückers, Cordula Wagner. Evaluatie Sneller Beter pijler 3: geleerde lessen van ziekenhuizen. Utrecht, NIVEL, 2008 (Rapport, ISBN 978-906905-920-4).

Leti Vos, Michel Dückers, Cordula Wagner. Evaluatie Sneller Beter pijler 3: resultaten van een verbeterprogramma voor ziekenhuizen. Utrecht, NIVEL, 2008 (Rapport, ISBN 978-90-6905-916-7). 
Notes 
